\title{
Improvement and further development in CESM/CAM5: gas-phase chemistry and inorganic aerosol treatments
}

\author{
J. He and Y. Zhang
}

Air Quality Forecasting Laboratory, Department of Marine, Earth, and Atmospheric Sciences, North Carolina State University, Raleigh, NC, 27695, USA

Correspondence to: Y. Zhang (yang_zhang@ @ncsu.edu)

Received: 10 October 2013 - Published in Atmos. Chem. Phys. Discuss.: 28 October 2013

Revised: 14 May 2014 - Accepted: 15 July 2014 - Published: 8 September 2014

\begin{abstract}
Gas-phase chemistry and subsequent gas-toparticle conversion processes such as new particle formation, condensation, and thermodynamic partitioning have large impacts on air quality, climate, and public health through influencing the amounts and distributions of gaseous precursors and secondary aerosols. Their roles in global air quality and climate are examined in this work using the Community Earth System Model version 1.0.5 (CESM1.0.5) with the Community Atmosphere Model version 5.1 (CAM5.1) (referred to as CESM1.0.5/CAM5.1). CAM5.1 includes a simple chemistry that is coupled with a 7-mode prognostic Modal Aerosol Model (MAM7). MAM7 includes classical homogenous nucleation (binary and ternary) and activation nucleation (empirical first-order power law) parameterizations, and a highly simplified inorganic aerosol thermodynamics treatment that only simulates particulate-phase sulfate and ammonium. In this work, a new gas-phase chemistry mechanism based on the 2005 Carbon Bond Mechanism for Global Extension (CB05_GE) and several advanced inorganic aerosol treatments for condensation of volatile species, ion-mediated nucleation (IMN), and explicit inorganic aerosol thermodynamics for sulfate, ammonium, nitrate, sodium, and chloride have been incorporated into CESM/CAM5.1-MAM7. Compared to the simple gasphase chemistry, CB05_GE can predict many more gaseous species, and thus could improve model performance for $\mathrm{PM}_{2.5}, \mathrm{PM}_{10}$, PM components, and some PM gaseous precursors such as $\mathrm{SO}_{2}$ and $\mathrm{NH}_{3}$ in several regions as well as aerosol optical depth (AOD) and cloud properties (e.g., cloud fraction $(\mathrm{CF})$, cloud droplet number concentration (CDNC), and shortwave cloud forcing, SWCF) on the global scale. The modified condensation and aqueous-phase chemistry could
\end{abstract}

further improve the prediction of additional variables such as $\mathrm{HNO}_{3}, \mathrm{NO}_{2}$, and $\mathrm{O}_{3}$ in some regions, and new particle formation rate $(J)$ and AOD on the global scale. IMN can improve the prediction of secondary $\mathrm{PM}_{2.5}$ components, $\mathrm{PM}_{2.5}$, and $\mathrm{PM}_{10}$ over Europe as well as AOD and CDNC on the global scale. The explicit inorganic aerosol thermodynamics using the ISORROPIA II model improves the prediction of all major $\mathrm{PM}_{2.5}$ components and their gaseous precursors in some regions as well as downwelling shortwave radiation, SWCF, and cloud condensation nuclei at a supersaturation of $0.5 \%$ on the global scale. For simulations of 2001-2005 with all the modified and new treatments, the improved model predicts that on global average, SWCF increases by $2.7 \mathrm{~W} \mathrm{~m}^{-2}$, reducing the normalized mean bias (NMB) of SWCF from -5.4 to $1.2 \%$. Uncertainties in emissions can largely explain the inaccurate prediction of precursor gases (e.g., $\mathrm{SO}_{2}, \mathrm{NH}_{3}$, and $\mathrm{NO}$ ) and primary aerosols (e.g., black carbon and primary organic matter). Additional factors leading to the discrepancies between model predictions and observations include assumptions associated with equilibrium partitioning for fine particles assumed in ISORROPIA II, irreversible gas/particle mass transfer treatment for coarse particles, uncertainties in model treatments such as dust emissions, secondary organic aerosol formation, multiphase chemistry, cloud microphysics, aerosol-cloud interaction, dry and wet deposition, and model parameters (e.g., accommodation coefficients and prefactors of the nucleation power law) as well as uncertainties in model configuration such as the use of a coarse-grid resolution. 


\section{Introduction}

Atmospheric gases and aerosols play important roles in the Earth system due to their ability to alter the Earth's radiation balance. Atmospheric chemistry determines the formation of ozone $\left(\mathrm{O}_{3}\right)$ and fine particular matter $\left(\mathrm{PM}_{2.5}\right)$ through affecting the distribution of oxidants and their gaseous precursors. Different chemical reactions and kinetic parameters can lead to differences in the prediction of gases, secondary aerosols, and new particle formation rate $(J)$ as well as climatic variables such as cloud condensation nuclei $(\mathrm{CCN})$, cloud droplet number concentration (CDNC), and radiative forcing (Faraji et al., 2008; Zhang et al., 2012a). Meanwhile, climate change can strongly influence atmospheric chemistry and air quality.

Aerosol can influence the Earth's radiative balance by directly scattering and absorbing radiation and indirectly affecting cloud properties through acting as $\mathrm{CCN}$ and ice nuclei (IN). Therefore, it is important to accurately simulate aerosol size distribution, chemical composition and properties which can determine the magnitude of aerosol radiative forcing (Koloutsou-Vakakis et al., 1998). Aerosol and its influence on climate have been included in many global climate models (GCMs) such as the Community Climate System Model (CCSM) (Collins et al., 2006), the fifth generation of global climate model modified from European Centre for Medium-Range Weather Forecasts in Hamburg (ECHAM5) (Stier et al., 2005), and Earth system models such as the Community Earth System Model (CESM) (Ghan et al., 2012; Liu et al., 2012), the Integrated Global System Model (IGSM) (Dutkiewicz et al., 2005; Sokolov et al., 2005), and the Earth System Model (ESM) (Dunne et al., 2012). However, due to the complexity of aerosol microphysical processes and their interactions with cloud processes, it remains a challenge to accurately represent those properties and processes in GCMs.

Inorganic aerosols comprise $25-50 \%$ of fine aerosol mass (Heintzenberg, 1989), which mainly includes sulfate $\left(\mathrm{SO}_{4}^{2-}\right)$, ammonium $\left(\mathrm{NH}_{4}^{+}\right)$, nitrate $\left(\mathrm{NO}_{3}^{-}\right)$, chloride $\left(\mathrm{Cl}^{-}\right)$, and sodium $\left(\mathrm{Na}^{+}\right)$. Major gas-to-particle conversion processes of inorganic aerosols include condensation, nucleation, and thermodynamics. An important factor that determines the condensation of gases is the mass accommodation coefficient $(\alpha)$, which can be measured through laboratory experiments. The measured $\alpha$ values, however, are subject to large uncertainties and may vary in several orders of magnitudes under different laboratory conditions. To simulate aerosol condensational growth, a constant value of $\alpha$ is therefore often assumed in GCMs, which is a source of uncertainty in model predictions.

Homogeneous nucleation of $\mathrm{H}_{2} \mathrm{SO}_{4}$ vapor produces new particles that can grow to form CCN. Different nucleation parameterizations are used in GCMs or global aerosol models. For example, Sihto et al. (2006) derived empirical power laws with the first- or second-order dependen- cies of new particle formation rates $(J)$ on $\mathrm{H}_{2} \mathrm{SO}_{4}$ vapor concentration from observations based on cluster-activation or barrier-less kinetic mechanisms, which have been used in the Community Atmosphere Model (CAM) (Wang and Penner, 2009), the Global-through-Urban Weather Research and Forecasting model with Chemistry (GU-WRF/Chem) (Zhang et al., 2012b), and the Global Model of Aerosol Processes (GLOMAP) (Spracklen et al., 2006). An ion-mediated nucleation (IMN) model was developed to calculate $J$ based on ambient atmospheric conditions, $\mathrm{H}_{2} \mathrm{SO}_{4}$ vapor concentrations, ionization rate, and surface area of preexisting particles. It has been used in GEOS-Chem (Yu et al., 2008), CAM (Yu et al., 2012), and GU_WRF/Chem (Zhang et al., 2012b). Different nucleation parameterizations lead to significant differences in $J$ prediction by regional and global models (Zhang et al., 2010) and CCN/CDNC (Zhang et al., 2012b; Yu et al., 2012). Limited observations make it difficult to validate predicted $J$ values and appropriateness of various parameterizations.

A number of thermodynamic aerosol modules have been developed to understand physical and chemical properties of inorganic aerosols. For example, the EQUISOLV II model (Jacobson, 1999) has been used in the one-way nested (from global to local scales) GATOR-GCMOM (gas, aerosol, transport, radiation, general circulation, mesoscale, and ocean model) (Jacobson, 2010). EQUISOLV II uses analytical equilibrium iteration and mass flux iteration to solve equilibrium problems (Jacobson, 1999), which has relatively large computational costs. SCAPE2 is used in the California Institute of Technology (CIT) model (Meng et al., 1998). ISORROPIA (Nenes et al., 1998) has been used in several global models such as GEOS-Chem (Bey et al., 2001), the GISS Caltech (Liao et al., 2003), and the GU-WRF/Chem (Zhang et al., 2012b) and regional models such as the Community Multiscale Air Quality model (CMAQ) (Byun and Schere, 2006) and the Comprehensive Air Quality Model with Extensions (CAMx) (ENVIRON, 2010). An updated version, ISORROPIA II (Fountoukis and Nenes, 2007), has also been implemented in recent versions of CMAQ (e.g., CMAQ v4.7Dust (Wang et al., 2012) and CMAQ v5.0, Appel et al., 2013) and GEOS-Chem (Fountoukis and Nenes, 2007). The Multicomponent Equilibrium Solver for Aerosols (MESA) (Zaveri et al., 2005) has been used in the mesoscale WRF/Chem (Fast et al., 2006). These modules assume that particles simulated in a given particle size range have the same composition (i.e., internal mixture). Different aerosol thermodynamic models can lead to different aerosol predictions (Nenes et al., 1998; Zhang et al., 2000; Zaveri et al., 2005). Zhang et al. (2000) reported average absolute differences of 7.7$12.3 \%$ in total PM predictions between different thermodynamic modules under 400 test conditions but the differences could be as large as $68 \%$ under some cases (e.g., high nitrate/chloride and low/medium relative humidity, RH). Fountoukis and Nenes (2007) found the largest discrepancies between ISORROPIA II and SCAPE2 in water concentration 
predictions exist under low $\mathrm{RH}$ conditions $(\mathrm{RH}<60 \%$ ), primarily from differences in the treatment of water uptake and solid state composition. The 3-D atmospheric models with these modules include explicit thermodynamic treatments for sulfate, ammonium, nitrate, sodium, and chloride. The equilibrium assumption, however, is not valid under some conditions (e.g., coarse particles and cooler conditions) (Meng and Seinfeld, 1996). Kinetic approaches are therefore needed to treat gas/particle mass transfer under such conditions. Kinetic approaches, on the other hand, are computationally expensive (Zhang et al., 2004; Hu et al., 2008) and have only been implemented in a few 3-D models (e.g., Meng and Seinfeld, 1996; Jacobson, 2005; Zhang and Wexler, 2006; Zaveri et al., 2008). A hybrid approach that assumes equilibrium for fine particles and solves gas/particle mass transfer for coarse particles which provides the best compromise between numerical accuracy and computational efficiency has been thus developed (Capaldo et al., 2000; Kelly et al., 2010). A simple approach for gas/particle mass transfer used in some GCMs, such as CAM5, is to treat sulfate and ammonium only with a full neutralization (the $\mathrm{NH}_{4}^{+} / \mathrm{SO}_{4}^{2-}$ molar ratio of 2 for a mode) through an irreversible condensation.

In this work, a comprehensive gas-phase chemical mechanism and detailed inorganic aerosol treatments for nucleation and aerosol thermodynamics are incorporated into CAM version 5.1 (CAM5.1) in the CESM version 1.0.5 (CESM1.0.5). Several modifications are also made to the existing treatments such as condensation and aqueous-phase chemistry. The objectives are to improve the representations of gas-phase chemistry and inorganic aerosol treatments in CESM/CAM5.1, and reduce associated uncertainties. The improved model with enhanced capabilities can be applied for decadal simulations to study interactions among atmospheric chemistry, aerosols, and climate change.

\section{Model development and improvement}

CESM is a fully coupled global Earth system model, which includes land, ocean, atmosphere, and sea ice components. The atmosphere component used in this study is CAM5.1. Existing and new model treatments related to this study are described in this section. Further details on CAM5.1 can be found at http://www.cesm.ucar.edu/models/cesm1.0/cam/.

\subsection{Existing gas-phase chemistry and aerosol treatments in CESM/CAM5.1}

CAM5.1 uses a simple gas-phase chemistry for sulfur species, which includes one photolytic reaction and seven kinetic reactions among six gas-phase species (i.e., hydrogen peroxide $\left(\mathrm{H}_{2} \mathrm{O}_{2}\right)$, sulfuric acid $\left(\mathrm{H}_{2} \mathrm{SO}_{4}\right)$, sulfur dioxide $\left(\mathrm{SO}_{2}\right)$, dimethylsulfide (DMS), ammonia $\left(\mathrm{NH}_{3}\right)$, and semivolatile organic gas, SOAG). A more comprehensive gasphase mechanism with 40 photolytic reactions and $172 \mathrm{ki}-$ netic reactions among 103 species, i.e., the Model of OZone and Related chemical Tracers version 4 (MOZART-4) of Emmons et al. (2010), has been incorporated into the official released CAM5.1. It was only coupled with the bulk aerosol module (BAM) in CAM5.1 implemented in CESM 1.0.5 that is used in this work (it was coupled with MAM in CESM v1.1). In addition to BAM, CAM5.1 contains the modal aerosol model (MAM) that is based on modal representations of aerosols. In this study, MAM is used because it can represent more accurate size distributions as compared to BAM. There are two versions of MAM, one with seven lognormal modes (MAM7), and the other with three lognormal modes (MAM3) (Liu et al., 2012), and both are coupled with the simple gas-phase chemistry in the default model. MAM7 is used in this study because it contains explicit treatments for ammonium and size distributions for dust, seasalt, and primary carbon compared to MAM3. MAM7 explicitly treats sulfate, ammonium, sea-salt, dust, BC, primary organic matter (POM), and secondary organic aerosol (SOA). It simulates condensational growth of aerosol, nucleation, coagulation, dry deposition, wet removal, and water uptake. Condensation is simulated based on a kinetic approach in which MAM7 treats $\mathrm{H}_{2} \mathrm{SO}_{4}, \mathrm{NH}_{3}$, and methanesulfonic acids (MSA) as completely non-volatile species and treats SOAG as a volatile species, using a constant accommodation coefficient of 0.65 for all these condensing species based on Adams and Seinfeld (2002). $\mathrm{NH}_{3}$ condensation stops when the $\mathrm{NH}_{4}^{+} / \mathrm{SO}_{4}^{2-}$ molar ratio of a particle mode reaches 2 (i.e., fully neutralized by $\mathrm{SO}_{4}^{2-}$ ions). The net uptake rate, $I_{\text {net }}$, due to gas to particle mass transfer for each species to each mode is simulated as

$$
\begin{aligned}
& I_{\text {net }}=\int \mathrm{d} x \frac{\mathrm{d} N}{\mathrm{~d} x} I_{\text {cond }}, \\
& I_{\text {cond }}=2 \times \pi \times D_{\mathrm{g}} \times D_{\mathrm{p}} \times F(K n, \alpha), \\
& F(K n, \alpha)=\frac{0.75 \times(1+K n)}{K n \times\left(\frac{1+K n}{\alpha}+0.283\right)+0.75},
\end{aligned}
$$

where $D_{\mathrm{p}}$ is the particle diameter; $x$ is the logarithmic diameter of particle, $=\ln \left(D_{\mathrm{p}}\right) ; \mathrm{d} N / \mathrm{d} x$ is the log-normal particle number density distribution; $I_{\text {net }}$ is the gas condensation rate; $K n$ is the Knudsen number; $\alpha$ is the accommodation coefficient of condensable vapor; $D_{\mathrm{g}}$ is the gas diffusivity, and $F(K n, \alpha)$ is the Fuchs-Sutugin correction factor that describes the resistance to uptake caused by gas-phase diffusion. Equation (1) is solved using the Gauss-Hermite quadrature of order 2. Based on Eq. (3), as $\alpha$ approaches zero, $F(K n$, $\alpha$ ) approaches zero. Consequently, $I_{\text {cond }}$ (i.e., the uptake rate) approaches zero in Eq. (1).

There are three nucleation parameterizations in MAM7. The empirical power law of Wang and Penner (2009) (WP09) is used in the planetary boundary layer (PBL), which includes a first-order dependence on $\mathrm{H}_{2} \mathrm{SO}_{4}$ vapor with a prefactor of $1 \times 10^{-6}$. The binary $\mathrm{H}_{2} \mathrm{SO}_{4}-\mathrm{H}_{2} \mathrm{O}$ homogeneous 
nucleation of Vehkamaki et al. (2002) (VE02) and ternary $\mathrm{H}_{2} \mathrm{SO}_{4}-\mathrm{NH}_{3}-\mathrm{H}_{2} \mathrm{O}$ homogeneous nucleation of Merikanto et al. (2007) (ME07) are used above the PBL. MAM7 also only considers the neutralization of $\mathrm{SO}_{4}^{2-}$ by $\mathrm{NH}_{4}^{+}$during condensational growth. A more detailed description of MAM can be found in Liu et al. (2012).

\subsection{New and modified model treatments implemented in this work}

\subsubsection{Gas-phase chemical mechanism}

Highly simplified gas-phase mechanism as used in default CAM5.1 can result in large uncertainties in the prediction of oxidants and gaseous precursors for secondary aerosols. Therefore, a new gas-phase mechanism, the 2005 Carbon Bond Mechanism for Global Extension (CB05_GE) (Karamchandani et al., 2012) has been implemented into CAM5.1 using the same chemical preprocessor as MOZART-4 (Lamarque et al., 2012) and coupled with both MAM3 and MAM7. CB05_GE was developed to simulate major chemical reactions for global-through-urban applications as illustrated in Zhang et al. (2012b). A more detailed description of CB05_GE can be found in Karamchandani et al. (2012). In this study, gas precursors for SOA in CB05_GE are mapped to SOAG to make it compatible in MAM7. As the first study of CESM/CAM5.1 with CB05_GE, this work focuses on the impact of gas-phase chemistry. The heterogeneous chemistry on the surface of aerosol is turned off. CB05_GE implemented in CESM/CAM5 contains a total of 273 reactions including 50 photolytic reactions and 223 kinetic reactions among 93 gas-phase species in this study. The gas-phase chemical system is solved using an implicit backward Euler method.

\subsubsection{Ion-mediated nucleation parameterization}

Ions generated by cosmic radiation and natural radioactive decay have been studied for a long time as an important source for enhancing nucleation (Raes et al., 1986). An IMN model is developed by $\mathrm{Yu}$ (2010) (Yu10) for the $\mathrm{H}_{2} \mathrm{SO}_{4}-$ $\mathrm{H}_{2} \mathrm{O}$ system, and explicitly solves the dynamic equations in terms of temperature, $\mathrm{RH}, \mathrm{H}_{2} \mathrm{SO}_{4}$ vapor concentration, ionization rate, and surface area of preexisting particles. Different from classic binary nucleation theory, which is based on the minimization of changes in Gibbs free energy (Seinfeld and Pandis, 2006), IMN is based on a kinetic model that considers the interactions among ions, neutral and charged clusters, vapor molecules, and preexisting particles (Yu, 2010). The global ionization rates due to cosmic rays are calculated based on the schemes given in Usoskin and Kovaltsov (2006) and the contribution of radioactive materials from soil to ionization rates is parameterized based on the profiles given in Reiter (1992). To reduce the computing cost using IMN in 3D models, Yu et al. (2008) developed lookup tables with sim- ple interpolation subroutines to calculate nucleation rates under typical atmospheric conditions. In this work, IMN based on YU10 is implemented into MAM7 and combined with default nucleation parameterizations (VE02, ME07, and WP09) in order to improve $J$ prediction and aerosol number concentrations in the upper troposphere. The $J$ value above the PBL is taken as the maximum value among predictions from IMN (YU10) and homogeneous nucleation (VE02 or ME07), and the $J$ value within the PBL is taken as the maximum value among predictions from IMN (YU10), homogeneous nucleation (VE02 or ME07), and the first-order parameterization (WP09).

\subsubsection{Inorganic aerosol thermodynamics}

Gas/particle partitioning is an important process in the formation and evolution of secondary aerosols. Several factors affect gas/particle partitioning, such as temperature, RH, saturation vapor pressures of species, the physical state of the condensed phase, and the interactions among aerosol components (Zuend et al., 2010). Most models focus on inorganic aerosols. Fountoukis and Nenes (2007) developed a computationally efficient thermodynamics equilibrium model, ISORROPIA II, for the magnesium $\left(\mathrm{Mg}^{2+}\right)$-potassium $\left(\mathrm{K}^{+}\right)$-calcium $\left(\mathrm{Ca}^{2+}\right)-\mathrm{NH}_{4}^{+}-\mathrm{Na}^{+}-\mathrm{SO}_{4}^{2-}$ $\mathrm{NO}_{3}-\mathrm{Cl}-\mathrm{H}_{2} \mathrm{O}$ aerosol system. An important difference between ISORROPIA II and most other thermodynamics equilibrium models is that ISORROPIA II simulates crustal species, such as $\mathrm{Mg}^{2+}, \mathrm{K}^{+}$, and $\mathrm{Ca}^{2+}$, which are important constituents of atmospheric aerosols, in particular, mineral dust. Therefore, to explicitly simulate aerosol thermodynamics, ISORROPIA II has been implemented into MAM7 and applied for accumulation, Aitken, fine sea-salt, and fine dust modes to explicitly simulate thermodynamics of $\mathrm{SO}_{4}^{2-}$, $\mathrm{NH}_{4}^{+}, \mathrm{NO}_{3}^{-}, \mathrm{Cl}^{-}$, and $\mathrm{Na}^{+}$as well as the impact of crustal species associated with fine dust modes on aerosol thermodynamics. The concentrations of $\mathrm{K}^{+}, \mathrm{Ca}^{2+}$, and $\mathrm{Mg}^{2+}$ as the input for ISORROPIA II are calculated from dust concentrations, using the mass ratios of $1.022 \times 10^{-3}, 1.701 \times 10^{-3}$, and $7.084 \times 10^{-4}$, respectively (Van Pelt and Zobeck, 2007). The resulted concentrations of aerosol components from ISORROPIA are mapped back to fine aerosol modes based on their mass ratios to the total mass over all fine modes at the previous time step.

Aerosol thermodynamics involving coarse particles (in coarse sea-salt and dust modes) is currently not treated explicitly in this work, given the high computational cost (by at least a factor of 3 compared to the cost for fine particles) for solving the non-equilibrium system involving coarse particles. Instead, the simple kinetic approach used in the default CAM5.1 is used to simulate the condensation of inorganic gases onto coarse modes (see Sect. 2.2.4). For fine mode particles, before thermodynamic calculation using ISORROPIA II, the condensation and nucleation processes are simulated to allow a more realistic allocation of gaseous 
$\mathrm{H}_{2} \mathrm{SO}_{4}$ between these two competing processes. Such a treatment for fine mode particles is similar to the kinetic approach used in regional air quality models, except that the condensation is assumed to be irreversible with lower limit values of mass accommodation coefficients in this work.

\subsubsection{Modifications of existing aerosol treatments}

MAM7 does not treat $\mathrm{NO}_{3}^{-}$and it treats $\mathrm{NaCl}$ as one species. In this work, MAM7 is modified to explicitly simulate $\mathrm{NO}_{3}^{-}$, $\mathrm{Cl}^{-}$, and $\mathrm{Na}^{+}$using a similar method to the condensation of $\mathrm{H}_{2} \mathrm{SO}_{4}$ and $\mathrm{NH}_{3}$. $\mathrm{NO}_{3}^{-}$and $\mathrm{Cl}^{-}$are simulated in all modes except for primary carbon mode. $\mathrm{Na}^{+}$is simulated in sea-salt modes. The source of $\mathrm{Na}^{+}$is calculated based on the mass ratio of $\mathrm{Na}$ and $\mathrm{Cl}$ from sea-salt emissions. The source of $\mathrm{Cl}^{-}$includes sea-salt emissions, and the condensation of $\mathrm{HCl}$ resulting from $\mathrm{HCl}$ emissions and gas/particle partitioning of total chloride.

Species-dependent accommodation coefficients are used for $\mathrm{H}_{2} \mathrm{SO}_{4}, \mathrm{NH}_{3}, \mathrm{HNO}_{3}$, and $\mathrm{HCl}$, with the values of 0.02 , 0.097, 0.0024, and 0.005 (Zhang et al., 1998; Sander et al., 2003), respectively. Since by default the model treats the condensation of inorganic volatile gas species as irreversible process (no evaporation) (see Eq. 1), the lower limit values of mass accommodation coefficients are used for these species to represent their net fluxes from the gas phase to the liquid/solid phases. Such lower limit values correspond to uptake coefficients, which represent the net fluxes and are smaller than mass accommodation coefficients. To ensure electroneutrality in each mode after kinetically condensing $\mathrm{H}_{2} \mathrm{SO}_{4}, \mathrm{NH}_{3}, \mathrm{HNO}_{3}$, and $\mathrm{HCl}$ at different condensation (or uptake) rates, the condensation of $\mathrm{NH}_{3}$ will stop when the mole concentration of cations (i.e., $\mathrm{NH}_{4}^{+}$) is equal to the sum of those of anions (i.e., $\left.\left[\mathrm{NH}_{4}^{+}\right]=2 \times\left[\mathrm{SO}_{4}^{2-}\right]+\left[\mathrm{NO}_{3}^{-}\right]+\left[\mathrm{Cl}^{-}\right]\right)$. While such an approach allows the gas/particle portioning of those volatile species over both fine and coarse modes, the irreversible condensation with lower limit mass accommodation coefficients assumed in this work, however, may contribute to model biases in simulating condensation of volatile species on coarse mode particles. A more accurate method (i.e., reversible condensation) should be used for volatile species for future work. The original MAM7 treats $\mathrm{NH}_{3}(\mathrm{~g}) / \mathrm{NH}_{4}^{+}$ in cloud water. In this work, the dissolution and dissociation of $\mathrm{HNO}_{3}$ and $\mathrm{HCl}$ to produce $\mathrm{NO}_{3}^{-}$and $\mathrm{Cl}^{-}$in cloud water are added in the model based on Marsh and McElroy (1985) and Seinfeld and Pandis (2006), that is,

$\mathrm{HNO}_{3(\mathrm{~g})} \rightleftharpoons \mathrm{HNO}_{3}(\mathrm{aq}) \rightleftharpoons \mathrm{H}^{+}+\mathrm{NO}_{3}^{-}$,

$\mathrm{HCl}_{(\mathrm{g})} \rightleftharpoons \mathrm{HCl}_{(\mathrm{aq})} \rightleftharpoons \mathrm{H}^{+}+\mathrm{Cl}^{-}$.

The concentration of $\mathrm{H}^{+}$(thus the $\mathrm{pH}$ value of the solution) is obtained by solving the electroneutrality equation using the bisection method. The aqueous-phase chemical system is solved analytically.

\section{Model configurations and evaluation protocols}

\subsection{Model setup and simulation design}

Table 1 summarizes the CESM/CAM5.1 simulations that are designed to examine the impacts of individual new and modified treatments on model prediction. The first set of simulations includes two simulations with the same default MAM7 coupled with different gas-phase mechanisms: one uses the simple gas-phase chemistry (MAM_SIM) with a total of 37 prognostic species and one uses the CB05_GE (MAM_CB05_GE) with a total of 127 prognostic species. A comparison of the two simulations provides an estimate of the impacts of gas-phase chemical mechanisms. The second set of simulations consists of five simulations that use the same CB05_GE gas-phase mechanism but with modified and new aerosol treatments individually and jointly. The first one is MAM_CON which uses an explicit treatment for $\mathrm{NO}_{3}^{-}, \mathrm{Cl}^{-}$, and $\mathrm{Na}^{+}$, and species-dependent mass accommodation coefficients for condensation and that includes the aqueous-phase chemistry of $\mathrm{HNO}_{3} / \mathrm{NO}_{3}^{-}$and $\mathrm{HCl} / \mathrm{Cl}^{-}$. This simulation includes a total of 139 prognostic species. The second one is MAM_CON/IMN which uses the same treatments as MAM_CON but with IMN as one of the nucleation mechanisms and a prefactor of $1.0 \times 10^{-8}$ in WP09. The third one is MAM_CON/ISO which uses the same treatments as MAM_CON but with ISORROPIA II for aerosol thermodynamics assuming metastate equilibrium (i.e., liquid only). The fourth one is MAM_NEWA which uses the same treatments as MAM_CON but with all new and modified aerosol treatments and a prefactor of $1.0 \times 10^{-9}$ for WP09. The fifth one is MAM_NEWB which uses the same treatments as MAM_NEWA, but with ISORROPIA II assuming stable conditions (i.e., solid and liquid coexist). A comparison of MAM_CB05_GE with MAM_CON indicates the impact of modified condensation and aqueous-phase chemistry. A comparison of MAM_CON/IMN, MAM_CON/ISO, and MAM_NEWA with MAM_CON indicates the impacts of IMN, ISORROPIA II, and combined new and modified aerosol treatments, respectively. Comparison of MAM_NEWB with MAM_NEWA indicates the impacts of thermodynamic conditions on gas-aerosol partitioning. The third set of simulation includes one simulation using the same configuration as MAM_NEWA but with adjusted emissions (MAM_NEW/EMIS). Its comparison with MAM_NEWA indicates the impacts of uncertainties in emissions on model prediction. The fourth set of simulation includes one simulation using the same configuration as MAM_SIM but with prescribed sea surface temperature (SST) for a 5-year period during 2001-2005 (MAM_SIM_5Y), and two simulations both using the same configuration as MAM_NEW/EMIS for 2001-2005 but one with prescribed SST (MAM_NEW_5YA) and the other in a fully coupled mode (MAM_NEW_5YB). 
Table 1. Simulation design and purposes.

\begin{tabular}{|c|c|c|}
\hline Index run & Model configuration & Purpose \\
\hline MAM_SIM & $\begin{array}{l}\text { Simple gas-phase chemistry coupled with } \\
\text { default MAM7 }\end{array}$ & $\begin{array}{l}\text { A baseline run for the first set of simula- } \\
\text { tions (see text) }\end{array}$ \\
\hline MAM_CB05_GE & CB05_GE coupled with default MAM7 & $\begin{array}{l}\text { Differences of MAM_SIM and } \\
\text { MAM_CB05_GE indicate the impacts of } \\
\text { gas-phase chemical mechanisms }\end{array}$ \\
\hline MAM_CON & $\begin{array}{l}\text { Same as MAM_CB05_GE, but with ex- } \\
\text { plicit treatments for } \mathrm{NO}_{3}^{-}, \mathrm{Cl}^{-} \text {, and } \mathrm{Na}^{+} \text {; } \\
\mathrm{HNO}_{3} \text { and } \mathrm{HCl} \text { condensation and aqueous- } \\
\text { phase chemistry; species-dependent accom- } \\
\text { modation coefficients }\end{array}$ & $\begin{array}{l}\text { A baseline run for the second set of sim- } \\
\text { ulations; differences of MAM_SIM and } \\
\text { MAM_CB05_GE indicate the impact } \\
\text { of modified condensation and aqueous- } \\
\text { phase chemistry treatments }\end{array}$ \\
\hline MAM_CON/IMN & $\begin{array}{l}\text { Same as MAM7_CON, but combine IMN } \\
\text { with modified default nucleation parameter- } \\
\text { izations with a prefactor of } 1.0 \times 10^{-8}\end{array}$ & $\begin{array}{l}\text { Differences of MAM_CON and } \\
\text { MAM_CON/IMN indicate the im- } \\
\text { pacts of IMN and the lower prefactor for } \\
\text { WP09 }\end{array}$ \\
\hline MAM_CON/ISO & $\begin{array}{l}\text { Same as MAM7_CON, but with ISOR- } \\
\text { ROPIA II for aerosol thermodynamics un- } \\
\text { der metastable conditions }\end{array}$ & $\begin{array}{l}\text { Differences between MAM_CON and } \\
\text { MAM_IMN/ISO indicate the impacts of } \\
\text { explicit aerosol thermodynamics }\end{array}$ \\
\hline MAM_NEWA & $\begin{array}{l}\text { Same as MAM7_CON, but with all modi- } \\
\text { fied and new treatments and using a pref- } \\
\text { actor of } 1.0 \times 10^{-9} \text { for default nucleation } \\
\text { parameterization }\end{array}$ & $\begin{array}{l}\text { Differences between MAM_CB05_GE } \\
\text { and MAM_NEWA indicate the impacts } \\
\text { of all new and modified treatments for in- } \\
\text { organic aerosols }\end{array}$ \\
\hline MAM_NEWB & $\begin{array}{l}\text { Same as MAM_NEWA, but with ISOR- } \\
\text { ROPIA II under stable condition }\end{array}$ & $\begin{array}{l}\text { Differences between MAM_NEWA } \\
\text { and MAM_NEWB indicate the im- } \\
\text { pacts of thermodynamic conditions on } \\
\text { gas-aerosol partitioning }\end{array}$ \\
\hline MAM_NEW/EMIS & $\begin{array}{l}\text { Same as MAM7_NEW, but with adjusted } \\
\text { emissions of } \mathrm{SO}_{2}, \mathrm{NH}_{3}, \mathrm{BC}, \mathrm{POM} \text {, and } \mathrm{CO} \\
\text { over CONUS, Europe, and East Asia }\end{array}$ & $\begin{array}{l}\text { Differences between MAM_NEWA and } \\
\text { MAM_NEW/EMIS indicate the impact } \\
\text { of emissions }\end{array}$ \\
\hline MAM_SIM_5Y & $\begin{array}{l}\text { Same as MAM_SIM, but with prescribed } \\
\text { SST for 2001-2005 }\end{array}$ & $\begin{array}{l}\text { A baseline run for fourth set of simula- } \\
\text { tions }\end{array}$ \\
\hline MAM_NEW_5YA & $\begin{array}{l}\text { Same as MAM_NEW/EMIS, but with pre- } \\
\text { scribed SST for 2001-2005 }\end{array}$ & $\begin{array}{l}\text { Differences between MAM_SIM_5Y } \\
\text { and MAM_NEW_5YA indicate the indi- } \\
\text { cate the impacts of all new and modified } \\
\text { treatments for inorganic aerosols }\end{array}$ \\
\hline MAM_NEW_5YB & $\begin{array}{l}\text { Same as MAM_NEW/EMIS, but with fully } \\
\text { coupled model for 2001-2005 }\end{array}$ & $\begin{array}{l}\text { Difference between MAM_NEW_5YB } \\
\text { and MAM_NEW_5YA indicate the im- } \\
\text { pacts of processes from component mod- } \\
\text { els in the fully coupled Earth system }\end{array}$ \\
\hline
\end{tabular}

All these simulations use the same approach for photolytic rate calculations based on Lamarque et al. (2012), the same aqueous-phase chemistry of Barth et al. (2000), and the same physical options as those in MAM_SIM. Major physical options include the cloud microphysics parameterization of Morrison and Gettelman (2008), the moisture PBL scheme of Bretherton and Park (2009), the shallow convection scheme and deep convection scheme of Park and Bretherton (2009) and Zhang and McFarlane (1995), re- spectively, the aerosol activation parameterization of AbdulRazzak and Ghan (2000), and the Rapid Radiative Transfer Model for GCMs (RRTMG) of Iacono et al. (2003, 2008) for long- and shortwave radiation. The land surface processes are simulated by the Community Land Model (CLM) of Lawrence et al. (2011) in CESM that is coupled with CAM5.1.

All simulations except for MAM_SIM_5Y and MAM_NEW_5YA are performed with fully coupled 
CESM1.0.5 with a standard B_1850-2000_CAM5_CN configuration, which represents 1850 to 2000 transient conditions and includes all active components in CESM with biogeochemistry in the land model. MAM_SIM_5Y and MAM_NEW_5YA are performed with a standard F_AMIP_CAM5 configuration, which uses a climatological data set for SST provided by the National Center for Atmospheric Research (NCAR) for the ocean model. The simulations are conducted for the full year of 2001 and 2001-2005 at a horizontal resolution of $0.9^{\circ} \times 1.25^{\circ}$ and a vertical resolution of 30 layers for CAM5.1. The initial conditions for ice and ocean models are from CESM default settings. The initial conditions for the land model are based on the output from the NCAR's CESM/CAM4 B_1850-2000_CN simulation. The initial conditions for CAM5 are derived from a $10 \mathrm{yr}$ (1990-2000) CAM5 stand-alone simulation with the MOZART chemistry provided by NCAR. A 1 yr (1 January-31 December 2000) CESM/CAM5 simulation using NCAR's CESM B_18502000_CAM5_CN component set is performed as spin-up to provide the initial conditions for meteorological variables and chemical species that are treated in both MOZART and CB05_GE. An additional 3-month (1 October-31 December 2000) CESM/CAM5 simulation based on a 10-month (January-October 2000) CESM/CAM5 output using initial conditions from NCAR's CESM B_1850-2000_CAM5_CN is performed as spin-up to provide initial conditions for chemical species that are treated in CB05_GE but not in MOZART. All production simulations of 2001 are from 1 January-31 December 2001 and those of 2001-2005 are from 1 January 2001-31 December 2005. The offline anthropogenic emissions used in all simulations except for MAM_NEW/EMIS are taken from Zhang et al. (2012b) (see Table 2 of Zhang et al. (2012b) for the sources of those anthropogenic emissions). Anthropogenic emissions used in MAM_NEW/EMIS are adjusted emissions based on those of Zhang et al. (2012b), with adjustment factors of 0.7, 0.5, and 1.2 for $\mathrm{SO}_{2}$ over CONUS (contiguous United States), Europe, and Asia, respectively, and 1.2 for $\mathrm{NH}_{3}$, $\mathrm{BC}$, and organic carbon (OC), and 1.3 for carbon monoxide (CO) over all three regions. Those emissions are adjusted based on the comparison with the emission inventories from the Representative Concentration Pathways (RCPs), the MOZART version 4 (MOZART-4), the Reanalysis of the TROpospheric chemical composition (RETRO), the Global Fire Emissions Database (GFED) version 2, and preliminary evaluation of CESM/CAM5.1 with modified and new gas and aerosol treatments using available observations. The online emissions include biogenic volatile organic carbon (Guenther et al., 2006), mineral dust (Zender et al., 2003), and sea-salt (Martensson et al., 2003).

\subsection{Available measurements for model validation}

A number of observational data sets from surface networks and satellites are used for model evaluation. They are summarized along with the variables to be evaluated in Table S1 in the Supplement. Global surface networks include the Baseline Surface Radiation Network (BSRN) and the National Oceanic and Atmospheric Administration Climate Diagnostics Center (NOAA/CDC). The satellite data sets include the Moderate Resolution Imaging Spectroradiometer (MODIS), the Clouds and the Earth's Radiant Energy System (CERES), the Total Ozone Mapping Spectrometer/the Solar Backscatter UltraViolet (TOMS/SBUV), the Measurements Of Pollution In The Troposphere (MOPITT), and the Global Ozone Monitoring Experiment (GOME). Other satellite-based data include the MODIS-derived CDNC from Bennartz (2007) (BE07).

Regional observational networks include the Clean Air Status and Trends Network (CASTNET), the Interagency Monitoring of Protected Visual Environments (IMPROVE), and the Speciation Trends Network (STN) over CONUS; the European Monitoring and Evaluation Programme (EMEP), the Base de Données sur la Qualité de l'Air (BDQA), and the European air quality database (AirBase) over Europe; the Ministry of Environmental Protection of China (MEP of China), the National Institute for Environmental Studies of Japan (NIES of Japan), and Taiwan Air Quality Monitoring Network (TAQMN) over East Asia. The observational data for particle formation rate $J$ is compiled from Kulmala et al. (2004) and Yu et al. (2008), which include land-, ship-, and aircraft-based measurements.

\subsection{Evaluation protocol}

The protocols for performance evaluation include spatial distributions and statistics, following the approach of Zhang et al. (2012b). The analysis of the performance statistics will focus on mean bias (MB), normalized mean bias (NMB), normalized mean error (NME), and root mean square error (RMSE). The radiative variables are evaluated annually, including downwelling shortwave radiation (SWD) and downwelling long-wave radiation (LWD) from BSRN; outgoing long-wave radiation (OLR) from NOAA/CDC; shortwave cloud forcing (SWCF) from CERES; cloud fraction (CF), aerosol optical depth (AOD), cloud optical thickness (COT), cloud water path (CWP), precipitating water vapor (PWV), and CCN from MODIS; and CDNC from BE07. Chemical concentrations evaluated include seasonal and annual averaged concentrations of $\mathrm{CO}, \mathrm{O}_{3}, \mathrm{SO}_{2}, \mathrm{NH}_{3}, \mathrm{NO}_{2}, \mathrm{HNO}_{3}, \mathrm{PM}$, and its major components (i.e., $\mathrm{SO}_{4}^{2-}, \mathrm{NO}_{3}^{-}$, and $\mathrm{NH}_{4}^{+}, \mathrm{BC}$, $\mathrm{OC}$, total carbon (TC) for CONUS and Europe). The chemical observations over East Asia are very limited, and they only include surface concentrations of $\mathrm{CO}, \mathrm{SO}_{2}, \mathrm{NO}_{2}, \mathrm{O}_{3}$, and $\mathrm{PM}_{10}$. Column concentrations of tropospheric $\mathrm{CO}$ and 
Table 2. Mean bias (MB) and normalized mean bias (NMB, in \%) of radiative/cloud predictions for the 2001 simulations.

\begin{tabular}{|c|c|c|c|c|c|c|c|c|c|}
\hline \multirow[t]{2}{*}{ Species/variables } & \multirow[t]{2}{*}{ Data set } & & \multicolumn{7}{|c|}{ Simulations $^{\mathrm{a}}$} \\
\hline & & Obs. & $\begin{array}{l}\mathrm{MAM}_{-} \\
\text {SIM }\end{array}$ & $\begin{array}{l}\text { MAM_ } \\
\text { CB05_GE }\end{array}$ & $\begin{array}{l}\mathrm{MAM}_{-} \\
\mathrm{CON}\end{array}$ & $\begin{array}{l}\text { MAM_ } \\
\text { CON/IMN }\end{array}$ & $\begin{array}{c}\text { MAM_ } \\
\text { CON/ISO }\end{array}$ & $\begin{array}{l}\text { MAM_- }_{-} \\
\text {NEWA }\end{array}$ & $\begin{array}{r}\text { MAM_- } \\
\text { NEW/EMIS }\end{array}$ \\
\hline \multirow{2}{*}{$\operatorname{LWD}\left(\mathrm{W} \mathrm{m}^{-2}\right)^{\mathrm{b}}$} & \multirow{2}{*}{ BSRN } & 312.5 & $309.2 /$ & $309.6 /$ & 308.4/ & $308.0 /$ & $308.3 /$ & $308.7 /$ & 309.1/ \\
\hline & & & $-3.4 /-1.1$ & $-2.9 /-0.9$ & $-4.2 /-1.3$ & $-4.5 /-1.4$ & $-4.2 /-1.3$ & $-3.8 /-1.2$ & $-3.5 /-1.1$ \\
\hline \multirow{2}{*}{$\operatorname{SWD}\left(\mathrm{W} \mathrm{m}^{-2}\right)^{\mathrm{c}}$} & \multirow{2}{*}{ BSRN } & 181.2 & $179.2 /$ & $177.0 /$ & $169.4 /$ & $170.2 /$ & $177.3 /$ & $174.5 /$ & $177.0 /$ \\
\hline & & & $-2.0 /-1.1$ & $-4.2 /-2.3$ & $-11.8 /-6.5$ & $-11.0 /-6.1$ & $-3.9 /-2.2$ & $-6.8 /-3.7$ & $-4.2 /-2.3$ \\
\hline \multirow{2}{*}{$\operatorname{OLR}\left(\mathrm{W} \mathrm{m}^{-2}\right)$} & \multirow{2}{*}{ NOAA-CDC } & 214.4 & $223.2 /$ & $222.4 /$ & $219.3 /$ & $219.3 /$ & $220.7 /$ & $221.2 /$ & $221.2 /$ \\
\hline & & & $8.8 / 4.1$ & $8.1 / 3.8$ & $4.9 / 2.3$ & $4.9 / 2.3$ & $6.2 / 2.9$ & $6.9 / 3.2$ & $6.9 / 3.2$ \\
\hline \multirow{2}{*}{$\operatorname{SWCF}\left(\mathrm{W} \mathrm{m}^{-2}\right)$} & \multirow{2}{*}{ CERES } & -41.0 & $-37.8 /$ & $-38.4 /$ & $-43.2 /$ & $-43.3 /$ & $-40.4 /$ & $-40.7 /$ & $-40.5 /$ \\
\hline & & & $-3.2 /-7.9$ & $-2.7 /-6.5$ & $2.2 / 5.3$ & $2.3 / 5.6$ & $-0.7 /-1.6$ & $-0.4 /-0.9$ & $-0.6 /-1.4$ \\
\hline \multirow{2}{*}{$\mathrm{CF}(\%)$} & \multirow{2}{*}{ MODIS } & 66.9 & $65.6 /$ & $65.9 /$ & $67.5 /$ & 67.6/ & $66.4 /$ & $66.5 /$ & $66.6 /$ \\
\hline & & & $-1.4 /-2.0$ & $-1.0 /-1.5$ & $0.5 / 0.8$ & $0.7 / 1.0$ & $-0.5 /-0.8$ & $-0.4 /-0.6$ & $-0.3 /-0.5$ \\
\hline \multirow{3}{*}{ COT } & \multirow{3}{*}{ MODIS } & 17.1 & $6.9 /$ & $7.1 /$ & $8.7 /$ & $8.8 /$ & $7.7 /$ & $7.7 /$ & $7.7 /$ \\
\hline & & & $-10.2 /-59.5$ & $-10.1 /-58.8$ & $-8.4 /-49.2$ & $-8.3 /-48.4$ & $-9.4 /-55.1$ & $-9.4 /-54.9$ & $-9.4 /-55.2$ \\
\hline & & 148.1 & $33.0 /$ & $33.5 /$ & $42.3 /$ & $42.7 /$ & $36.4 /$ & $36.5 /$ & $36.2 /$ \\
\hline \multirow[t]{2}{*}{ CWP $\left(\mathrm{g} \mathrm{m}^{-2}\right)$} & \multirow[t]{2}{*}{ MODIS } & & $-115.1 /$ & $-114.7 /$ & $-105.8 /$ & $-105.4 /$ & $-111.7 /$ & $-111.7 /$ & $-111.9 /$ \\
\hline & & & -77.7 & -77.4 & -71.4 & -71.2 & -75.4 & -75.4 & -75.5 \\
\hline \multirow{4}{*}{ PWV (cm) } & \multirow{4}{*}{ MODIS } & 1.9 & $1.9 /$ & $1.9 /$ & $1.9 /$ & $1.9 /$ & $1.9 /$ & $1.9 /$ & $1.9 /$ \\
\hline & & & $-2.5 \times 10^{-2} /$ & $-1.8 \times 10^{-2} /$ & $-3.3 \times 10^{-2} /$ & $-3.9 \times 10^{-2} /$ & $-1.8 \times 10^{-2} /$ & $-1.4 \times 10^{-2} /$ & $-1.2 \times 10^{-2} /$ \\
\hline & & & -1.3 & -0.9 & -1.7 & -2.0 & -0.9 & -0.7 & -0.6 \\
\hline & & $1.5 \times 10^{-1}$ & $9.8 \times 10^{-2} /$ & $1.0 \times 10^{-1 /} /$ & $1.2 \times 10^{-1 /}$ & $1.3 \times 10^{-1} /$ & $1.0 \times 10^{-1 /}$ & $1.0 \times 10^{-1} /$ & $1.0 \times 10^{-1 /}$ \\
\hline \multirow[t]{2}{*}{ AOD } & \multirow[t]{2}{*}{ MODIS } & & $-5.5 \times 10^{-2} /$ & $-5.2 \times 10^{-2} /$ & $-3.0 \times 10^{-2} /$ & $-2.6 \times 10^{-2} /$ & $-5.3 \times 10^{-2} /$ & $-5.0 \times 10^{-2} /$ & $-5.2 \times 10^{-2} /$ \\
\hline & & & -36.1 & -33.9 & -19.8 & -17.1 & -34.4 & -32.9 & -34.0 \\
\hline \multirow{3}{*}{$\begin{array}{l}\text { Column CCN5 } \\
\text { (ocean) }\left(\mathrm{cm}^{-2}\right)\end{array}$} & \multirow[t]{3}{*}{ MODIS } & $2.4 \times 10^{8}$ & $5.8 \times 10^{7} /$ & $5.2 \times 10^{7} /$ & $1.8 \times 10^{8} /$ & $2.0 \times 10^{8} /$ & $9.1 \times 10^{7} /$ & $8.5 \times 10^{7} /$ & $8.2 \times 10^{7} /$ \\
\hline & & & $-1.9 \times 10^{8} /$ & $-1.9 \times 10^{8} /$ & $-6.7 \times 10^{7} /$ & $-4.6 \times 10^{7} /$ & $-1.5 \times 10^{8} /$ & $-1.6 \times 10^{8} /$ & $-1.6 \times 10^{8} /$ \\
\hline & & & -76.4 & -78.6 & -27.5 & -18.8 & -62.7 & -65.3 & -66.6 \\
\hline \multirow{2}{*}{$\operatorname{CDNC}\left(\mathrm{cm}^{-3}\right)$} & \multirow{2}{*}{ BE07 } & 113.1 & $45.5 /$ & $46.7 /$ & $89.7 /$ & 93.1/ & $65.0 /$ & $66.7 /$ & $67.0 /$ \\
\hline & & & $-67.7 /-59.9$ & $-66.5 /-58.8$ & $-23.4 /-20.7$ & $-20.0 /-17.7$ & $-48.1 /-42.5$ & $-46.4 /-41.0$ & $-46.1 /-40.8$ \\
\hline
\end{tabular}

$\mathrm{NO}_{2}$, and tropospheric $\mathrm{O}_{3}$ residual (TOR) are evaluated on the global scale.

All observational data used for evaluating 2001 simulations are based on 2001 only except for particle formation rates $(J)$ that are based on different years compiled from Kulmala et al. (2004) and Yu et al. (2008). All observational data used for evaluating 2001-2005 simulations are based on 2001-2005.

\section{Model evaluation for MAM_SIM based on original model treatments}

Tables 2 and 3 show MBs and NMBs of radiative/cloud and chemical predictions, respectively. The model performance of the baseline simulation, MAM_SIM, is discussed below, and the performance of all other simulations will be discussed in Sect. 5.

As shown in Table 2, radiative variables such as LWD and SWD are underpredicted, by $3.4 \mathrm{~W} \mathrm{~m}^{-2}(\sim-1.1 \%)$ and $2.0 \mathrm{~W} \mathrm{~m}^{-2}(\sim-1.1 \%)$, respectively, whereas OLR and SWCF are overpredicted, by $8.8 \mathrm{~W} \mathrm{~m}^{-2}(\sim 4.1 \%)$ and $3.2 \mathrm{~W} \mathrm{~m}^{-2}(\sim 7.9 \%)$ respectively. Cloud variables such as CF and PWV are slightly underpredicted, whereas COT, CWP, column CCN at a supersaturation of $0.5 \%$ (CCN5), and CDNC are largely underpredicted, with NMBs of -77.8 to $-55.6 \%$, which is likely due to the limitations in the cur- rent model treatments of cloud microphysics and aerosolcloud interactions in CAM5.1.

AOD is also underpredicted, by $36.1 \%$, which is likely due to inaccurate prediction of aerosol concentrations and uncertainties in the assumed hygroscopicity of aerosol components in the calculation of optical properties and water uptake. For example, as shown in Table $3, \mathrm{PM}_{2.5}$ concentrations over CONUS and Europe, and $\mathrm{PM}_{10}$ concentrations over CONUS, Europe, and East Asia are underpredicted, with NMBs of -67.5 to $-31.8 \%$, which is due to the inaccurate prediction of $\mathrm{SO}_{4}^{2-}, \mathrm{NH}_{4}^{+}$, and organic aerosols, and missing major inorganic aerosol species such as nitrate and chloride. The concentrations of $\mathrm{BC}, \mathrm{OC}$, and $\mathrm{TC}$ are underpredicted (by $\sim 50 \%$ ), which is likely due to the uncertainties in the $\mathrm{BC}$ and primary $\mathrm{OC}$ emissions as well as treatments for SOA formation. In particular, the SOA treatment used in CAM5.1 is based on a highly simplified aerosol yield approach with a single lumped semi-volatile organic gas (i.e., $\mathrm{SOAG}$ ). For gaseous species, $\mathrm{SO}_{2}$ concentrations over CONUS and Europe are significantly overpredicted, by $10.3 \mu \mathrm{g} \mathrm{m}^{-3}(\sim 264.8 \%)$ and $6.6 \mu \mathrm{g} \mathrm{m}^{-3}(\sim 97.5 \%)$, respectively, whereas $\mathrm{SO}_{2}$ concentrations over East Asia are largely underpredicted, by $7.9 \mu \mathrm{g} \mathrm{m}^{-3}$ (by $\sim 63.0 \%$ ). $\mathrm{NH}_{3}$ concentrations over Europe are also largely underpredicted, by $82.0 \%$. These large biases in $\mathrm{SO}_{2}$ and $\mathrm{NH}_{3}$ are likely due in part to the uncertainties in the emissions of $\mathrm{SO}_{2}$ and $\mathrm{NH}_{3}$, 
which in turn affect the prediction of $\mathrm{SO}_{4}^{2-}$ and $\mathrm{NH}_{4}^{+}$. The $J$ values in the PBL are highly underpredicted, by $99.6 \%$, which is mainly due to the inaccurate calculation of $\mathrm{H}_{2} \mathrm{SO}_{4}$ vapor concentration that participates in the nucleation and uncertainties in the nucleation parameterizations used in the default CESM/CAM5.1.

\section{Sensitivity simulations}

\subsection{Impacts of new gas-phase chemistry}

Compared to simple gas-phase chemistry, many more gaseous species and chemical reactions simulated in CB05_GE can affect secondary aerosol formation through gas-to-particle mass transfer and aqueous-phase chemistry and affect climatic variables through chemistry feedbacks to the climate system. Figure $1 \mathrm{a}$ shows the absolute differences of $\mathrm{H}_{2} \mathrm{O}_{2}, \mathrm{SO}_{2}, \mathrm{SO}_{4}^{2-}$, and $\mathrm{SOA}$ between MAM_CB05_GE and MAM_SIM. MAM_CB05_GE treats more gaseous species and chemical reactions than MAM_SIM, leading to large changes in the concentrations of gaseous and PM species. Compared with MAM_SIM, MAM_CB05_GE predicts higher $\mathrm{H}_{2} \mathrm{O}_{2}$ by $0.4 \mathrm{ppb}, \mathrm{SO}_{2}$ by $7.3 \mathrm{ppt}, \mathrm{SO}_{4}^{2-}$ by $0.01 \mu \mathrm{g} \mathrm{m}^{-3}$, and SOA by $0.06 \mu \mathrm{g} \mathrm{m}^{-3}$, in terms of global mean. Those changes are mainly caused by different gas-phase chemical mechanisms used in MAM_SIM and MAM_CB05_GE. While MAM_CB05_GE explicitly simulates $\mathrm{OH}, \mathrm{HO}_{2}, \mathrm{NO}_{3}$, and $\mathrm{O}_{3}$, MAM_SIM uses climatology data for these species. OH simulated by MAM_CB05_GE is lower than that prescribed by MAM_SIM by up to $2.8 \times 10^{6}$ molecules $\mathrm{cm}^{-3}$, or higher by up to $3.0 \times 10^{6}$ molecules $\mathrm{cm}^{-3}$ in different regions (figure not shown), with a higher global mean than MAM_CB05_GE. MAM_SIM includes the production of $\mathrm{H}_{2} \mathrm{O}_{2}$ from the self-destruction of $\mathrm{HO}_{2}$ and the loss of $\mathrm{H}_{2} \mathrm{O}_{2}$ through its photolytic reaction and its reaction with $\mathrm{OH}$. Higher $\mathrm{H}_{2} \mathrm{O}_{2}$ in MAM_CB05_GE is mainly due to greater production of $\mathrm{H}_{2} \mathrm{O}_{2}$ from additional chemical reactions (e.g., $\mathrm{OH}+\mathrm{OH}$ ) than loss of $\mathrm{H}_{2} \mathrm{O}_{2}$ through the reactions of $\mathrm{OH}+\mathrm{H}_{2} \mathrm{O}_{2}, \mathrm{O}+\mathrm{H}_{2} \mathrm{O}_{2}, \mathrm{Cl}+\mathrm{H}_{2} \mathrm{O}_{2}$, and $\mathrm{Hg}+\mathrm{H}_{2} \mathrm{O}_{2}$. Different predictions of $\mathrm{H}_{2} \mathrm{O}_{2}$ can in turn affect $\mathrm{OH}$ mixing ratios in MAM_CB05_GE but not in MAM_SIM. In addition, the photolytic reactions of volatile organic compounds (VOCs) (e.g., HCHO, peroxyacyl nitrates (PAN), and peroxyacetic and higher peroxycarboxylic acids, $\mathrm{PACD}$ ) and other gases (e.g., $\mathrm{HNO}_{3}, \mathrm{HONO}, \mathrm{HNO}_{4}, \mathrm{HOCl}$, and $\mathrm{HOBr}$ ) treated in MAM_CB05_GE can produce OH. Figure $1 \mathrm{~b}$ shows the absolute differences between the mixing ratios of major oxidants predicted from MAM_CB05_GE and climatology values used in MAM_SIM. The global mean mixing ratios of oxidants are higher in MAM_CB05_GE than the climatology data in MAM_SIM, leading to more oxidation of VOCs and therefore more SOA in MAM_CB05_GE. Higher $\mathrm{O}_{3}$ predicted from MAM_CB05_GE over most of the domain is mainly due to more $\mathrm{O}_{3}$ precursors (e.g., $\mathrm{NO}_{2}$ and VOCs) treated in the model. Despite higher $\mathrm{OH}$ mixing ratios in MAM_CB05_GE, many gaseous species such as $\mathrm{NO}_{\mathrm{x}}, \mathrm{SO}_{2}$, $\mathrm{HNO}_{3}, \mathrm{HONO}$, and other VOCs are oxidized by $\mathrm{OH}$ to form secondary inorganic and organic aerosols. Those oxidation reactions compete for limited $\mathrm{OH}$, leading to less oxidation of $\mathrm{SO}_{2}$, and thus higher $\mathrm{SO}_{2}$ mixing ratios over most land areas by MAM_CB05_GE. Lower $\mathrm{SO}_{2}$ mixing ratios over the oceanic areas in MAM_CB05_GE are due to the combined effects of less production of $\mathrm{SO}_{2}$ from lower DMS mixing ratios (due to increased $\mathrm{OH}$ levels) and greater $\mathrm{SO}_{2}$ oxidation from higher $\mathrm{OH}$ mixing ratios.

The changes in the concentrations of PM and its components are due to the change in the mixing ratios of gaseous precursors. CB05_GE contains more photolytic reactions, which affect the mixing ratios of $\mathrm{OH}, \mathrm{SO}_{2}$, and $\mathrm{H}_{2} \mathrm{SO}_{4}$, and subsequently the concentration of $\mathrm{SO}_{4}^{2-}$ through condensation and homogeneous nucleation. Higher $\mathrm{SO}_{2}$ mixing ratios in MAM_CB05_GE result in more $\mathrm{H}_{2} \mathrm{SO}_{4}$ and thus more $\mathrm{SO}_{4}^{2-}$. For example, both $\mathrm{SO}_{2}$ mixing ratios and $\mathrm{SO}_{4}^{2-}$ concentrations are higher over eastern China in MAM_CB05_GE. More $\mathrm{SO}_{4}^{2-}$ over the oceanic areas is mainly due to more oxidation of $\mathrm{SO}_{2}$ by $\mathrm{OH}$. Due to the simplification of aerosol thermodynamics in default MAM7, the concentrations of $\mathrm{SO}_{4}^{2-}$ can affect the concentrations of $\mathrm{NH}_{4}^{+}$ directly and therefore $\mathrm{NH}_{3}$ mixing ratios and $\mathrm{PM}$ number concentrations $\left(\mathrm{PM}_{\text {num }}\right)$. For example, the increase of $\mathrm{SO}_{4}^{2-}$ results in an increase in $\mathrm{NH}_{4}^{+}$and $\mathrm{PM}_{\text {num }}$, and a decrease in $\mathrm{NH}_{3}$. The increase of $\mathrm{SO}_{4}^{2-}$ and $\mathrm{PM}_{\text {num }}$ can increase AOD, $\mathrm{CF}, \mathrm{COT}, \mathrm{CWP}, \mathrm{PWV}$, and CDNC and therefore affect radiation by increasing LWD and SWD (figures not shown, see changes in performance statistics of these affected variables in Table 2). The increase of SOA is due to the inclusion of more gaseous precursor emissions (e.g., isoprene, terpene, xylene, and toluene) in MAM_CB05_GE, which contribute to SOAG and thus SOA through gas-to-particle conversion.

Figure 2 shows the spatial distributions of $\mathrm{CO}, \mathrm{O}_{3}$, $\mathrm{NO}_{2}, \mathrm{HNO}_{3}$, hydrochloric acid ( $\mathrm{HCl}$ ), and isoprene (ISOP) that can be predicted by MAM_CB05_GE but not by MAM_SIM. CO mixing ratio is higher in most of Asia, central Africa, South Africa, and the eastern US, which is mainly due to higher $\mathrm{CO}$ emissions in those regions and the production of $\mathrm{CO}$ from the photolytic reactions of VOCs (e.g., formaldehyde, acetaldehyde, and isoprene). Higher $\mathrm{O}_{3}$ mixing ratios in the Northern Hemisphere than Southern Hemisphere are mainly due to much higher mixing ratios of $\mathrm{O}_{3}$ precursors. Higher $\mathrm{O}_{3}$ mixing ratios over the Mediterranean Sea are mainly due to the transport of $\mathrm{O}_{3}$ and its precursors from source regions and less deposition onto ocean surface. Higher $\mathrm{O}_{3}$ mixing ratios over Tibet are mainly due to the stratospheric influences from high altitude and no titration of $\mathrm{O}_{3}$ due to low $\mathrm{NO}$ mixing ratios $(<0.2 \mathrm{ppb})$ in this region. Higher mixing ratios of $\mathrm{NO}_{2}$ over most of Asia, the eastern US, Europe, and central Africa are mainly due to 
Table 3. Mean bias (MB) and normalized mean bias (NMB, in \%) of chemical predictions for the 2001 simulations.

\begin{tabular}{|c|c|c|c|c|c|c|c|c|c|c|}
\hline \multirow{2}{*}{$\begin{array}{l}\text { Species/ } \\
\text { variables }^{\mathrm{a}}\end{array}$} & \multirow[t]{2}{*}{ Domain } & \multirow[t]{2}{*}{ Obs. } & \multicolumn{8}{|c|}{ Simulations ${ }^{\mathrm{b}}$} \\
\hline & & & MAM_SIM & MAM_CB05_GE & MAM_CON & MAM_CON/IMN & MAM_CON/ISO & MAM_NEWA & MAM_NEWB & $\begin{array}{r}\text { MAM_NEW/ } \\
\text { EMIS }\end{array}$ \\
\hline \multirow[t]{2}{*}{$\mathrm{CO}$} & Europe & 123.0 & - & $112.4 /-10.6 /-8.6$ & $115.0 /-8.0 /-6.5$ & $107.9 /-15.1 /-12.3$ & $114.0-9.0 /-7.3$ & $118.8 /-4.2 /-3.4$ & $113.6 /-9.4 /-7.6$ & $137.9 / 14.9 / 12.1$ \\
\hline & East Asia & 0.6 & - & $0.1 /-0.5 /-82.1$ & $0.1 /-0.5 /-82.0$ & $0.1 /-0.5 /-81.8$ & $0.1 /-0.5 /-81.8$ & $0.1 /-0.5 /-82.0$ & $0.1 /-0.5 /-81.7$ & $0.1 /-0.5 /-78.7$ \\
\hline \multirow[t]{3}{*}{$\mathrm{SO}_{2}$} & CONUS & 3.9 & $14.2 / 10.3 / 264.8$ & $14.4 / 10.5 / 270.1$ & 15.6/11.7/301.2 & $15.1 / 11.2 / 286.1$ & $15.4 / 11.5 / 295.8$ & $15.3 / 11.4 / 291.8$ & 15.3/11.4/293.0 & 9.8/5.9/152.2 \\
\hline & Europe & 6.8 & $13.4 / 6.6 / 97.5$ & 13.8/7.0/103.2 & 15.2/8.4/123.0 & $13.6 / 6.8 / 100.3$ & $14.6 / 7.8 / 114.7$ & $15.7 / 8.9 / 130.7$ & $14.5 / 7.7 / 114.0$ & $6.8 / 0.0 / 0.3$ \\
\hline & East Asia & 12.5 & $4.6 /-7.9 /-63.0$ & $4.8 /-7.7 /-61.3$ & $4.8 /-7.7 /-61.4$ & $4.8 /-7.7 /-61.8$ & $4.9-7.6 /-61.0$ & $4.8 /-7.7 /-61.2$ & $4.8 /-7.7 /-61.2$ & $5.8 /-6.7 /-53.4$ \\
\hline $\mathrm{NH}_{3}$ & Europe & 9.4 & $1.7 /-7.7 /-82.0$ & $1.8 /-7.6 /-80.8$ & $1.2 /-8.2 /-86.8$ & $1.1 /-8.3 /-87.8$ & $1.4 /-8.0 /-84.7$ & $1.5 /-7.9 /-84.3$ & $1.1 /-8.3 /-84.0$ & $2.1 /-7.3 /-77.5$ \\
\hline \multirow[t]{2}{*}{$\mathrm{NO}_{2}$} & Europe & 20.2 & - & $4.6 /-15.6 /-77.0$ & $5.2 /-15.0 /-74.1$ & $4.7 /-15.5 /-76.5$ & $5.0 /-15.2 /-75.2$ & $5.2 /-15.0 /-74.1$ & $4.9 /-15.3 /-75.7$ & $4.9 /-15.3 /-75.9$ \\
\hline & East Asia & 14.0 & - & $1.6 /-12.4 /-88.4 /$ & $1.7 /-12.3 /-88.0$ & $1.7 /-12.3 /-88.2$ & $1.6 /-12.4 /-88.4$ & $1.7 /-12.3 /-88.3$ & $1.6 /-12.4 /-88.5$ & $1.7 /-12.3 /-88.2$ \\
\hline \multirow[t]{3}{*}{$\mathrm{O}_{3}$} & CONUS & 34.6 & - & $44.6 / 10.0 / 28.9$ & $42.6 / 8.0 / 23.0$ & $42.5 / 7.9 / 22.7$ & $44.4 / 9.8 / 28.4$ & $44.1 / 9.5 / 27.4$ & $43.7 / 9.1 / 26.4$ & $44.4 / 9.8 / 28.1$ \\
\hline & Europe & 53.5 & - & $90.2 / 36.7 / 68.6$ & $84.4 / 30.9 / 57.7$ & $84.5 / 31.0 / 58.0$ & $87.6 / 34.1 / 63.7$ & $87.0 / 33.5 / 62.7$ & $87.7 / 34.2 / 63.9$ & $88.4 / 34.9 / 65.2$ \\
\hline & East Asia & 26.4 & - & $42.8 / 16.4 / 62.2$ & $42.7 / 16.3 / 61.7$ & $40.7 / 14.3 / 54.3$ & $42.6 / 16.2 / 65.9$ & $42.1 / 15.7 / 59.6$ & $43.0 / 16.6 / 63.0$ & $42.5 / 16.1 / 61.2$ \\
\hline \multirow[t]{2}{*}{$\mathrm{HNO}_{3}$} & CONUS & 1.5 & - & $2.5 / 1.0 / 68.1$ & $0.6 /-0.9 /-60.2$ & $0.6 /-0.9 /-59.7$ & $1.7 / 0.2 / 15.8$ & $1.8 / 0.3 / 17.7$ & 1.8/0.3/19.0 & $1.6 / 0.1 / 4.1$ \\
\hline & Europe & 0.5 & - & $1.8 / 1.3 / 268.5$ & $0.3 /-0.2 /-34.1$ & $0.3 /-0.2 /-35.8$ & $0.9 / 0.4 / 86.1$ & $0.9 / 0.4 / 83.6$ & $1.0 / 0.5 / 103.8$ & $0.9 / 0.4 / 73.8$ \\
\hline \multirow[t]{2}{*}{$\mathrm{SO}_{4}^{2-}$} & CONUS & 2.6 & $2.5 /-0.1 /-5.1$ & $2.4 /-0.2 /-7.2$ & $2.6 / 4.4 \times 10^{-2} / 1.7$ & $2.6 / 4.2 \times 10^{-2} / 1.6$ & $2.4 /-0.2 /-7.9$ & $2.4 /-0.2 /-6.3$ & $2.5 /-0.1 /-5.5$ & $1.9 /-0.7 /-28.4$ \\
\hline & Europe & 2.2 & $3.0 / 0.8 / 36.5$ & 2.9/0.7/33.1 & $3.1 / 0.9 / 40.3$ & $3.0 / 0.8 / 35.8$ & $2.9 / 0.7 / 32.6$ & $3.1 / 0.9 / 39.4$ & $3.0 / 0.8 / 36.8$ & $2.0 /-0.2 /-7.2$ \\
\hline \multirow[t]{2}{*}{$\mathrm{NH}_{4}^{+}$} & CONUS & 1.4 & $1.0 /-0.4 /-32.1$ & $0.8 /-0.6 /-39.6$ & $1.7 / 0.3 / 20.0$ & $1.7 / 0.3 / 19.7$ & $1.3 /-0.1 /-6.4$ & $1.3 /-0.1 /-6.5$ & $1.3 /-0.1 /-4.3$ & $1.2 /-0.2 /-13.1$ \\
\hline & Europe & 1.2 & $1.1 /-0.1 /-9.1$ & $1.0 /-0.2 / 18.3$ & $2.2 / 1.0 / 85.0$ & $2.0 / 0.8 / 65.7$ & $1.8 / 0.6 / 49.4$ & $1.9 / 0.7 / 54.8$ & $1.7 / 0.5 / 37.7$ & $1.6 / 0.4 / 32.5$ \\
\hline \multirow[t]{2}{*}{$\mathrm{NO}_{3}^{-}$} & CONUS & 1.0 & - & - & $3.0 / 2.0 / 198.2$ & 2.9/1.9/192.7 & $1.0 /-4.8 \times 10^{-2} /-4.8$ & $0.9 /-0.1 /-9.6$ & $1.0 /-2.2 \times 10^{-2} /-2.1$ & $1.0 / 4.0 \times 10^{-3} / 0.4$ \\
\hline & Europe & 2.0 & - & - & $3.4 / 1.4 / 67.8$ & $3.0 / 1.0 / 49.4$ & $1.9 /-0.1 /-4.3$ & $2.0 /-4.0 \times 10^{-2} /-2.0$ & $1.8 /-0.2 /-12.5$ & $2.1 / 0.1 / 5.2$ \\
\hline \multirow[t]{2}{*}{$\mathrm{Cl}^{-}$} & CONUS & 0.1 & - & - & $0.5 / 0.4 / 359.9$ & $0.5 / 0.4 / 373.1$ & $0.1 /-1.5 \times 10^{-2} /-14.5$ & $0.1 /-1.8 \times 10^{-2} /-17.5$ & $0.1 /-1.5 \times 10^{-2} /-12.1$ & $0.1 /-2.8 \times 10^{-3} /-2.8$ \\
\hline & Europe & 0.7 & - & - & $1.4 / 0.7 / 102.8$ & 1.3/0.6/89.9 & $0.7 / 2.1 \times 10^{-3} / 0.3$ & $0.7 / 1.4 \times 10^{-2} / 2.0$ & $0.6 /-0.1 /-14.5$ & $-4.7 \times 10^{-2} /-6.7$ \\
\hline $\mathrm{BC}$ & CONUS & 0.6 & $0.3 /-0.3 /-54.6$ & $0.3 /-0.3 /-55.8$ & $0.3 /-0.3 /-54.7$ & $0.3 /-0.3 /-54.6$ & $0.3 /-0.3 /-53.8$ & $0.3 /-0.3 /-54.3$ & $0.3 /-0.3 /-54.9$ & $0.4 /-0.2 /-29.4$ \\
\hline $\mathrm{OC}$ & CONUS & 1.1 & $0.8 /-0.3 /-22.7$ & $1.0 /-0.1 /-12.1$ & $1.0 /-0.1 /-11.4$ & $1.0 /-0.1 /-11.9$ & $1.0 /-0.1 /-8.6$ & $1.0 /-0.1 /-9.1$ & $1.0 /-0.1 /-11.3$ & $1.0 / 5.6 \times 10^{-3} / 0.5$ \\
\hline TC & CONUS & 2.5 & $1.3 /-1.2 /-47.9$ & $1.4 /-1.1 /-43.1$ & $1.4 /-1.1 /-42.2$ & $1.4 /-1.1 /-42.5$ & $1.4 /-1.0 /-40.9$ & $1.5 /-1.0 /-41.1$ & $1.4 /-1.1 /-42.5$ & $1.6 /-0.9 /-35.0$ \\
\hline \multirow[t]{2}{*}{$\mathrm{PM}_{2.5}$} & CONUS & 7.9 & $4.9 /-3.0 /-37.6$ & $5.0 /-2.9 /-36.8$ & $9.5 / 1.6 / 20.1$ & $6.6 / 1.3 / 16.7$ & $7.8 /-0.1 /-1.7$ & $6.9 /-1.0 /-13.2$ & $7.2 /-0.7 /-8.8$ & $6.8 /-1.1 /-13.5$ \\
\hline & Europe & 14.5 & $8.4 /-6.1 /-41.8$ & $7.9 /-6.6 /-45.3$ & $13.7 /-0.8 /-5.5$ & $14.4 /-0.1 /-0.9$ & $11.0 /-3.5 /-24.4$ & $11.9 /-2.6 /-17.7$ & $10.9 /-3.6 /-24.9$ & $10.6 /-3.9 /-27.2$ \\
\hline \multirow[t]{2}{*}{$\mathrm{PM}_{10}$} & Europe & 25.7 & $17.5 /-8.2 /-31.8$ & $16.5 /-9.2 /-35.8$ & $22.5 /-3.2 /-12.3$ & $23.0 /-2.7 /-10.5$ & $20.1 /-4.8 /-18.5$ & $21.4 /-4.3 /-16.6$ & $20.7 /-5.0 /-19.4$ & $20.9 /-4.8 /-18.8$ \\
\hline & East Asia & 118.5 & $38.5 /-80.0 /-67.5$ & $44.9 /-73.6 /-62.1$ & $55.9 /-62.6 /-52.8$ & $58.8 /-57.7 /-48.7$ & $48.5 /-70.0 /-59.1$ & $65.5 /-53.0 /-44.7$ & $55.6 /-62.9 /-53.1$ & $48.2 /-70.3 /-59.3$ \\
\hline \multirow[t]{2}{*}{ Col.CO } & Globe & $1.3 \times 10^{18}$ & - & $1.2 \times 10^{18}$ & $1.2 \times 10^{18}$ & $1.2 \times 10^{18}$ & $1.2 \times 10^{18}$ & $1.2 \times 10^{18}$ & $1.2 \times 10^{18}$ & $1.3 \times 10^{18}$ \\
\hline & & & & $7.4 \times 10^{16} /-5.7$ & $-5.7 \times 10^{16} /-4.4$ & $-6.3 \times 10^{16} /-4.8$ & $-6.4 \times 10^{16} /-4.9$ & $-6.3 \times 10^{16} /-4.8$ & $-5.6 \times 10^{16} /-4.3$ & $2.3 \times 10^{16} / 1.8$ \\
\hline \multirow[t]{2}{*}{$\mathrm{Col}_{\mathrm{NO}}$} & Globe & $4.7 \times 10^{14}$ & - & $6.7 \times 10^{14}$ & $6.2 \times 10^{14}$ & $6.2 \times 10^{14}$ & $6.5 \times 10^{14}$ & $6.5 \times 10^{14}$ & $6.5 \times 10^{14}$ & $6.5 \times 10^{14}$ \\
\hline & & & & $1.9 \times 10^{14 / 40.5}$ & $1.4 \times 10^{14} / 30.4$ & $1.4 \times 10^{14} / 30.0$ & $1.8 \times 10^{14} / 37.5$ & $1.8 \times 10^{14} / 37.2$ & $1.8 \times 10^{14} / 37.9$ & $1.8 \times 10^{14 / 37.3}$ \\
\hline TOR & Globe & 30.3 & $29.8 /-0.5 / 1.6$ & $29.2 /-1.1 /-3.7$ & $27.6 /-2.7 /-9.0$ & $27.4 /-2.9 /-9.6$ & $28.8 /-1.5 /-4.9$ & $28.7 /-1.6 /-5.2$ & $28.6 /-1.5 /-5.0$ & $28.6-1.5 /-4.9$ \\
\hline$J$ & Globe & 0.6 & $0.003 /-0.6 /-99.6$ & $0.1 /-0.5 /-99.5$ & $0.5 /-0.1 /-12.8$ & $0.3 /-0.3 /-49.6$ & $0.8 / 0.2 / 36.1$ & $0.3 /-0.3 /-53.1$ & $0.3 /-0.3 /-51.7$ & $0.3 /-0.3 /-62.0$ \\
\hline
\end{tabular}

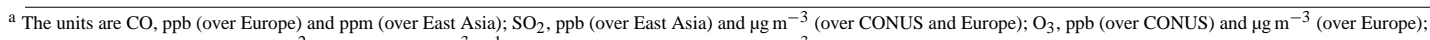

column $\mathrm{CO}$ and $\mathrm{NO}_{2}$, molecules $\mathrm{cm}^{-2}$; TOR, DU; $J, \mathrm{~cm}^{-3} \mathrm{~s}^{-1}$. All other concentrations are in $\mathrm{\mu g} \mathrm{m}^{-3}$.

$\mathrm{b}$ The values of modeled results (Sim), MBs, and NMBs are expressed as Sim/MB/NMB.

higher $\mathrm{NO}_{\mathrm{x}}$ emissions over those regions, which also result in higher $\mathrm{HNO}_{3}$ in those regions. Higher mixing ratios of $\mathrm{HCl}$ over Europe, India, and East Asia are mainly due to the higher anthropogenic $\mathrm{HCl}$ emissions in those regions. In addition, MAM_CB05_GE includes oceanic emissions of $\mathrm{HCl}$, leading to higher $\mathrm{HCl}$ over the ocean. Higher isoprene mixing ratios over South Africa, central Africa, and Oceania are mainly due to higher isoprene emissions in those regions, which also contribute to the formation of SOA in those regions.

The aforementioned changes in the concentrations of gaseous species and PM due to new gas-phase chemistry implemented in the model and its feedbacks to radiation through the climate system result in a change in predicted cloud properties and radiation balance that in turn affect the prediction of all chemical species during subsequent time steps. As a consequence of interwoven changes due to complex feedback mechanisms, the two simulations perform differently, with noticeable improvement with MAM_CB05_GE. As shown in Table 2, compared with MAM_SIM, MAM_CB05_GE reduces MB of LWD by $17.6 \%$, OLR by $8.0 \%$, CF by $28.6 \%$, COT by $1.0 \%$, PWV by $28.0 \%$, AOD by $5.5 \%$, and CDNC by $1.8 \%$, leading to $0.3-2.2 \%$ absolute reduction in their NMBs. Although MAM_CB05_GE increases MB of SWD by $26.2 \%$, the increases in their NMBs are only $1.2 \%$. As shown in Table S1 in the Supplement, the changes in most cloud and radiative variables between MAM_SIM and MAM_CB05_GE are sta- tistically significant. As shown in Table 3, MAM_CB05_GE also reduces $\mathrm{MBs}$ of $\mathrm{SO}_{2}$ by $2.5 \%$ and $\mathrm{PM}_{10}$ by $8.1 \%$ over East Asia, $\mathrm{NH}_{3}$ by $1.3 \%$ and $\mathrm{SO}_{4}^{2-}$ by $12.5 \%$ over Europe, OC by $11.1 \%$, TC by $8.3 \%$, and $\mathrm{PM}_{2.5}$ by $3.3 \%$ over CONUS, leading to $0.8-6.5 \%$ absolute reductions in NMBs. Despite the model improvement with CB05_GE, large biases still remain for some chemical species. For example, $\mathrm{CO}$ over East Asia is largely underpredicted with an NMB of $-82.1 \%$ (see Table 3 ), which results from the uncertainties in $\mathrm{CO}$ emissions over East Asia. However, the column $\mathrm{CO}$ on the global scale is predicted very well, with an NMB of $-5.7 \%$. Large biases in $\mathrm{SO}_{2}$ prediction over CONUS, Europe, and East Asia is mainly due to the uncertainties in the $\mathrm{SO}_{2}$ emissions over those regions. Large biases in $\mathrm{O}_{3}$ over Europe are likely due to the uncertainties in the $\mathrm{O}_{3}$ precursor emissions (e.g., $\mathrm{NO}_{\mathrm{x}}$ ) and inaccurate prediction of radiation over Europe. In particular, the large underprediction in $\mathrm{NO}_{2}$ concentrations (likely due to the uncertainties in the $\mathrm{NO}_{\mathrm{x}}$ emissions and overprediction in radiation, see Sect. 5.5 for more detailed discussions) indicate insufficient $\mathrm{NO}_{\mathrm{x}}$ for titration of $\mathrm{O}_{3}$, leading to a large overprediction in $\mathrm{O}_{3}$ concentrations in Europe. The large biases in $\mathrm{HNO}_{3}$ are due to no treatment for gas/particle partitioning in both simulations. 


\section{MAM_CB05_GE - MAM_SIM}

\section{1}

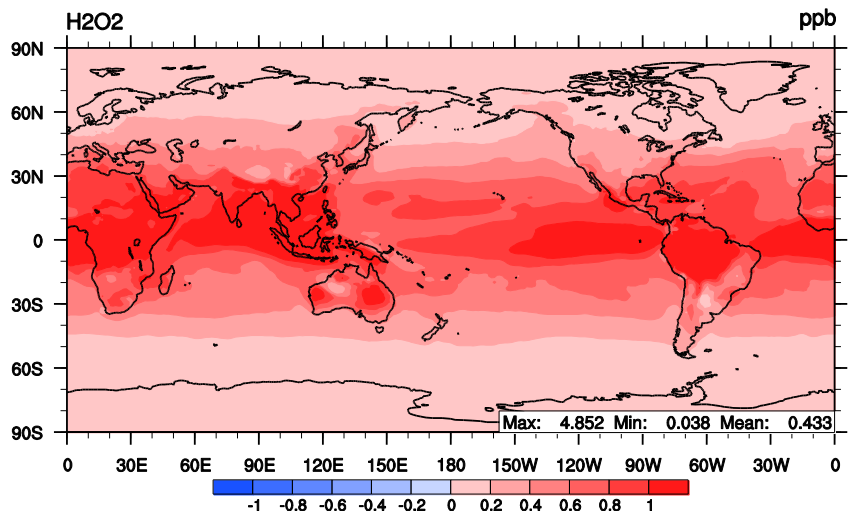

2001

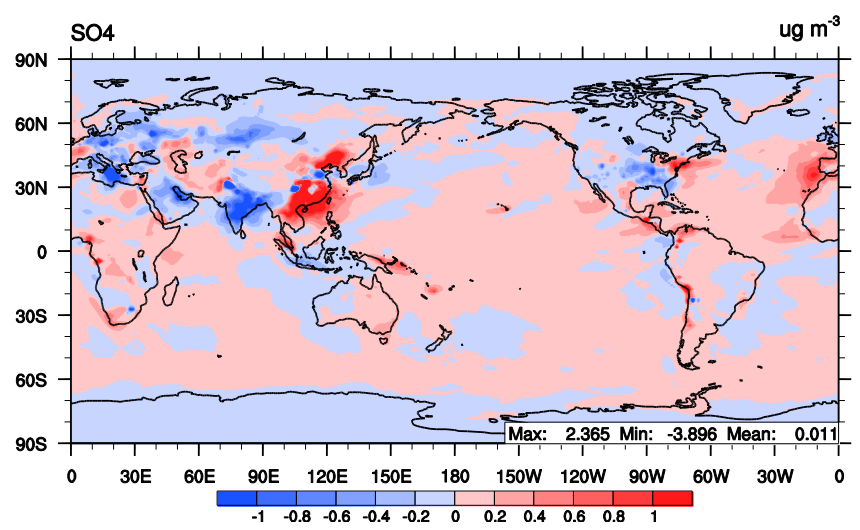

2001

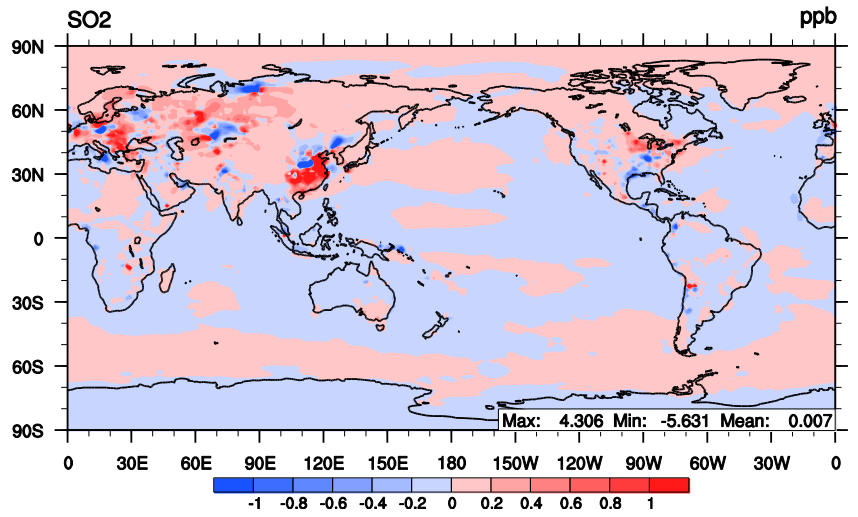

2001

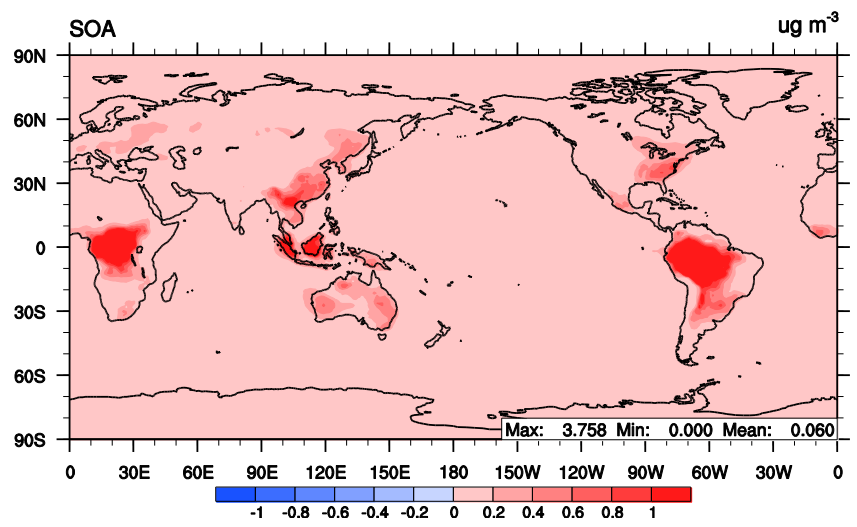

Figure 1a. Absolute differences of $\mathrm{H}_{2} \mathrm{O}_{2}, \mathrm{SO}_{2}, \mathrm{SO}_{4}^{2-}$, and SOA between MAM_CB05_GE and MAM_SIM for 2001.

\subsection{Impacts of condensation and aqueous-phase chemistry}

The mass accommodation coefficient $(\alpha)$ for $\mathrm{H}_{2} \mathrm{SO}_{4}$ vapor is subject to considerable uncertainty. The default condensation module with a default $\alpha$ value of 0.65 gives a very low concentration of $\mathrm{H}_{2} \mathrm{SO}_{4}$, resulting in very low nucleation rates and aerosol number concentrations. Considering that the original model treats $\mathrm{H}_{2} \mathrm{SO}_{4}$ and $\mathrm{NH}_{3}$ condensation as an irreversible process, the default $\alpha$ value of 0.65 for $\mathrm{H}_{2} \mathrm{SO}_{4}$ and $\mathrm{NH}_{3}$ is reduced to 0.02 and 0.097 , respectively, based on Zhang et al. (1998). This change in $\alpha$ value provides sufficient $\mathrm{H}_{2} \mathrm{SO}_{4}$ and $\mathrm{NH}_{3}$ for nucleation with a typical $\mathrm{H}_{2} \mathrm{SO}_{4}$ concentration range of $10^{6}-10^{8}$ molecules $\mathrm{cm}^{-3}$. Because $\mathrm{HNO}_{3}$ and $\mathrm{HCl}$ are semi-volatile species, the lower limits of $\alpha$ (0.0024 and 0.005, respectively) based on Sander et al. (2003) are selected for their irreversible condensation process. $\mathrm{NH}_{4}^{+}$from $\mathrm{NH}_{3}$ condensation will be constrained by the available $\mathrm{SO}_{4}^{2-}, \mathrm{NO}_{3}^{-}$, and condensed $\mathrm{Cl}^{-}$to neutralize the system.

Figure 3 shows the absolute differences of $\mathrm{NH}_{3}, \mathrm{SO}_{2}$, $\mathrm{HNO}_{3}, \mathrm{HCl}, \mathrm{H}_{2} \mathrm{SO}_{4}$, total particulate ammonium $\left(\mathrm{TNH}_{4}\right)$, total particulate sulfate $\left(\mathrm{TSO}_{4}\right)$, total particulate nitrate $\left(\mathrm{TNO}_{3}\right)$, and total particulate chloride (TCL) in all the modes except primary carbon mode, and $\mathrm{PM}_{2.5}$ between MAM_CON and MAM_CB05_GE in June, July, and August (JJA), 2001. Due to the inclusion of $\mathrm{HNO}_{3}$ and $\mathrm{HCl}$ condensation in MAM_CON, the concentrations of $\mathrm{HNO}_{3}$ and $\mathrm{HCl}$ decrease by $0.1 \mathrm{ppb}(\sim 72 \%)$ and $0.097 \mathrm{ppb}(\sim 84 \%)$, respectively. $\mathrm{NO}_{3}^{-}$is not simulated in the original model and the concentration of $\mathrm{NO}_{3}^{-}$is assumed to be zero in MAM_CB05_GE. Therefore, the concentration of $\mathrm{NO}_{3}^{-}$increases due to the condensation of $\mathrm{HNO}_{3}$ in MAM_CON. The concentration of TCL in MAM_CB05_GE is calculated from the mass ratio of chloride in sea salt. Over land, TCL increases significantly due to the condensation of $\mathrm{HCl}$ to form $\mathrm{Cl}^{-}$. The change of TCL over the ocean is mainly due to the change of sea-salt emissions. The changes in $\mathrm{SO}_{2}$ mixing ratios are mainly due to the differences in mixing ratios of species in sulfur chemistry in the two simulations. For example, compared to MAM_CB05_GE, the increase of $\mathrm{SO}_{2}$ over the eastern US in MAM_CON is likely due to less $\mathrm{SO}_{2}$ oxidation in clouds (figure not shown), which results from lower 


\section{MAM_CB05_GE - Climatology}

2001

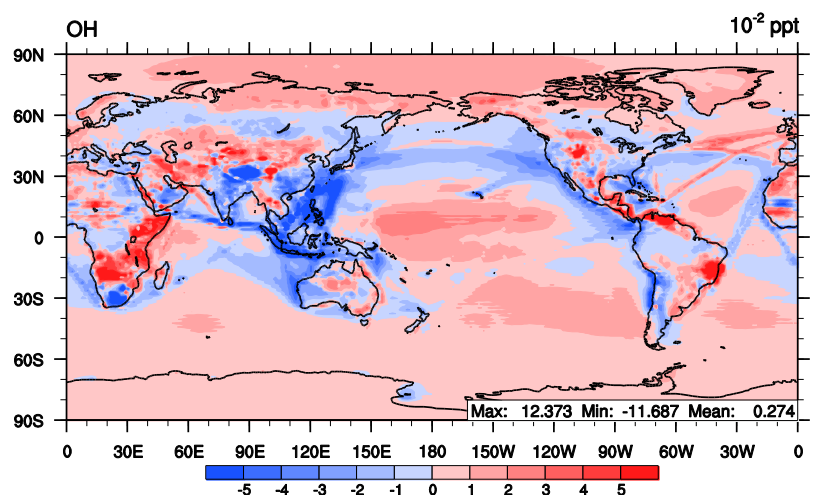

2001

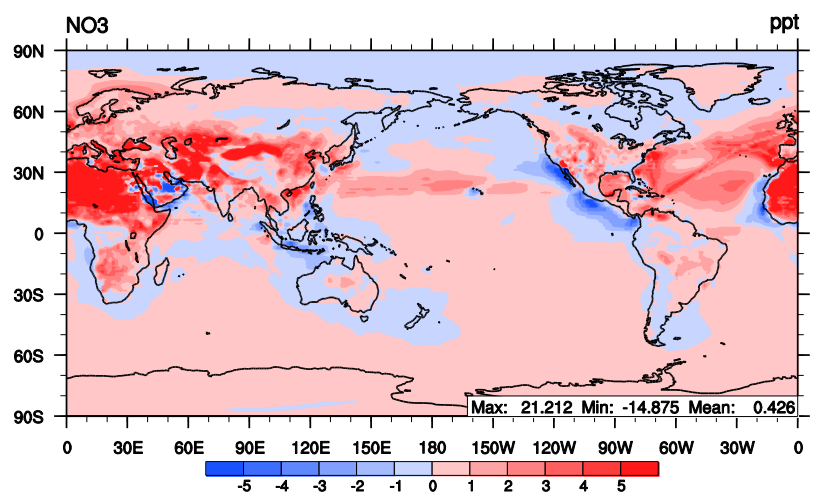

2001

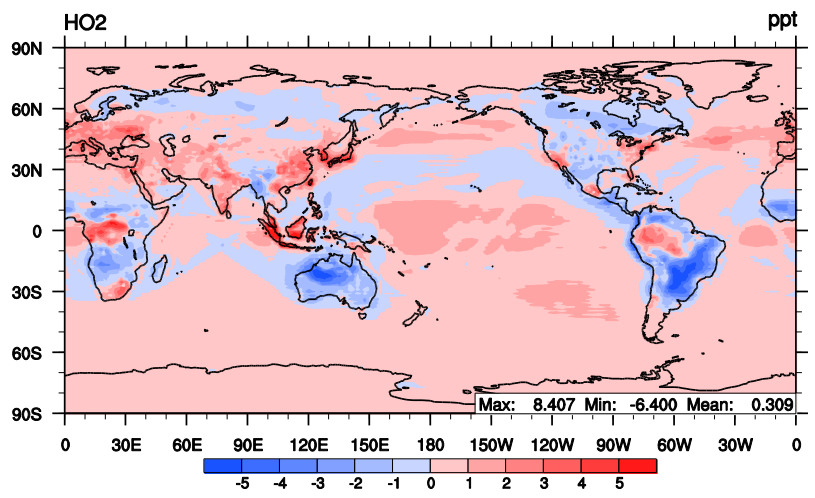

2001

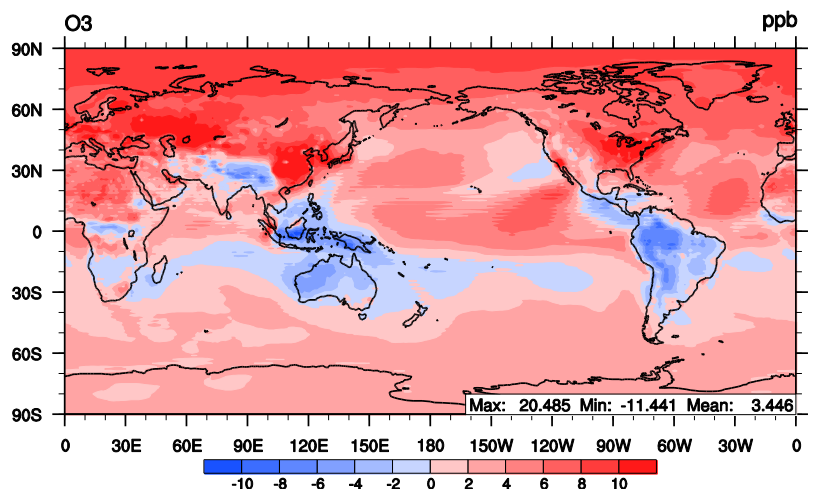

Figure 1b. Absolute differences between the mixing ratios of surface $\mathrm{OH}, \mathrm{HO}_{2}, \mathrm{NO}_{3}$, and $\mathrm{O}_{3}$ predicted from MAM_CB05_GE and climatology values used in MAM_SIM for 2001.

$\mathrm{CF}$. The decrease of $\mathrm{SO}_{2}$ mixing ratios over most oceanic areas is likely due to the combined effects of DMS oxidation and $\mathrm{SO}_{2}$ oxidations in MAM_CON. More $\mathrm{SO}_{2}$ can result in more $\mathrm{H}_{2} \mathrm{SO}_{4}$ and therefore more $\mathrm{SO}_{4}^{2-}$ through condensation and homogeneous nucleation of $\mathrm{H}_{2} \mathrm{SO}_{4}$. The changes in $\mathrm{H}_{2} \mathrm{SO}_{4}$ concentrations are the results of changes in $\mathrm{SO}_{2}$ mixing ratios. The mass accommodation coefficient of $\mathrm{H}_{2} \mathrm{SO}_{4}$ is reduced significantly (by a factor of 32.5), allowing more $\mathrm{H}_{2} \mathrm{SO}_{4}$ to participate in binary/ternary homogeneous nucleation and produce more secondary $\mathrm{SO}_{4}^{2-}$, improving prediction of $\mathrm{SO}_{4}^{2-}$ over CONUS but degrading the performance of $\mathrm{SO}_{4}^{2-}$ over Europe (see Table 3). Although the mass accommodation coefficient of $\mathrm{NH}_{3}$ is reduced significantly (by a factor of 67), more available $\mathrm{NH}_{3}$ can participate in the ternary homogeneous nucleation and produce secondary $\mathrm{NH}_{4}^{+}$. Meanwhile, the secondary $\mathrm{NH}_{4}^{+}$formed from $\mathrm{NH}_{3}$ condensation is also constrained by available $\mathrm{SO}_{4}^{2-}, \mathrm{NO}_{3}^{-}$, and condensed $\mathrm{Cl}^{-}$. As a result, the concentrations of $\mathrm{NH}_{3}$ decrease and those of $\mathrm{NH}_{4}^{+}$increase. Due to more available $\mathrm{H}_{2} \mathrm{SO}_{4}$ participating in the nucleation, $J$ is improved significantly, reducing the NMB from -99.5 to $-12.8 \%$. With an inclusion of the dissolution and dissociation of $\mathrm{HNO}_{3}$ and
$\mathrm{HCl}$ in cloud water, more $\mathrm{NH}_{3}$ is required to dissolve to maintain cation-anion equilibrium in the cloud water, which further reduces the mixing ratios of $\mathrm{NH}_{3}, \mathrm{HNO}_{3}$, and $\mathrm{HCl}$.

As shown in Table 3, compared with MAM_CB05_GE, MAM_CON gives better performance against observations in terms of $\mathrm{CO}, \mathrm{NO}_{2}, \mathrm{O}_{3}, \mathrm{HNO}_{3}, \mathrm{PM}_{2.5}$, and $\mathrm{PM}_{10}$ over Europe, $\mathrm{CO}$ and $\mathrm{PM}_{10}$ over East Asia, $\mathrm{O}_{3}, \mathrm{HNO}_{3}, \mathrm{SO}_{4}^{2-}$, $\mathrm{NH}_{4}^{+}, \mathrm{BC}, \mathrm{OC}, \mathrm{TC}$, and $\mathrm{PM}_{2.5}$ over CONUS, and column CO, column $\mathrm{NO}_{2}$, TOR, and $J$ on the global scale. As also shown in Table 2, the improved chemical predictions improve the prediction of OLR, SWCF, CF, COT, CWP, AOD, and CDNC. As shown in Table S1 in the Supplement, the changes in most cloud/radiative variables between MAM_CB05_GE and MAM_CON are statistically significant, indicating the significant impacts of the modified condensation and aqueous-phase chemistry treatments on radiation. Treating condensation and aqueous-phase chemistry of $\mathrm{HNO}_{3}$ and $\mathrm{HCl}$ enables an explicit simulation of $\mathrm{NO}_{3}^{-}$and $\mathrm{Cl}^{-}$in MAM7. However, the mass concentrations of $\mathrm{SO}_{2}$ remain significantly overpredicted, with NMBs of $301.2 \%$ for CONUS, and $123.0 \%$ for Europe, mainly because of the uncertainties in $\mathrm{SO}_{2}$ emissions over those regions. Due 


\section{MAM_CB05_GE}

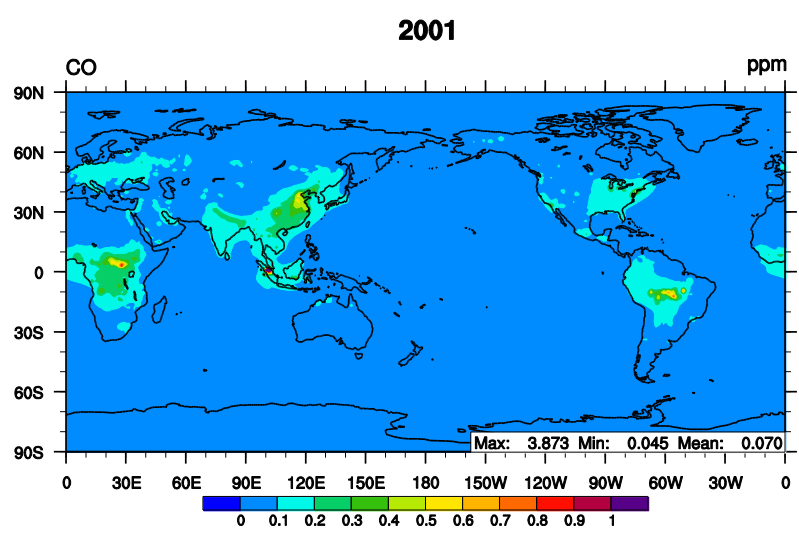

2001

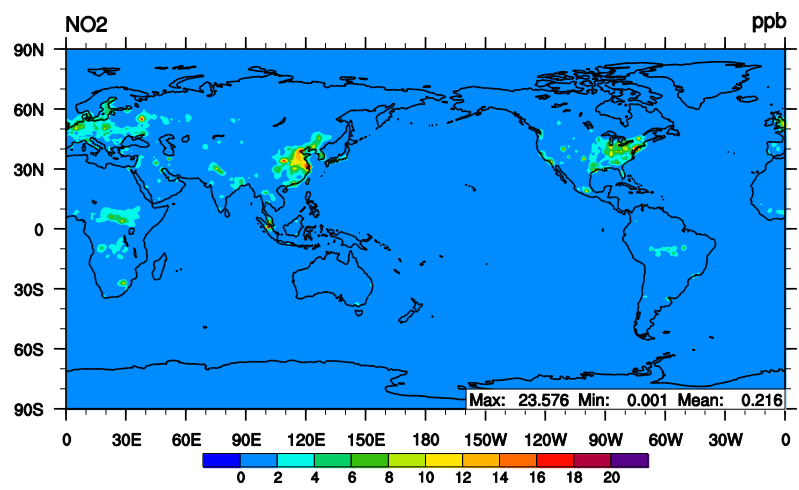

2001

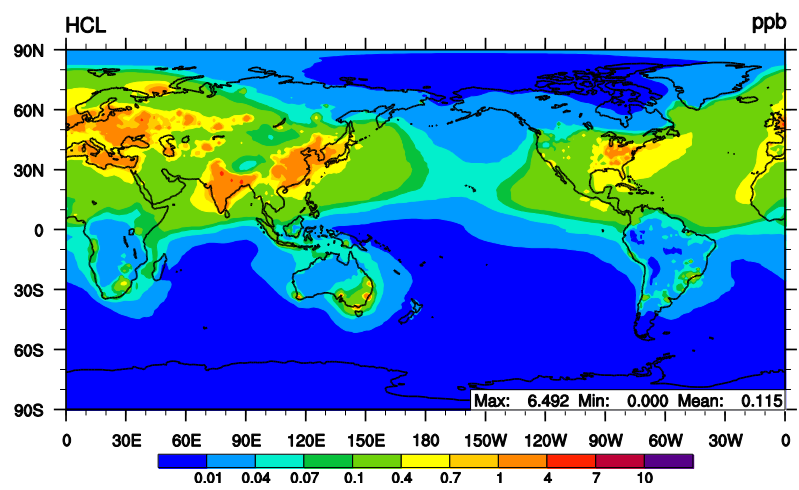

2001

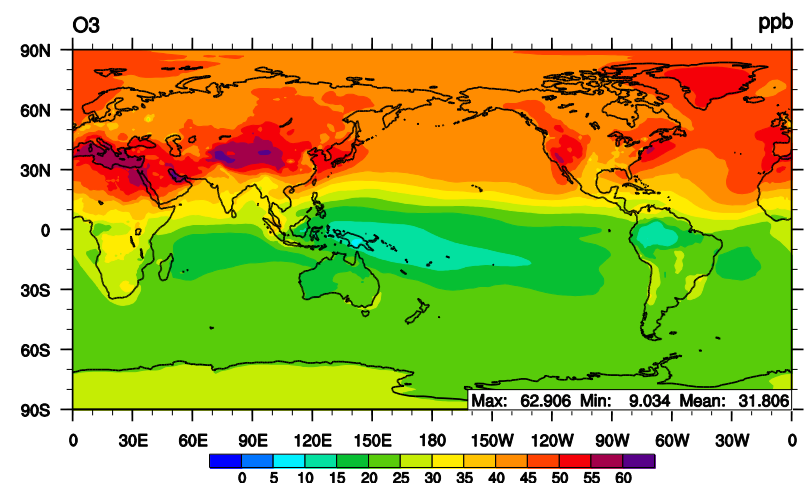

2001

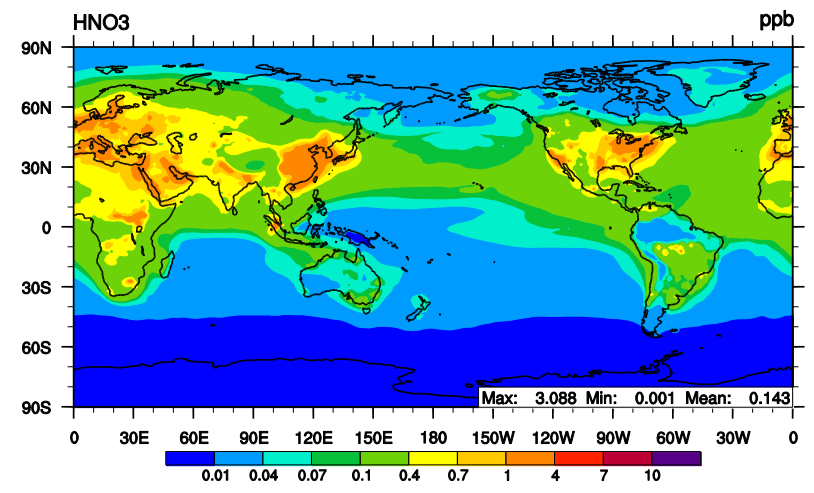

2001

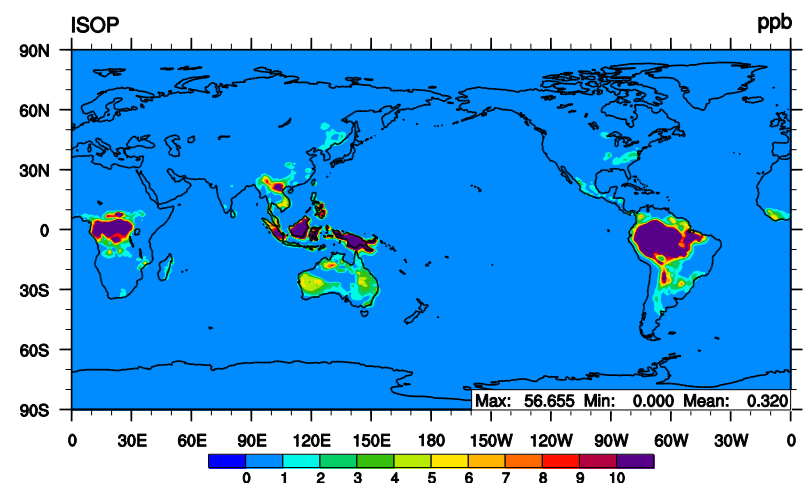

Figure 2. Spatial distributions of $\mathrm{CO}, \mathrm{O}_{3}, \mathrm{NO}_{2}, \mathrm{HNO}_{3}, \mathrm{HCl}$, and isoprene (ISOP) at the surface simulated by MAM_CB05_GE for 2001.

to the simplified irreversible treatment for gas condensation, the mass concentrations of $\mathrm{SO}_{4}^{2-}, \mathrm{NH}_{4}^{+}, \mathrm{NO}_{3}^{-}$, and $\mathrm{Cl}^{-}$are overpredicted, although the lower limit of mass accommodation coefficient for each precursor is used in MAM_CON. As shown in Table 3, the concentrations of $\mathrm{SO}_{4}^{2-}, \mathrm{NH}_{4}^{+}, \mathrm{NO}_{3}^{-}$, and $\mathrm{Cl}^{-}$from MAM_CON are overpredicted by 1.7, 20.0, 198.2, and $359.9 \%$, respectively, for CONUS, and 40.3, 85.0, 67.8, and $102.8 \%$, respectively, for Europe. The large NMBs of $\mathrm{NO}_{3}^{-}$and $\mathrm{Cl}^{-}$in MAM_CON are due to the small observed values for $\mathrm{NO}_{3}^{-}$(i.e., $1.0 \mu \mathrm{g} \mathrm{m}^{-3}$ over CONUS and $2.0 \mu \mathrm{g} \mathrm{m}^{-3}$ over Europe) and $\mathrm{Cl}^{-}$(i.e., $0.1 \mu \mathrm{g} \mathrm{m}^{-3}$ over CONUS and $0.7 \mu \mathrm{g} \mathrm{m}^{-3}$ over Europe), the uncertainties in treating $\mathrm{HNO}_{3}$ and $\mathrm{HCl}$ as non-volatile species using their lower limits of accommodation coefficients, and lack of treatments for $\mathrm{NO}_{3}^{-}$and $\mathrm{Cl}^{-}$thermodynamics.

\subsection{Impacts of new particle formation}

Figure 4 shows the annual mean vertical distributions of particle formation rate $(J)$ values and aerosol number 

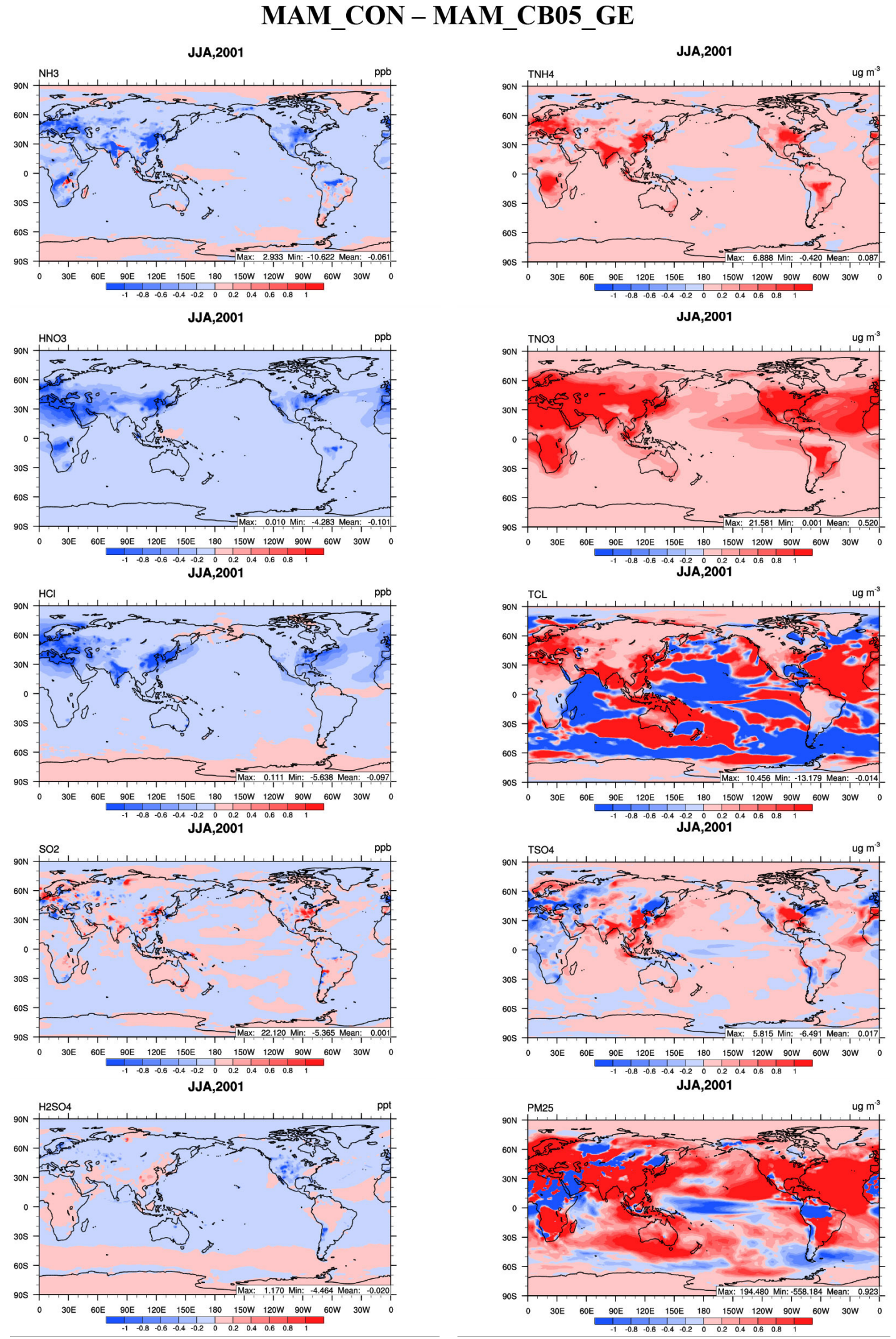

Figure 3. Spatial distributions of total ammonium, total sulfate, total nitrate, total chloride, $\mathrm{PM}_{2.5}, \mathrm{NH}_{3}, \mathrm{SO}_{2}, \mathrm{H}_{2} \mathrm{SO}_{4}, \mathrm{HNO}_{3}$, and $\mathrm{HCl}$ at the surface between MAM_CON and MAM_CB05_GE for summer (June, July, and August, JJA), 2001. 
concentrations, and simulated $J$ values averaged between the ground level and $1000 \mathrm{~m}$ overlaid with observations within the same layers. In MAM_CON/IMN, IMN is combined with three default nucleation parameterizations to predict $J$ throughout the atmosphere. In MAM_CON, $J$ over the ocean is overpredicted by factors of 5-50, despite a seemingly good NMB of $-12.8 \%$ in the global mean (see Table 3 ). $J$ values at several sites over land are underpredicted by factors of $1-$ 10 , which compensates for the large overprediction at most sites over the ocean. The large underprediction at those sites are likely due to the uncertainties in $\mathrm{SO}_{2}$ emissions and nucleation parameterizations, and the missing species that may have participated in nucleation. For example, several other species may contribute to new particle formation, including methanesulfonic acid (van Dingenen and Raes, 1993), hydrochloric acid (Arstila et al., 1999), organic compounds (Berndt, et al., 2014), iodine-containing compounds (Hoffmann et al., 2001), and amines (Berndt et al., 2014). Limited observations also introduce some uncertainties in the model validation. The overprediction of $J$ over the ocean is mainly due to the use of the prefactor of $1 \times 10^{-6}$ in WP09. This prefactor is derived from limited in situ measurements ( $\mathrm{Si}$ hto et al., 2006). It can vary by up to 3-4 orders of magnitude based on measurements in different areas and seasons (Zhang et al., 2010), introducing a large uncertainty for its application to the global scale. In MAM_CON/IMN, a prefactor of $1 \times 10^{-8}$ is used in WP09 in the PBL on the global scale, which then decreases $J$ and aerosol number concentrations in the PBL (see Fig. 4). $J$ in the PBL is very sensitive to the prefactor in WP09, and the uncertainty of the prefactor can result in a large bias in the prediction of $J$ and aerosol number in the PBL. With the implementation of IMN, $J$ values in the troposphere increase by factors of $2-10$, which in turn increase the aerosol number concentrations in the troposphere. Due to a stronger radiation in the upper layer, more available ions can contribute to new particle formation, therefore increasing the aerosol number concentrations in the middle/upper troposphere and lower stratosphere by factors of 2-4.

Figure 5 shows the absolute differences of $\mathrm{PM}_{2.5}, \mathrm{AOD}$, column CCN5, CF, SWCF, and SWD between MAM_CON and MAM_CON/IMN for 2001. Aerosol number can directly affect $\mathrm{CCN}$, which can affect cloud formation and properties as well as radiation. Changes in PM concentrations also have impacts on $\mathrm{AOD}, \mathrm{CCN}, \mathrm{CF}, \mathrm{COT}$, and SWCF through both aerosol direct and indirect effects. As a net result of all those interwoven changes initially triggered by the increase of aerosol number concentrations in troposphere/stratosphere, AOD and column CCN5 increase by 0.004 (or by $3.3 \%$ ) and $2.1 \times 10^{7} \mathrm{~cm}^{-2}$ (or by $11.9 \%$ ), respectively, and SWCF and SWD decrease by $0.1 \mathrm{~W} \mathrm{~m}^{-2}$ (or by $0.2 \%$ ) and $0.8 \mathrm{~W} \mathrm{~m}^{-2}$ (or by $0.5 \%$ ), respectively, in terms of global mean. As shown in Table S1 in the Supplement, the changes in SWD, AOD, and cloud variables such as column CCN5, CDNC, and COT between MAM_CON and
MAM_CON/IMN are statistically significant, indicating the significant impacts of IMN on aerosol number concentration and cloud prediction.

Compared with MAM_CON, IMN (MAM_CON/IMN) improves the prediction of $\mathrm{SO}_{2}, \mathrm{NO}_{3}^{-}$, and $\mathrm{PM}_{2.5}$ over CONUS, $\mathrm{SO}_{2}, \mathrm{SO}_{4}^{2-}, \mathrm{NH}_{4}^{+}, \mathrm{NO}_{3}^{-}, \mathrm{Cl}^{-}, \mathrm{PM}_{2.5}$, and $\mathrm{PM}_{10}$ over Europe, and $\mathrm{PM}_{10}$ over East Asia (see Table 3). The improved performance in aerosol concentrations and increased aerosol numbers in the troposphere and lower stratosphere contribute to the improved performance of aerosol and cloud parameters, with increased AOD, CCN, and CDNC, and consequently increased CF, COT, CWP, and SWCF, as shown in Table 2. However, there are still large biases for some chemical species prediction. For example, $\mathrm{CO}$ mixing ratio is underpredicted over East Asia, which is mainly due to the uncertainty in $\mathrm{CO}$ emissions in this region. Large biases in $\mathrm{SO}_{2}$ prediction over CONUS, Europe, and East Asia are mainly due to the uncertainties in $\mathrm{SO}_{2}$ emissions in those regions. Large biases in $\mathrm{NO}_{2}$ and $\mathrm{HNO}_{3}$ prediction over Europe is mainly due to the uncertainties in $\mathrm{NO}_{\mathrm{x}}$ emissions and inaccurate prediction of radiation over this region. The performance of $J$ degrades with NMBs from -21.8 to $-49.6 \%$ on the global scale, which is due to the use of a smaller prefactor of WP09 in MAM_CON/IMN than in MAM_CON. $J$ in the PBL is very sensitive to the prefactor in WP09. Although the prediction of $J$ over the ocean in the PBL is improved in MAM_CON/IMN, $J$ over land areas in the PBL is largely underpredicted, by factors of 1-100, resulting in degraded $J$ performance in terms of global mean. The underprediction of $J$ over land in the PBL is likely due to the uncertainties in the nucleation parameterizations (e.g., the missing species as mentioned previously). Large NMBs still remain for COT, CWP, and CCN, indicating the uncertainties in the treatments of related atmospheric processes such as cloud microphysics and aerosol-cloud interactions.

\subsection{Impacts of gas-aerosol partitioning}

The inclusion of ISORROPIA II changes the mass concentrations of major $\mathrm{PM}_{2.5}$ species and their gaseous precursors. Changes in PM concentrations then affect the prediction of cloud variables and therefore radiation. Changes in radiation can also affect $\mathrm{SO}_{2}$ oxidation by $\mathrm{OH}$, which affects $\mathrm{H}_{2} \mathrm{SO}_{4}$ concentrations. Figure 6 shows the absolute differences of $\mathrm{H}_{2} \mathrm{SO}_{4}$, fine particulate sulfate ( $\mathrm{SO} 4 \mathrm{f}$ ), $\mathrm{NH}_{3}$, fine particulate ammonium (NH4f), $\mathrm{HNO}_{3}$, fine particulate nitrate (NO3f), $\mathrm{HCl}$, and fine particulate chloride (Clf) for summer 2001 between MAM_CON and MAM_CON/ISO. Similar plots for winter (December, January, and February, DJF) 2001 are shown in Fig. S1 in the Supplement. Compared to MAM_CON, MAM_CON/ISO gives higher $\mathrm{H}_{2} \mathrm{SO}_{4}$ mixing ratios but lower SO4f concentrations. SWD increases with the global mean of $8.9 \mathrm{~W} \mathrm{~m}^{-2}(\sim 5.8 \%)$ in MAM_CON/ISO, which allows more production of $\mathrm{OH}$ from photolytic reactions of VOCs, $\mathrm{HONO}, \mathrm{HNO}_{3}, \mathrm{HNO}_{4}$, 

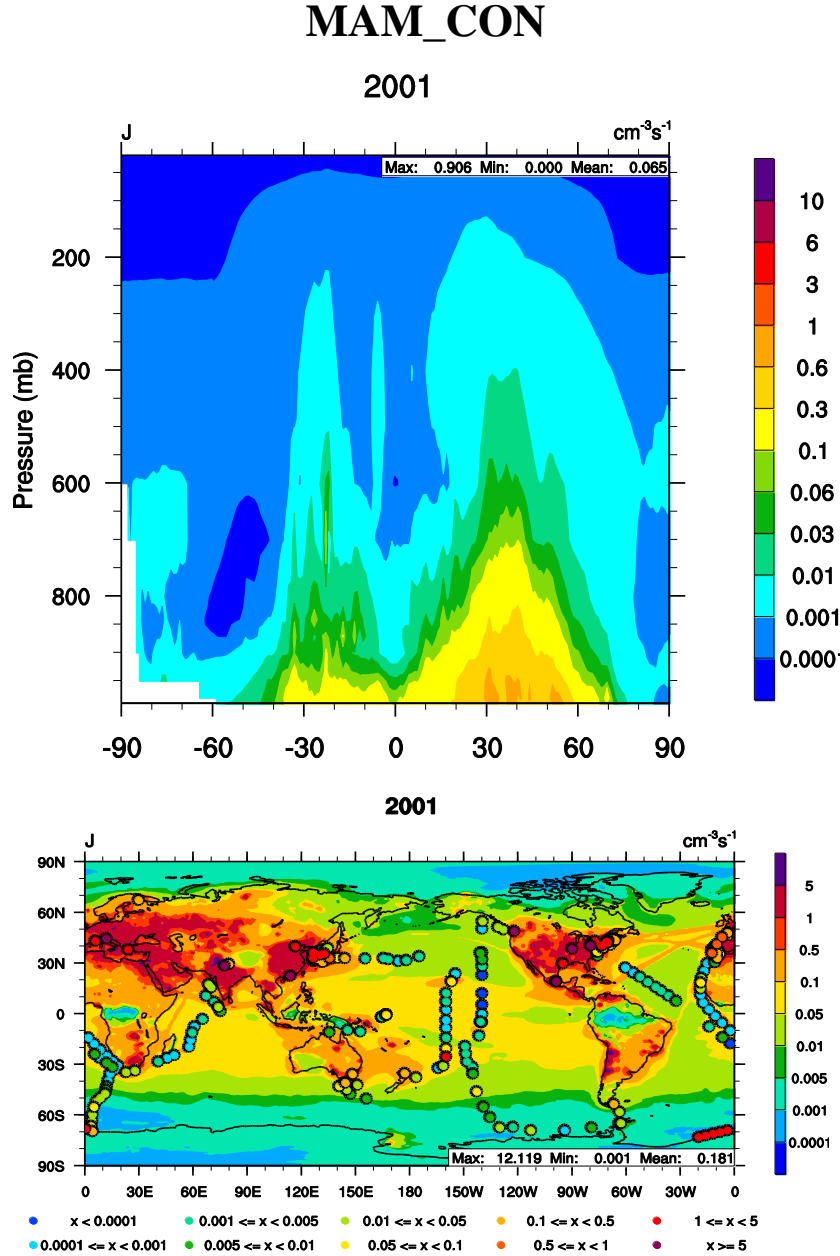

2001

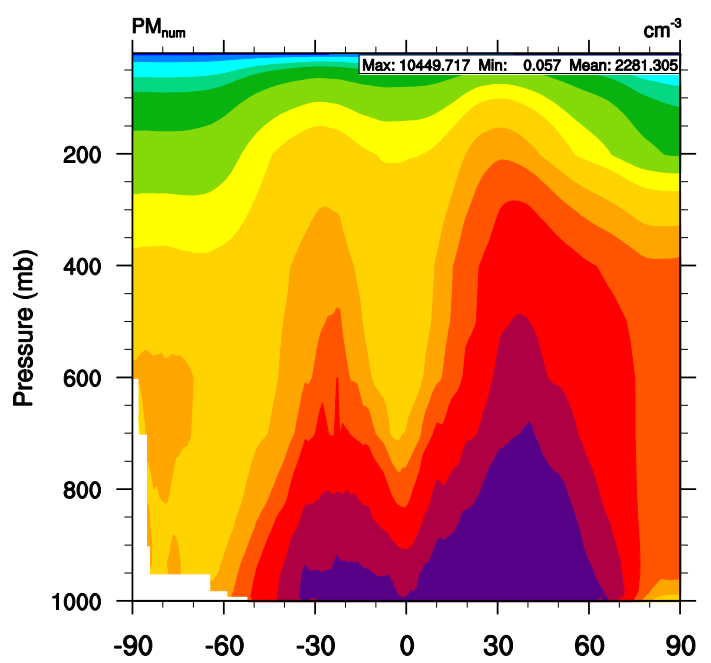

\section{MAM_CON/IMN}
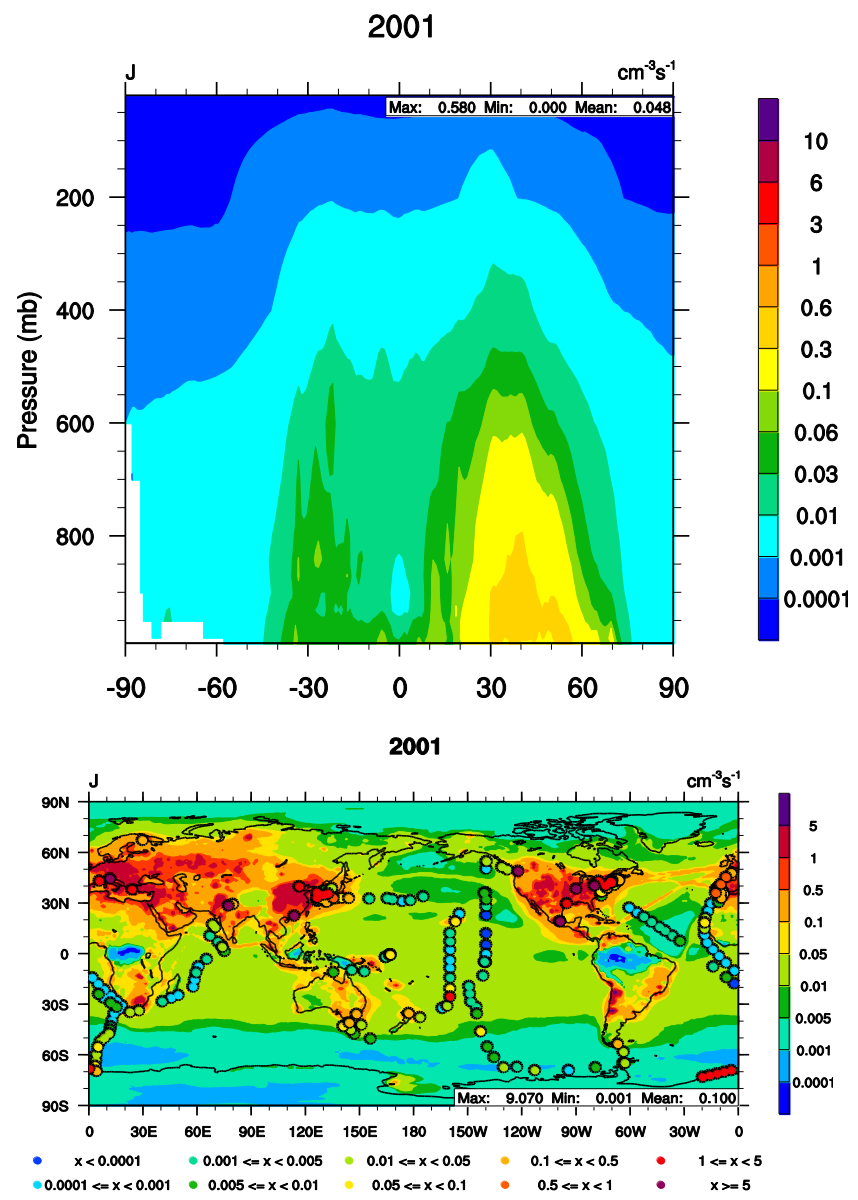

2001

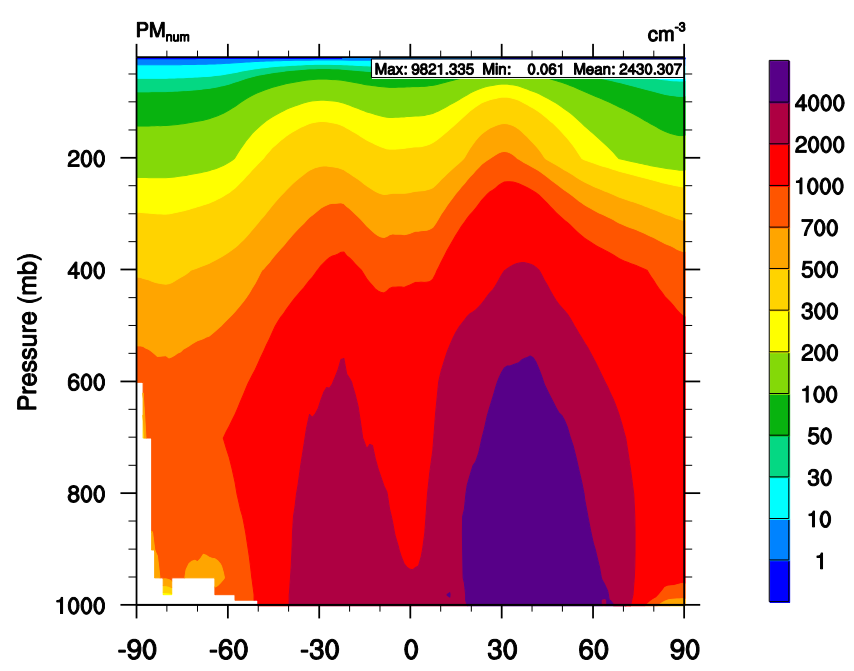

Figure 4. Vertical distributions of new particle formation rate $(J)$ (row 1) and aerosol number $\left(\mathrm{PM}_{\text {num }}\right.$ ) (row 3) simulated by MAM_CON/IMN for 2001. The overlay plots in row 2 show the distributions of simulated and observed $J$ in the bottom $1000 \mathrm{~m}$ of the atmosphere. Circles on overlay plots represent observations for $J$. Different colors of circles represent different values of $J$, using the same color scale as simulated $J$. 


\section{MAM_CON/IMN - MAM_CON}
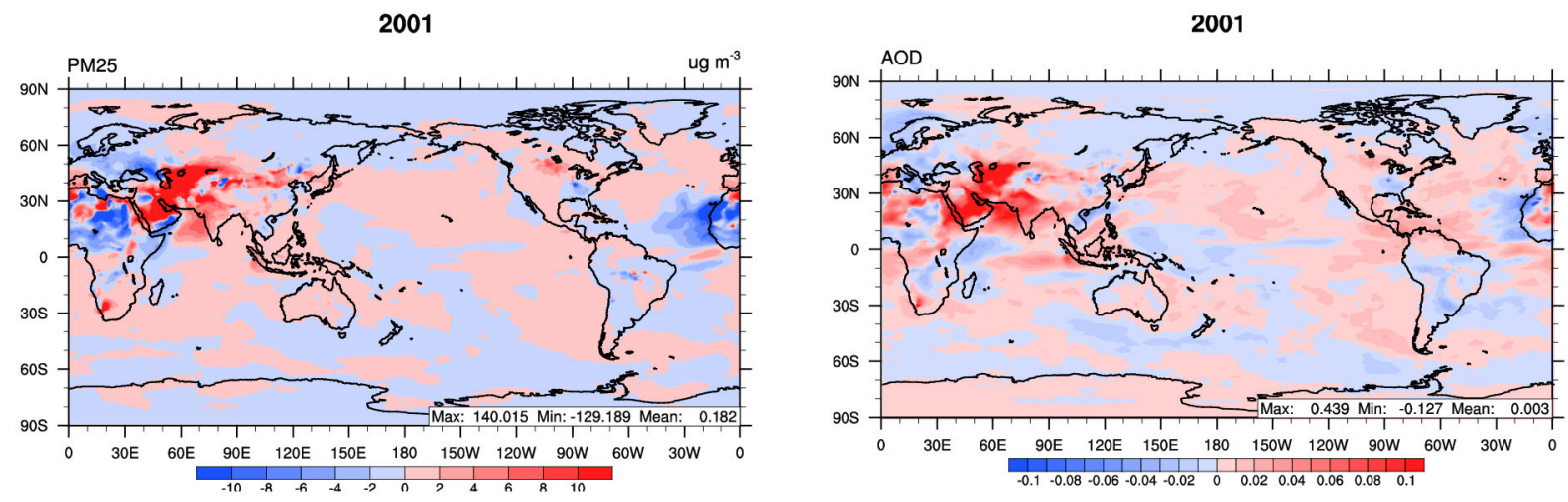

2001
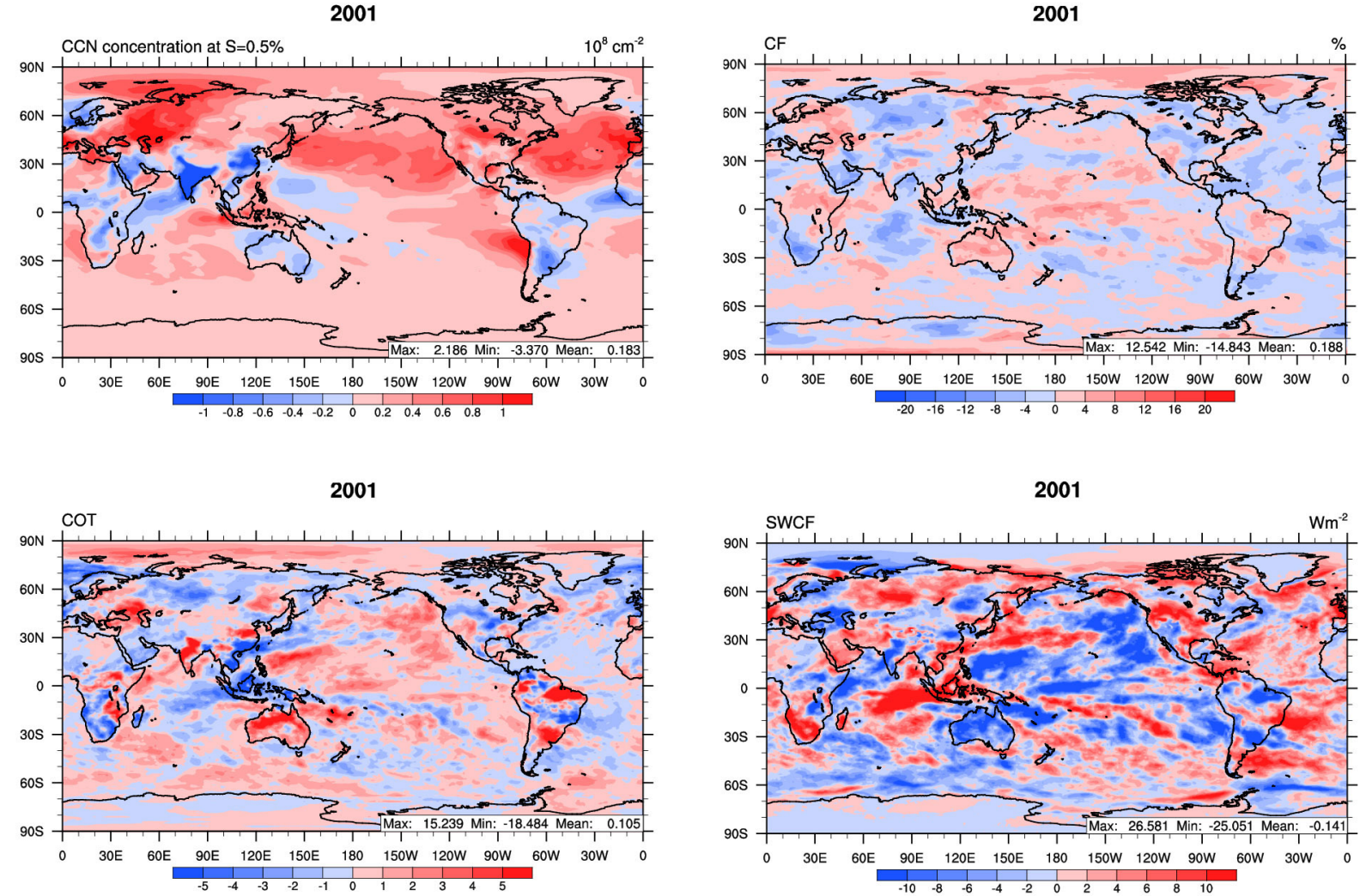

Figure 5. Absolute differences of $\mathrm{PM}_{2.5}$, AOD, column CCN5, CF, COT, and SWCF between MAM_CON/IMN and MAM_CON for 2001.

$\mathrm{H}_{2} \mathrm{O}_{2}, \mathrm{HOCl}$, and $\mathrm{HOBr}$, and therefore enhanced oxidation of $\mathrm{SO}_{2}$ to form $\mathrm{H}_{2} \mathrm{SO}_{4}$. As shown in Fig. 6, the mixing ratios of $\mathrm{H}_{2} \mathrm{SO}_{4}$ either increase by up to $0.76 \mathrm{ppt}$ or decrease by as much as $1.14 \mathrm{ppt}$, leading to a net increase of $0.002 \mathrm{ppt}$ in terms of global mean. The mass concentration of SO4f is mainly affected by $\mathrm{H}_{2} \mathrm{SO}_{4}$ condensation. Although the mixing ratios of $\mathrm{H}_{2} \mathrm{SO}_{4}$ increase with the global mean change of $0.002 \mathrm{ppt}, \mathrm{SO} 4 \mathrm{f}$ concentrations decrease with the global mean of $0.02 \mu \mathrm{g} \mathrm{m}^{-3}$, which are mainly due to less condensation of $\mathrm{H}_{2} \mathrm{SO}_{4}$ under higher temperature conditions. In sum- mer, the increase or decrease of $\mathrm{H}_{2} \mathrm{SO}_{4}$ can result in an increase or a decrease of SO4f (e.g., over most oceanic areas). However, the decrease of SO4f with the increase of $\mathrm{H}_{2} \mathrm{SO}_{4}$ over the Indian Ocean is mainly due to less $\mathrm{H}_{2} \mathrm{SO}_{4}$ condensation. For the regions where SO4f increases over land, the increase of SO4f is due to more oxidation of $\mathrm{SO}_{2}$ by OH. Compared to MAM_CON, the concentrations of $\mathrm{NH}_{3}, \mathrm{HNO}_{3}$, and $\mathrm{HCl}$ increase significantly over most land areas whereas NH4f, NO3f, and Clf decrease significantly over most land areas in MAM_CON/ISO. Such changes can be explained 
based on the chemical regimes and their spatial distributions as shown in Fig. S2 in the Supplement. Compared to MAM_CON, the prediction of SWD in MAM_CON/ISO is improved with the NMB decreasing from -6.5 to $-2.2 \%$. The prediction of involved species such as $\mathrm{NH}_{4}^{+}, \mathrm{NO}_{3}^{-}$, and $\mathrm{Cl}^{-}$is improved significantly by $13.6-345.4 \%$, although there is a slight degradation in the prediction of $\mathrm{SO}_{4}^{2-}$ and $\mathrm{O}_{3}$ over CONUS, $\mathrm{CO}, \mathrm{O}_{3}, \mathrm{PM}_{2.5}$, and $\mathrm{PM}_{10}$ over Europe, $\mathrm{PM}_{10}$ over East Asia, and column $\mathrm{CO}, \mathrm{NO}_{2}$, TOR, and $J$ on the global scale. MAM_CON/ISO improves the prediction of $\mathrm{HNO}_{3}, \mathrm{NH}_{4}^{+}, \mathrm{NO}_{3}^{-}, \mathrm{Cl}^{-}, \mathrm{BC}, \mathrm{OC}, \mathrm{TC}$, and $\mathrm{PM}_{2.5}$ over CONUS, $\mathrm{SO}_{2}, \mathrm{NH}_{3}, \mathrm{NO}_{2}, \mathrm{SO}_{4}^{2-}, \mathrm{NH}_{4}^{+}, \mathrm{NO}_{3}^{-}$, and $\mathrm{Cl}^{-}$ over Europe, and $\mathrm{CO}$ and $\mathrm{SO}_{2}$ over East Asia, which leads to improved performance in SWD, column CCN5, and SWCF on the global scale, as shown in Table 3. As shown in Table $\mathrm{S} 1$ in the Supplement, the changes in most radiative and cloud variables between MAM_CON and MAM_CON/ISO are statistically significant, indicating the significant impacts of ISORROPIA II on the prediction of radiation, aerosol, and cloud. ISORROPIA II calculates gas-aerosol partitioning under different atmospheric conditions, significantly improving the prediction of major gas precursors (e.g., $\mathrm{HNO}_{3}$ ) over CONUS and secondary aerosols (e.g., $\mathrm{NO}_{3}^{-}$and $\mathrm{Cl}^{-}$) over CONUS and Europe. Large decreases in the concentrations of $\mathrm{NO}_{3}^{-}$and $\mathrm{Cl}^{-}$result in a decrease in $\mathrm{NH}_{4}^{+}, \mathrm{PM}_{2.5}$, and $\mathrm{PM}_{10}$, thus decreasing CCN, CDNC, AOD, and the absolute value of SWCF.

MAM_CO/ISO assumes metastable conditions (i.e., assuming all salts in an aqueous solution), which may introduce errors in gas/particle partitioning. The validity of this assumption is examined by taking the absolute differences of the concentrations of major inorganic gas and aerosol species between metastable (MAM_NEWA) and stable (MAM_NEWB) conditions (i.e., Fig. S3 in the Supplement). Compared with MAM_NEWA, the global average changes predicted by MAM_NEWB are within 5\% for most gaseous and aerosol species over non-desert/arid regions, indicating that the assumption of metastable conditions is not a significant source of uncertainty in this work. However, the irreversible gas-to-particle mass transfer treatment for coarse particles can potentially overpredict the concentrations of coarse particles (e.g., overprediction of $\mathrm{Cl}^{-}$and $\mathrm{NO}_{3}^{-}$over Europe).

\subsection{Overall impacts of all new and modified model treatments}

Compared to MAM_CB05_GE, the simulations with modified or new aerosol treatments (MAM_CON, MAM_CON/IMN, MAM_CON/ISO, MAM_NEWA) slightly degrade the prediction of LWD (increasing NMB from -0.9 to $-1.4 \%$ ), but improve the prediction of OLR, CF, COT, and CWP slightly (with $0.6-10.4 \%$ decreases in their NMBs) and CDNC significantly (reducing NMBs from -57.5 up to $-13.4 \%$ ). Although the $\mathrm{CCN}$ predictions are somewhat degraded in MAM_CON and MAM_CON/IMN, they are improved significantly in MAM_CON/ISO and MAM_NEWA (reducing NMBs from -61.6 to $1.8-6.3 \%$ ). As shown in Table $\mathrm{S} 2$ in the Supplement, changes in most radiative and cloud variables between MAM_SIM and MAM_NEWA are statistically significant, indicating the significant impacts of new and modified treatments on the prediction of radiation and clouds. Among all new and modified model treatments, the new gas-phase chemistry simulates more gaseous species and improves the prediction of $\mathrm{NH}_{3}$ over Europe, $\mathrm{PM}_{2.5}$ over CONUS, and $\mathrm{PM}_{10}$ over East Asia. The modified condensation and aqueous-phase chemistry simulate more aerosol species $\left(\mathrm{NO}_{3}^{-}\right.$and $\left.\mathrm{Cl}^{-}\right)$ and improve the prediction of $\mathrm{HNO}_{3}$. MAM_CON also improves $J$ in the PBL due to more available $\mathrm{H}_{2} \mathrm{SO}_{4}$ involved in the homogeneous nucleation using an accommodation coefficient of 0.02 for $\mathrm{H}_{2} \mathrm{SO}_{4}$ condensation, and they improve the prediction of CDNC and AOD significantly. MAM_CON/IMN increases PM $_{\text {num }}$ above the PBL and $\mathrm{PM}_{2.5}$ and $\mathrm{PM}_{10}$ over Europe and improves the prediction of $\mathrm{PM}_{2.5}$ over CONUS and Europe. MAM_CON/ISO improves the prediction of $\mathrm{HNO}_{3}, \mathrm{NH}_{4}^{+}, \mathrm{PM}_{2.5}, \mathrm{NO}_{3}^{-}$, and $\mathrm{Cl}^{-}$over CONUS, $\mathrm{NO}_{3}^{-}$and $\mathrm{Cl}^{-}$over Europe, and $\mathrm{CCN}$ on the global scale, and improves the prediction of SWCF most (with an NMB of $1.6 \%$ ).

Large biases in some variables remain in MAM_NEWA due to uncertainties in model inputs (e.g., meteorology and emissions) and model treatments (e.g., multi-phase chemistry, dust emission scheme, cloud microphysics, aerosol activation, SOA formation, and dry and wet deposition). The large NMBs of $\mathrm{CO}$ and $\mathrm{SO}_{2}$ over East Asia, $\mathrm{SO}_{2}, \mathrm{NH}_{3}$, and $\mathrm{NO}_{2}$ over Europe, $\mathrm{SO}_{2}$, and $\mathrm{BC}$ over CONUS are likely due to the uncertainties of emissions and the interpolation of emissions from a fine-grid scale in the original emission inventories (e.g., county-based emissions over CONUS) to a large-grid scale used in this work, which can result in large NMBs in secondary aerosols (e.g., $\mathrm{SO}_{4}^{2-}, \mathrm{NH}_{4}^{+}$, $\mathrm{NO}_{3}^{-}$, and thus $\mathrm{PM}_{2.5}$ and $\mathrm{PM}_{10}$ ). Heterogeneous reactions are not included in this work, which may help explain to some extent the reduced oxidation and underprediction for PM species (e.g., sulfate and nitrate) and overprediction for gaseous species. The large $\mathrm{NMB}$ of $\mathrm{O}_{3}$ prediction over $\mathrm{Eu}-$ rope in MAM_NEWA (with an NMB of $62.7 \%$ ) is mainly due to a lack of $\mathrm{NO}_{\mathrm{x}}$ titration (as indicated by large underprediction in $\mathrm{NO}_{2}$ ) and more production of $\mathrm{O}_{3}$ from the photolytic reaction of $\mathrm{NO}_{2}$ resulting from overprediction of SWD particularly in autumn and winter. Table 4 shows the seasonal statistics for $\mathrm{O}_{3}, \mathrm{NO}_{2}$, and $\mathrm{HNO}_{3}$ over Europe in MAM_NEWA. During autumn and winter, $\mathrm{O}_{3}$ is overpredicted by about $100-140 \%$, whereas $\mathrm{NO}_{2}$ is underpredicted by about -85 to $-20 \%$, indicating insufficient $\mathrm{NO}_{\mathrm{x}}$ for titration of $\mathrm{O}_{3}$ titration. SWD is overpredicted by $45.0 \mathrm{~W} \mathrm{~m}^{-2}$ (or by $58.4 \%$ ), favoring the photolytic reactions of $\mathrm{NO}_{2}$ to produce $\mathrm{O}_{3}$. Due to the uncertainties in the $\mathrm{NO}_{\mathrm{x}}$ emissions, $\mathrm{NO}_{2}$ 


\section{MAM_CON/ISO - MAM_CON}

JJA,2001

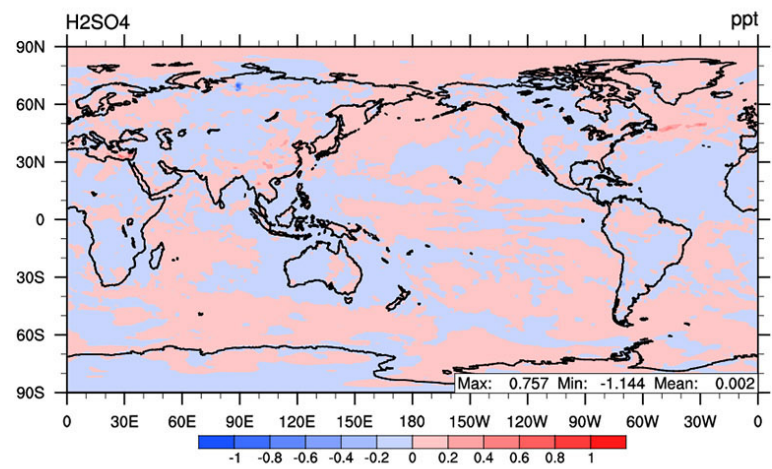

JJA,2001

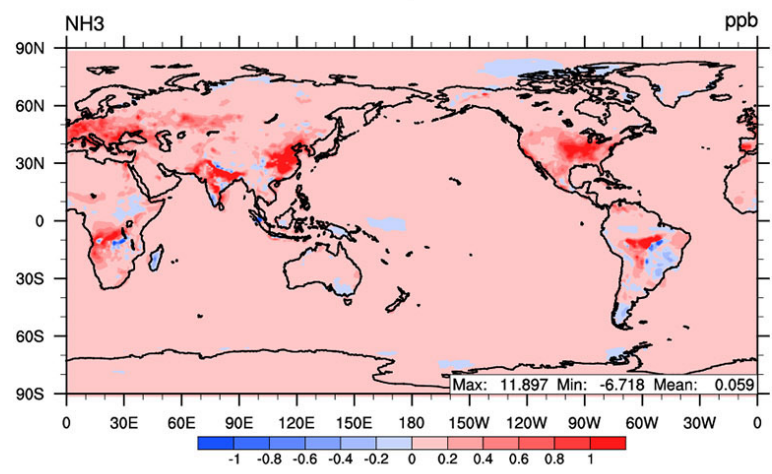

JJA,2001

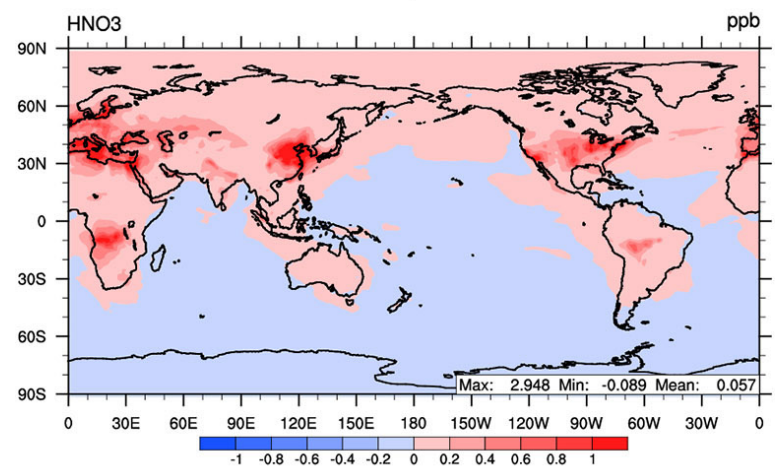

JJA,2001

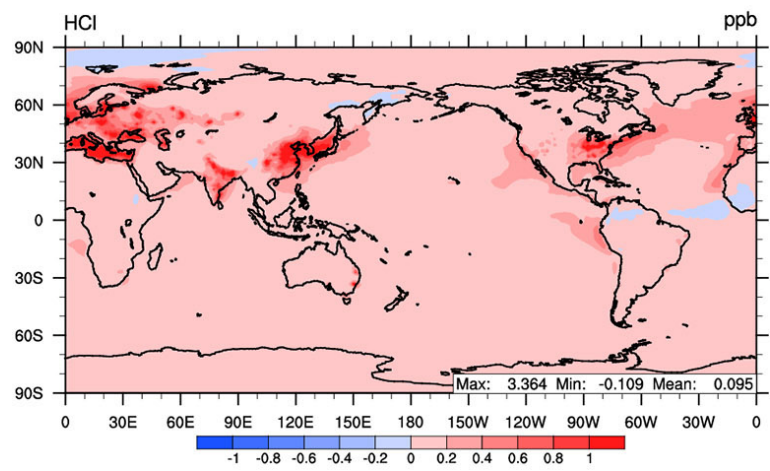

JJA,2001

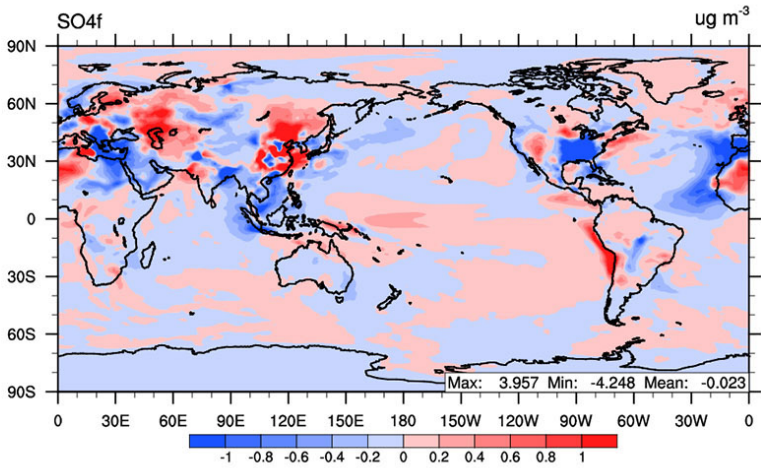

JJA,2001

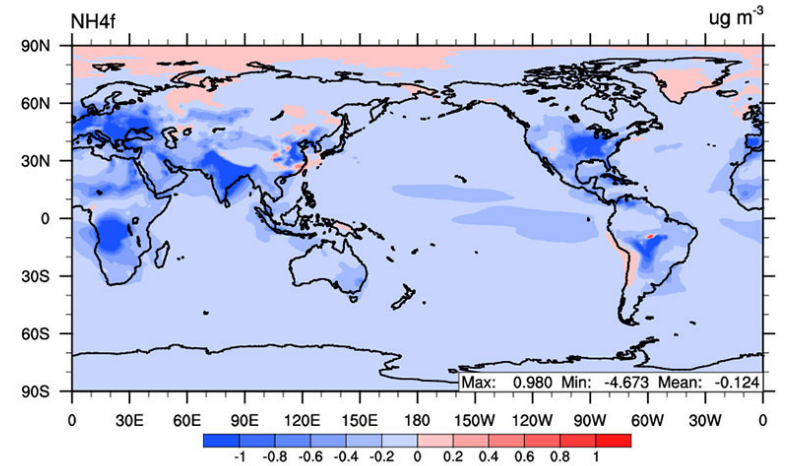

JJA,2001

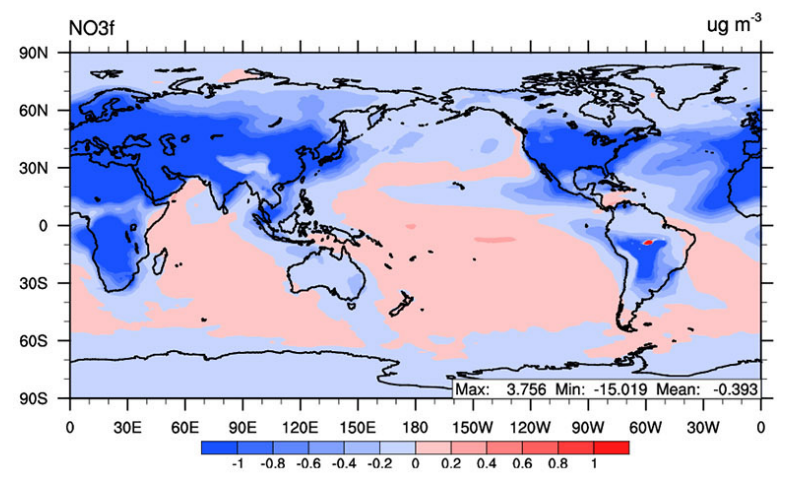

JJA,2001

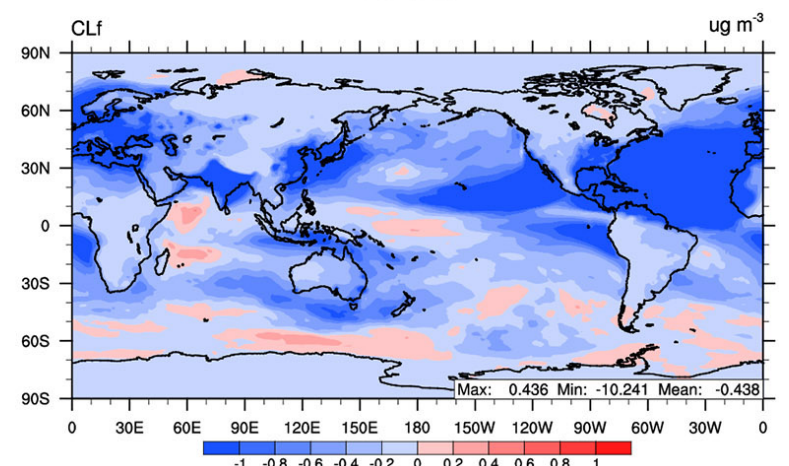

Figure 6. Absolute differences of major PM species and their gas precursors between MAM_CON/ISO and MAM_CON for summer, 2001. 
is underpredicted, causing less $\mathrm{NO}_{2}$ to be oxidized to produce $\mathrm{HNO}_{3}$, which results in an underprediction of $\mathrm{HNO}_{3}$ in winter. In autumn, SWD is overpredicted by $42.8 \mathrm{~W} \mathrm{~m}^{-2}$ (or by $37.9 \%$ ). However, in autumn, although $\mathrm{NO}_{2}$ is underpredicted due to the uncertainties in the $\mathrm{NO}_{\mathrm{x}}$ emissions, $\mathrm{HNO}_{3}$ mixing ratios are overpredicted. SWD is stronger in autumn than in winter, and mixing ratios of $\mathrm{OH}$ are higher due to photolytic reactions of overpredicted $\mathrm{O}_{3}$ and additional photolytic reactions of VOCs. Therefore, $\mathrm{OH}$ can oxidize $\mathrm{NO}_{2}$ to produce $\mathrm{HNO}_{3}$, resulting in the overprediction of $\mathrm{HNO}_{3}$. Simple aqueous-phase chemistry is included in this work, which could result in high uncertainty in predicting aerosols in clouds. Decreased aerosol number concentrations can result in a decrease of $\mathrm{CCN}$ and AOD directly. The underprediction of $\mathrm{CDNC}$ is likely due to uncertainties in the model treatments for aerosol activation and cloud microphysics, which then result in large NMBs in COT and CWP. The large biases in $\mathrm{OC}$ and TC indicate the uncertainties in the emissions of $\mathrm{BC}$ and primary $\mathrm{OC}$, and the treatments for SOA formation. The large NMB in particle formation rate $J$ is likely due to uncertainties in model inputs (e.g., $\mathrm{SO}_{2}$ emissions) and model treatments (e.g., the accommodation coefficient of $\mathrm{H}_{2} \mathrm{SO}_{4}$ and missing participants in the current nucleation schemes).

\subsection{Impacts of adjusted emissions}

The evaluation and analyses of MAM_NEWA indicate that some large biases are caused by inaccuracies in the emissions of $\mathrm{CO}, \mathrm{SO}_{2}, \mathrm{BC}, \mathrm{OC}$, and $\mathrm{NH}_{3}$. The sensitivity simulation with adjusted emissions of $\mathrm{CO}, \mathrm{SO}_{2}, \mathrm{BC}, \mathrm{OC}$, and $\mathrm{NH}_{3}$ (MAM_NEW/EMIS) is performed to further look into such impacts. For example, with a $30 \%$ increase in $\mathrm{CO}$ emissions and a $20 \%$ increase in $\mathrm{NH}_{3}$ emissions over Europe, the NMBs of surface concentrations of $\mathrm{CO}$ and $\mathrm{NH}_{3}$ change from -3.4 to $12.1 \%$ and -84.3 to $-77.5 \%$, respectively. On a global scale, the increased $\mathrm{CO}$ emissions result in $3.0 \%$ absolute reduction in the NMB of column $\mathrm{CO}$. The $30 \%$ reduction in $\mathrm{SO}_{2}$ emissions and $20 \%$ increase in $\mathrm{OC}$ and $\mathrm{BC}$ emissions over CONUS result in 139.6, 8.6, and $24.9 \%$ absolute reduction in their NMBs. The $30 \%$ increase in $\mathrm{CO}$ emissions and $20 \%$ increase in $\mathrm{SO}_{2}$ over East Asia result in 3.3 and $7.8 \%$ absolute reduction in their NMBs.

As shown in Table 3, compared with MAM_NEWA, MAM_NEW/EMIS shows an improved performance in the concentrations of $\mathrm{SO}_{2}, \mathrm{HNO}_{3}, \mathrm{SO}_{4}^{2-}, \mathrm{NH}_{3}$, and $\mathrm{NH}_{4}^{+}$over Europe; $\mathrm{SO}_{2}, \mathrm{HNO}_{3}, \mathrm{BC}, \mathrm{OC}, \mathrm{TC}, \mathrm{NO}_{3}^{-}$, and $\mathrm{Cl}^{-}$over CONUS; $\mathrm{CO}$ and $\mathrm{SO}_{2}$ over Asia; and column $\mathrm{CO}$ on the global scale. However, to some extent it degrades the performance of $\mathrm{SO}_{4}^{2-}$ and $\mathrm{NH}_{4}^{+}$over CONUS, $\mathrm{PM}_{2.5}$ and $\mathrm{PM}_{10}$ over Europe, $\mathrm{PM}_{10}$ over Asia, and $J$ on the global scale. Decreased $\mathrm{SO}_{2}$ emissions over CONUS result in a decrease of $\mathrm{H}_{2} \mathrm{SO}_{4}$ and therefore a decrease of $\mathrm{SO}_{4}^{2-}$. Based on aerosol thermodynamic treatments, decreased $\mathrm{SO}_{4}^{2-}$ will result in decreased $\mathrm{NH}_{4}^{+}$. Therefore, $\mathrm{PM}_{2.5}$ and $\mathrm{PM}_{10}$ decrease as well. Adjusted emissions can affect secondary aerosol formations and therefore radiative variables can be affected due to the direct and indirect effects of aerosols. As shown in Table 2, compared with MAM_NEWA, MAM_NEW/EMIS reduces MB of LWD by $9.3 \%$, SWD by $37.5 \%$, and CF by $18.9 \%$, leading to $0.1-1.6 \%$ absolute reduction in their NMBs. This illustrates the sensitivity of radiation to the perturbations in emissions through chemistry feedbacks to the climate system. As shown in Table S1 in the Supplement, only column CCN5 and AOD are significantly different between MAM_NEWA and MAM_NEW/EMIS, indicating the impacts of emissions are more significant on the prediction of gas and aerosol than radiative variables.

\section{Evaluation of the 2001-2005 simulations}

\subsection{Performance evaluation}

Tables 5 and 6 show the statistical performance for radiative/cloud variables and chemical prediction, respectively, from the 2001-2005 simulations using three different configurations. Compared with MAM_SIM_5Y, MAM_NEW_5YA improves the prediction of aerosol and cloud variables such as AOD, COT, CWP, CCN5, and CDNC (with 4.8 to $23.4 \%$ absolute reduction in their NMBs), and radiative variables such as SWD, LWD, OLR, and SWCF (with 0.4-4.2\% absolute reduction in their NMBs). MAM_NEW_5YA also shows slight improvement for the prediction of $\mathrm{SO}_{4}^{2-}$ and $\mathrm{BC}$ over CONUS and $\mathrm{SO}_{2}$ over East Asia (with $0.3-2.3 \%$ absolute reduction in their NMBs), but moderate-to-large improvements for the prediction of OC, TC, and $\mathrm{PM}_{2.5}$ over CONUS, $\mathrm{PM}_{10}$ over East Asia, and $\mathrm{SO}_{2}$, $\mathrm{PM}_{2.5}$, and $\mathrm{PM}_{10}$ over Europe (with 5.2-20.1\% absolute reduction in their NMBs). Compared to TOR calculated based on $\mathrm{O}_{3}$ climatology used in MAM_SIM_5Y, TOR predicted from MAM_NEW_5YA is slightly improved with 1.2, 1.3, and $0.3 \%$ absolute reduction in its NMB, NME, and RMSE, respectively. Evaluation of major radiative/cloud variables and chemical predictions are also conducted for June, July, and August (JJA) of 2001-2005, which is shown in Tables S3 and S4 in the Supplement. Compared with the full 5-year (2001-2005) average, the simulation for JJA gives similar predictions for chemical species but better model predictions for radiation (e.g., LWD, SWD, and OLR) and cloud (e.g., COT, CWP, column CCN5, and CDNC) variables.

Tables 5 and 6 also show the performance of MAM_NEW_5YB in which CAM5 is fully coupled with land, ocean, and ice models. The performance is overall similar for all radiative variables and most chemical species between MAM_NEW_5YA and MAM_NEW_5YB (most within a $5 \%$ difference in the absolute values of their NMBs). The performance of $\mathrm{HNO}_{3}$ over CONUS and Europe, $\mathrm{NH}_{4}^{+}, \mathrm{NO}_{3}^{-}$, and $\mathrm{Cl}^{-}$over Europe, $\mathrm{PM}_{10}$ over Europe and East Asia is improved appreciably (with 4.2-17.9\% 
Table 4. The observed values and the mean bias (MB) and normalized mean bias (NMB, in \%) of the prediction of $\mathrm{O}_{3} \mathrm{NO}_{2}$, and $\mathrm{HNO}_{3}$ mixing ratios over Europe in MAM_NEWA.

\begin{tabular}{|c|c|c|c|c|c|}
\hline & Network & & $\begin{array}{r}\text { Obs } \\
\left(\mu \mathrm{g} \mathrm{m}^{-3}\right)\end{array}$ & $\underset{\left(\mu \mathrm{g} \mathrm{m}^{-3}\right)}{\operatorname{Sim}}$ & $\mathrm{MB} / \mathrm{NMB}$ \\
\hline \multirow[t]{7}{*}{ Winter } & \multirow[t]{2}{*}{ Airbase } & $\mathrm{O}_{3}$ & 37.7 & 75.2 & $37.5 / 99.6^{*}$ \\
\hline & & $\mathrm{NO}_{2}$ & 26.0 & 7.6 & $-18.4 /-70.9$ \\
\hline & \multirow[t]{2}{*}{ BDQA } & $\mathrm{O}_{3}$ & 31.0 & 74.2 & 43.2/139.2 \\
\hline & & $\mathrm{NO}_{2}$ & 30.6 & 5.6 & $-25.0 /-81.9$ \\
\hline & \multirow[t]{3}{*}{ EMEP } & $\mathrm{O}_{3}$ & 50.7 & 75.7 & $25.0 / 49.3$ \\
\hline & & $\mathrm{NO}_{2}$ & 9.0 & 8.3 & $-0.7 /-7.8$ \\
\hline & & $\mathrm{HNO}_{3}$ & 0.5 & 0.5 & $-4.9 \times 10^{-3} / 1.0$ \\
\hline \multirow[t]{7}{*}{ Spring } & \multirow[t]{2}{*}{ Airbase } & $\mathrm{O}_{3}$ & 63.1 & 100.8 & $37.7 / 59.7$ \\
\hline & & $\mathrm{NO}_{2}$ & 20.0 & 4.6 & $-15.4 /-77.1$ \\
\hline & \multirow[t]{2}{*}{ BDQA } & $\mathrm{O}_{3}$ & 59.6 & 98.9 & $39.3 / 65.9$ \\
\hline & & $\mathrm{NO}_{2}$ & 23.6 & 3.1 & $-20.5 /-87.0$ \\
\hline & \multirow[t]{3}{*}{ EMEP } & $\mathrm{O}_{3}$ & 75.0 & 101.9 & $26.9 / 35.9$ \\
\hline & & $\mathrm{NO}_{2}$ & 5.9 & 4.9 & $-1.0 /-17.2$ \\
\hline & & $\mathrm{HNO}_{3}$ & 0.4 & 0.9 & $0.5 / 144.5$ \\
\hline \multirow[t]{7}{*}{ Summer } & \multirow[t]{2}{*}{ Airbase } & $\mathrm{O}_{3}$ & 64.9 & 93.5 & $28.6 / 44.0$ \\
\hline & & $\mathrm{NO}_{2}$ & 16.2 & 4.4 & $-11.8 /-72.8$ \\
\hline & \multirow[t]{2}{*}{ BDQA } & $\mathrm{O}_{3}$ & 64.5 & 94.5 & $30.0 / 46.5$ \\
\hline & & $\mathrm{NO}_{2}$ & 18.7 & 3.6 & $-15.1 /-80.9$ \\
\hline & \multirow[t]{3}{*}{ EMEP } & $\mathrm{O}_{3}$ & 72.2 & 91.2 & $19.0 / 26.3$ \\
\hline & & $\mathrm{NO}_{2}$ & 4.7 & 4.4 & $-0.3 /-6.2$ \\
\hline & & $\mathrm{HNO}_{3}$ & 0.5 & 1.3 & $0.8 / 169.6$ \\
\hline \multirow[t]{7}{*}{ Autumn } & \multirow[t]{2}{*}{ Airbase } & $\mathrm{O}_{3}$ & 40.5 & 79.5 & $39.0 / 96.4$ \\
\hline & & $\mathrm{NO}_{2}$ & 21.7 & 5.3 & $-16.4 /-75.6$ \\
\hline & \multirow[t]{2}{*}{ BDQA } & $\mathrm{O}_{3}$ & 35.7 & 80.9 & $45.2 / 126.5$ \\
\hline & & $\mathrm{NO}_{2}$ & 24.8 & 3.7 & $-21.1 /-85.2$ \\
\hline & \multirow[t]{3}{*}{ EMEP } & $\mathrm{O}_{3}$ & 51.7 & 78.2 & $26.5 / 51.2$ \\
\hline & & $\mathrm{NO}_{2}$ & 6.6 & 5.2 & $-1.4 /-21.1$ \\
\hline & & $\mathrm{HNO}_{3}$ & 0.6 & 0.9 & $0.3 / 45.0$ \\
\hline
\end{tabular}

* The values of MBs and NMBs are expressed as MB/NMB.

reduction in the absolute values of their $\mathrm{NMBs}$ ), and that of $\mathrm{SO}_{2}$ over CONUS and Europe and $\mathrm{NH}_{4}^{+}, \mathrm{NO}_{3}^{-}$, and $\mathrm{Cl}^{-}$over CONUS is degraded appreciably (with $4.3-8.5 \%$ increase in the absolute values of their NMBs). Those changes are mainly due to the interactions among Earth's components, particularly at the interfaces (e.g., air-sea, air-land, and sea-ice interfaces) and feedbacks to the climate system, which in turn affects gaseous and aerosol concentrations in the coupled system.

Large biases remain for some variables in MAM_NEW_5YA and MAM_NEW_5YB due to uncertainties in model inputs (e.g., meteorology and emissions) and model treatments (e.g., multi-phase chemistry, dust emission scheme, cloud microphysics, aerosol activation, SOA formation, and dry and wet deposition), which have been illustrated in Sect. 5.5. Large biases in $\mathrm{Cl}^{-}$prediction over Europe is likely due to the combined effects of a low concentration of observed $\mathrm{Cl}^{-}$, uncertainties in $\mathrm{HCl}$ emis- sions, and inaccurate prediction of coarse $\mathrm{Cl}^{-}$in the model since ISORROPIA II is only implemented for fine particles. Uncertainties in the mass accommodation coefficients of volatile gas species can also result in uncertainties in the prediction of condensable gases.

\subsection{Impact of new and modified treatments on 2001-2005 simulations}

Figure 7 shows the absolute differences of surface $\mathrm{SO}_{2}$, $\mathrm{NH}_{3}, \mathrm{SO}_{4}^{2-}, \mathrm{NH}_{4}^{+}, \mathrm{TC}, \mathrm{PM}_{2.5}, \mathrm{PM}_{10}, J$, and aerosol number $\left(\mathrm{PM}_{\text {num }}\right)$ and Fig. 8 shows the absolute differences of radiative variables between MAM_SIM_5Y and MAM_NEW_5YA. The new and modified model treatments in MAM_NEW_5YA cause changes in the concentrations of PM and precursor gases, which affect radiative variables through aerosol direct and indirect effects. The changes in radiative variables in turn affect gas-phase chemistry and aerosol processes. As shown in Fig. 7, the difference of $\mathrm{SO}_{2}$ 
Table 5. Statistical performance of radiative/cloud prediction (average of the 2001-2005 simulations).

\begin{tabular}{llrrrr}
\hline Species/variables & Data set & Obs. & \multicolumn{3}{c}{ Simulations ${ }^{c}$} \\
\hline & & & MAM_SIM_5Y & MAM_NEW_5YA & MAM_NEW_5YB \\
\hline LWD $\left(\mathrm{W} \mathrm{m}^{-2}\right)^{\mathrm{b}}$ & CERES & 307.6 & $302.9 /-4.7 /-1.5 / 2.9 / 11.6$ & $303.9 /-3.6 /-1.1 / 2.8 / 11.3$ & $304.4 /-3.1 /-1.0 / 2.9 / 11.3$ \\
SWD $\left(\mathrm{W} \mathrm{m}^{-2}\right)^{\mathrm{c}}$ & CERES & 163.9 & $169.9 / 5.9 / 3.6 / 7.0 / 14.1$ & $166.5 / 2.5 / 1.5 / 6.5 / 13.8$ & $167.0 / 3.1 / 1.9 / 6.7 / 13.7$ \\
OLR $\left(\mathrm{W} \mathrm{m}^{-2}\right)$ & NOAA-CDC & 215.9 & $222.5 / 6.6 / 3.1 / 3.5 / 8.9$ & $220.7 / 4.8 / 2.2 / 3.4 / 9.1$ & $221.4 / 5.5 / 2.6 / 3.5 / 9.0$ \\
SWCF $\left(\mathrm{W} \mathrm{m}^{-2}\right)$ & CERES & -41.0 & $-38.8 / 2.2 /-5.4 /-21.5 / 12.0$ & $-41.5 /-0.5 / 1.2 /-21.4 / 12.5$ & $-40.8 / 0.2 /-0.5 /-22.2 / 12.4$ \\
CF $(\%)$ & MODIS & 67.1 & $66.6 /-0.6 /-0.8 / 15.2 / 13.3$ & $67.3 / 0.2 / 0.3 / 14.7 / 13.0$ & $66.6 /-0.6 /-0.9 / 15.5 / 13.7$ \\
COT & MODIS & 17.3 & $7.1 /-10.3 /-59.3 / 70.2 / 15.1$ & $7.9 /-9.4 /-54.5 / 65.7 / 14.6$ & $7.8 /-9.6 /-55.2 / 65.6 / 14.5$ \\
CWP $\left(\mathrm{g} \mathrm{m}^{-2}\right)$ & MODIS & 86.0 & $38.2 /-47.8 /-55.5 / 55.7 / 52.9$ & $43.2 /-42.8 /-49.8 / 50.0 / 49.2$ & $43.4 /-42.6 /-49.5 / 49.7 / 49.2$ \\
PWV $\left(\mathrm{cm}^{-2}\right.$ & MODIS & 1.93 & $1.96 / 0.03 / 1.5 / 11.6 / 0.3$ & $1.99 / 0.06 / 2.9 / 10.9 / 0.3$ & $1.97 / 0.04 / 1.8 / 13.8 / 0.3$ \\
AOD & MODIS & 0.2 & $0.1 /-0.07 /-44.1 / 54.5 / 0.1$ & $0.1 /-0.06 /-39.2 / 51.3 / 0.1$ & $0.1 /-0.06 /-36.3 / 49.5 / 0.1$ \\
Column CCN5 & MODIS & $2.5 \times 10^{8}$ & $5.3 \times 10^{7} /-1.9 \times 10^{8} /$ & $8.6 \times 10^{7} / 1.6 \times 10^{8} /$ & $8.6 \times 10^{7} / 1.6 \times 10^{8} /$ \\
(ocean) $\left(\mathrm{cm}^{-2}\right)$ & & & $-78.6 / 78.6 / 5.7 \times 10^{8}$ & $-65.2 / 65.2 / 5.5 \times 10^{8}$ & $-65.3 / 65.3 / 5.5 \times 10^{8}$ \\
CDNC $\left(\mathrm{cm}^{-3}\right)$ & BE07 & 112.6 & $44.2 /-68.3 /-60.7 / 61.6 / 84.3$ & $69.2 /-43.4 /-38.6 / 44.2 / 66.8$ & $68.8 /-43.8 /-38.9 / 45.5 / 67.9$ \\
\hline
\end{tabular}

a The values are expressed as Sim/MB/NMB/NME/RMSE. Sim: simulated values; MB: mean bias; NMB: normalized mean bias (\%); NME: normalized mean error (\%); RMSE: root

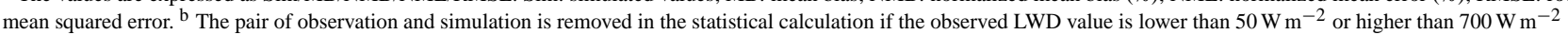
(http://www.pangaea.de).

${ }^{\mathrm{c}}$ The pair of observation and simulation is removed in the statistical calculation if the observed SWD value is lower than -10 or higher than $3000 \mathrm{~W} \mathrm{~m}^{-2}$ (http://www.pangaea.de).

between the two simulations varies from -1.7 to $3.8 \mathrm{ppb}$, with a global mean difference of 4.2 ppt. The decrease of $\mathrm{SO}_{2}$ over most oceanic areas is mainly due to the decrease of DMS resulting from less oxidation by $\mathrm{OH}$ radicals. The increase of $\mathrm{SO}_{4}^{2-}$ over East Asia and the eastern US drives more $\mathrm{NH}_{3}$ from gas phase to particulate phase to form $\mathrm{NH}_{4}^{+}$ through thermodynamic equilibrium, increasing the concentrations of $\mathrm{NH}_{4}^{+}$over these regions. However, the concentrations of $\mathrm{SO}_{4}^{2-}$ decrease over Europe due in part to less oxidation of $\mathrm{SO}_{2}$. Despite such a decrease, the concentrations of $\mathrm{NH}_{4}^{+}$are higher over Europe due to the neutralization of $\mathrm{NH}_{3}$ by $\mathrm{Cl}^{-}$and $\mathrm{NO}_{3}^{-}$that are treated in MAM_NEW_5YA but not treated in MAM_SIM_5Y.Compared with MAM_SIM_5Y, $J$ from MAM_NEW_5YA increases on the global scale with a global mean difference of $0.066 \mathrm{~cm}^{-3} \mathrm{~s}^{-1}$ due to the use of a lower mass accommodation coefficient of $\mathrm{H}_{2} \mathrm{SO}_{4}$ in MAM_NEW_5YA, resulting in more available $\mathrm{H}_{2} \mathrm{SO}_{4}$ vapor participating in nucleation. The increases in $J$ result in an increase in aerosol mass and number concentrations and thus higher concentrations of $\mathrm{PM}_{2.5}$ and $\mathrm{PM}_{10}$ (which improve appreciably their performance, see Table 5).

As shown in Fig. 8, compared with MAM_SIM_5Y, AOD increases by 0.007 , column CCN5 increases by $3.8 \times 10^{7} \mathrm{~cm}^{-2}$, and CDNC increases by $16.1 \mathrm{~cm}^{-3}$ in MAM_NEW_5YA. Higher PM $_{\text {num }}$ in MAM_NEW_5YA allows more aerosol to grow into the $\mathrm{CCN}$ size, leading to higher CCN in MAM_NEW_5YA. Higher aerosol concentrations in MAM_NEW_5YA result in higher AOD. The increased aerosol number and mass concentration result in an increase in the predictions of cloud variables through the aerosol-cloud interactions. For example, with all the modified and new treatments, COT increases by 0.8 , CWP increases by $4.1 \mathrm{~g} \mathrm{~m}^{-2}$, and PWV increases by $0.026 \mathrm{~cm}$ on global average. Due to the aerosol direct and indirect effects, the difference in simulated SWD varies from -19.3 to $10.4 \mathrm{~W} \mathrm{~m}^{-2}$ and decreases by $3.4 \mathrm{~W} \mathrm{~m}^{-2}(\sim 2.0 \%)$ on global average. The difference in LWD varies from -4.2 to $8.5 \mathrm{~W} \mathrm{~m}^{-2}$ and increases by $1.0 \mathrm{~W} \mathrm{~m}^{-2}(\sim 0.4 \%)$ on global average (figure not shown). The difference in SWCF varies from -8.4 to $17.9 \mathrm{~W} \mathrm{~m}^{-2}$ with a net increase of $2.7 \mathrm{~W} \mathrm{~m}^{-2}$ $(\sim 6.4 \%)$ on global average. The absolute differences of surface chemical species and major cloud/radiative variables for JJA average of 2001-2005 are shown in Figs. S4 and S5 in the Supplement. Compared with the 5-year average, the absolute changes of most radiative variables are smaller in JJA. The absolute changes in $\mathrm{PM}_{10}$ are smaller in JJA, which is mainly due to the dust events during other months (e.g., March-May over East Asia).

\subsection{Global burden analysis}

Table 7 shows the simulated global burdens of major gas and aerosol species for 2001-2005. The global burdens of most gaseous precursors of aerosol are higher in MAM_NEW_5YA than MAM_SIM_5Y (except for $\mathrm{NH}_{3}$ ), due mainly to the incorporation of ISORROPIA II in MAM_NEW_5YA. The global burden of tropospheric $\mathrm{O}_{3}$ is higher in MAM_NEW_5YA than MAM_SIM_5Y, which is due to higher mixing ratios of $\mathrm{O}_{3}$ precursors (e.g., $\mathrm{NO}_{2}$ and VOCs) that are simulated in MAM_NEW_5YA. The global burdens of most gas species are comparable with previous studies (Horowitz et al., 2006; Lamarque et al., 2005; Williams et al., 2009; Liu et al., 2012) with absolute differences of less than $20 \%$. One exception is $\mathrm{H}_{2} \mathrm{SO}_{4}$, which is higher by a factor of 5 in MAM_NEW_5YA than in MAM_SIM_5Y. The higher burden of $\mathrm{H}_{2} \mathrm{SO}_{4}$ in MAM_NEW_5YA is likely due to less condensation of 


\section{MAM_NEW_5YA-MAM_SIM_5Y}
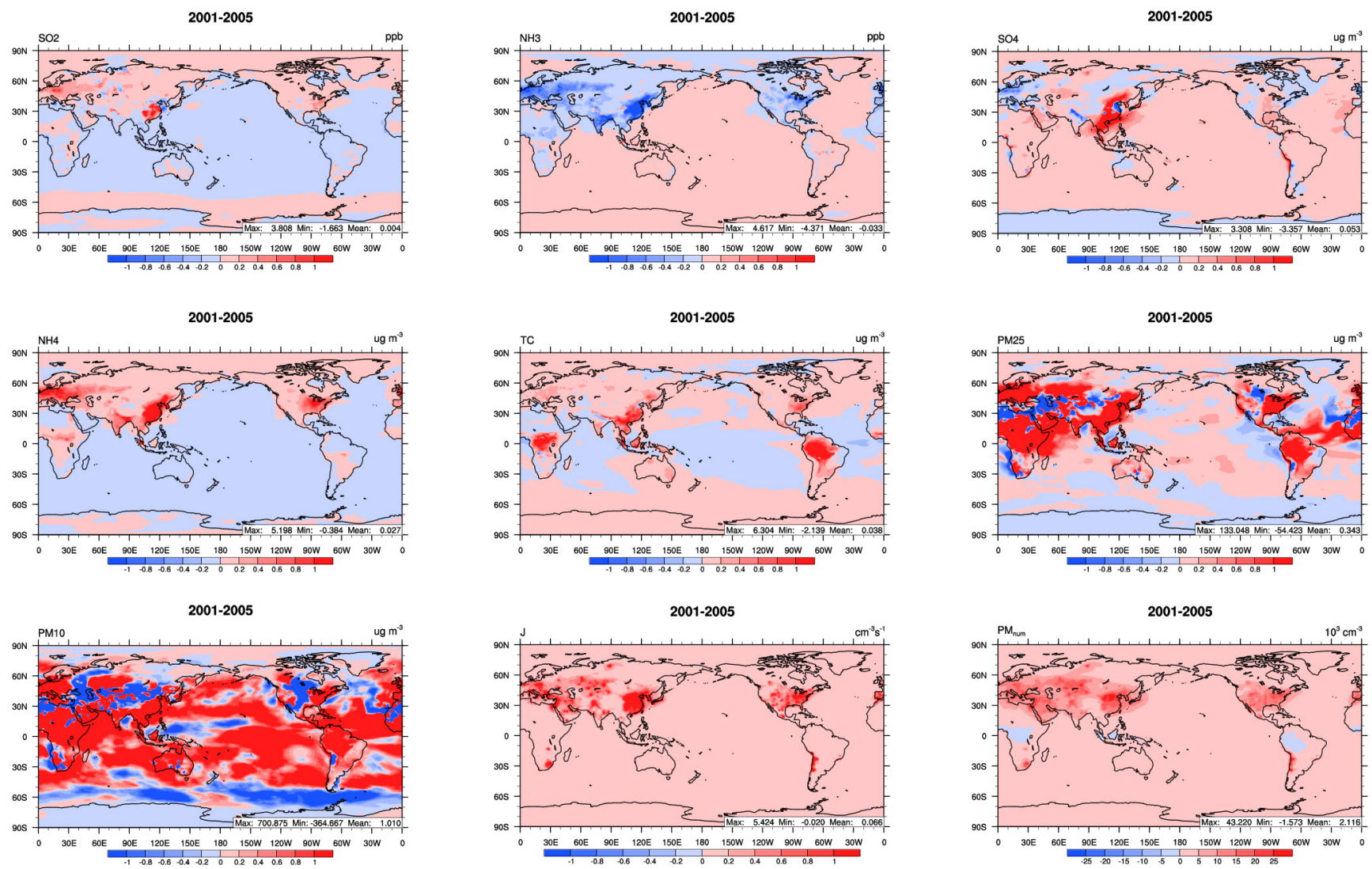

Figure 7. Absolute differences of major aerosol species and their gas precursors, new particle formation rate $(J)$, and aerosol number between MAM_NEW_5YA and MAM_SIM_5Y for 2001-2005.

\section{MAM_NEW_5YA-MAM_SIM_5Y}
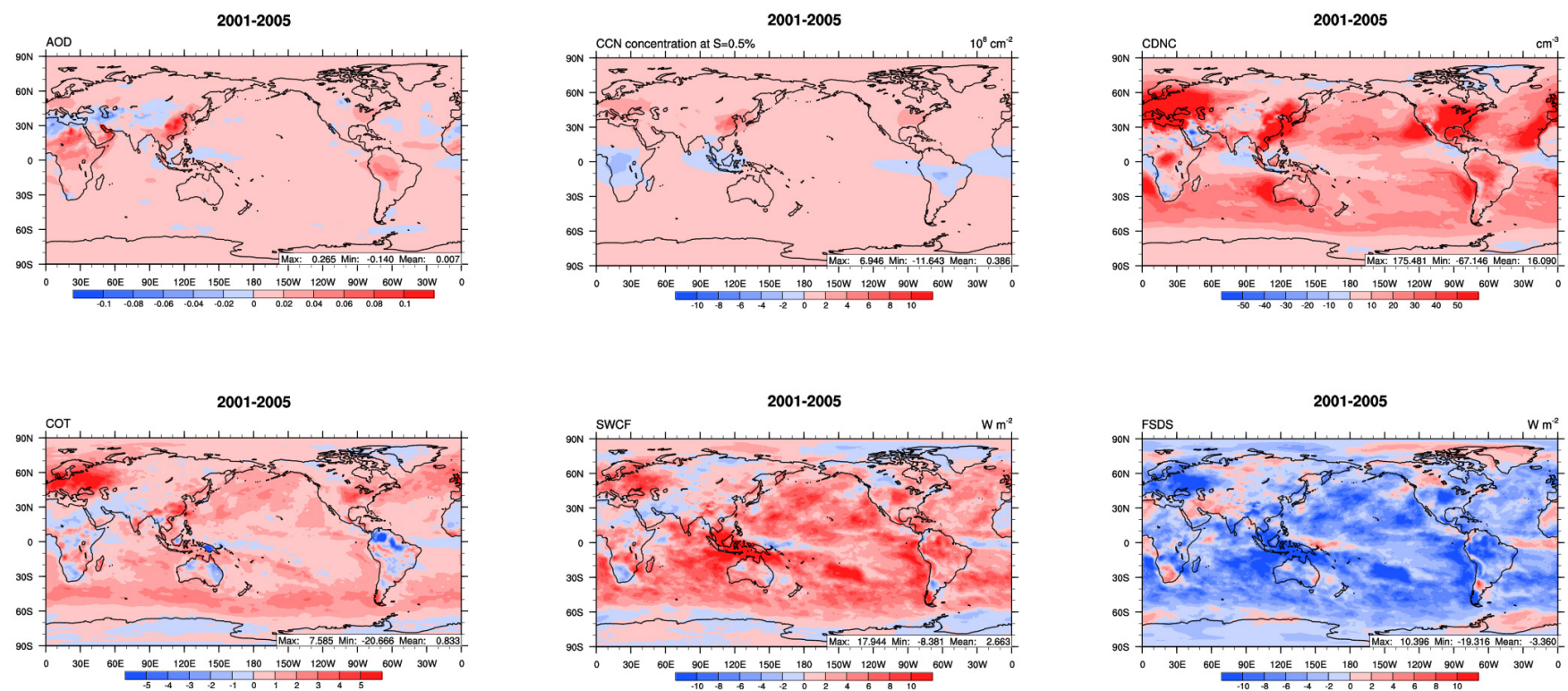

Figure 8. Absolute differences of major cloud and radiative variables between MAM_NEW_5YA and MAM_SIM_5Y for 2001-2005. 
Table 6. Statistical Performance of Chemical Prediction (Average from the 2001-2005 Simulations).

\begin{tabular}{|c|c|c|c|c|c|}
\hline \multirow{2}{*}{$\begin{array}{l}\text { Species/ } \\
\text { variables }^{\mathrm{a}}\end{array}$} & \multirow[t]{2}{*}{ Domain } & \multirow[t]{2}{*}{ Obs. } & \multicolumn{3}{|c|}{ Simulations ${ }^{\mathrm{b}}$} \\
\hline & & & MAM_SIM_5Y & MAM_NEW_5YA & MAM_NEW_5YB \\
\hline $\mathrm{CO}$ & East Asia & 562.0 & - & $139.7 /-422.3 /-75.1 / 75.1 / 451.8$ & $137.0 /-425.0 /-75.6 / 75.6 / 454.0$ \\
\hline \multirow[t]{3}{*}{$\mathrm{SO}_{2}$} & CONUS & 3.4 & 9.6/6.2/183.9/184.6/9.9 & 10.1/6.7/198.8/199.1/10.6 & 10.3/6.9/203.1/203.5/10.9 \\
\hline & Europe & 6.6 & $6.0 /-0.6 /-9.3 / 73.3 / 7.9$ & $6.6 /-0.06 /-0.9 / 77.2 / 8.3$ & $6.2 /-0.4 /-5.5 / 74.6 / 8.0$ \\
\hline & East Asia & 3.4 & $3.4 / 0.04 / 1.1 / 76.0 / 5.0$ & $3.4 / 0.01 / 0.4 / 76.2 / 5.0$ & $3.4 /-0.05 /-1.6 / 73.1 / 4.8$ \\
\hline $\mathrm{NH}_{3}$ & Europe & 6.3 & $3.0 /-3.3 /-52.0 / 81.0 / 25.3$ & $2.4 /-3.9 /-61.3 / 79.7 / 25.3$ & $2.4 /-3.9 /-62.0 / 79.3 / 25.3$ \\
\hline \multirow[t]{2}{*}{$\mathrm{NO}_{2}$} & Europe & 23.5 & - & $5.8 /-17.7 /-75.4 / 76.5 / 21.5$ & $5.5 /-18.0 /-76.7 / 77.7 / 21.7$ \\
\hline & East Asia & 13.5 & - & $2.3 /-11.2 /-83.3 / 83.3 / 12.2$ & $2.3 /-11.2 /-83.6 / 83.6 / 12.2$ \\
\hline \multirow[t]{3}{*}{$\mathrm{O}_{3}$} & CONUS & 35.1 & - & $43.9 / 8.8 / 25.1 / 27.3 / 11.3$ & $44.1 / 9.0 / 25.7 / 27.7 / 11.6$ \\
\hline & Europe & 52.7 & - & $86.6 / 33.9 / 64.5 / 64.6 / 36.4$ & $89.2 / 36.5 / 69.3 / 69.4 / 38.8$ \\
\hline & East Asia & 27.4 & - & 45.6/18.2/66.4/66.4/19.2 & $45.5 / 18.1 / 66.0 / 66.0 / 19.1$ \\
\hline \multirow[t]{2}{*}{$\mathrm{HNO}_{3}$} & CONUS & 1.4 & - & 1.6/0.2/16.3/39.5/0.7 & $1.6 / 0.2 / 12.1 / 38.2 / 0.7$ \\
\hline & Europe & 0.7 & - & $1.0 / 0.3 / 45.8 / 83.5 / 0.8$ & 1.0/0.3/37.9/79.8/0.8 \\
\hline \multirow{2}{*}{$\mathrm{SO}_{4}^{2-}$} & CONUS & 2.6 & $2.3 /-0.3 /-13.4 / 26.9 / 1.0$ & $2.3 /-0.3 /-13.1 / 23.0 / 0.8$ & $2.3 /-0.3 /-12.8 / 24.2 / 0.9$ \\
\hline & Europe & 2.3 & $2.3 /-0.04 /-1.9 / 37.3 / 1.4$ & $2.0 /-0.3 /-11.1 / 34.1 / 1.3$ & $2.0 /-0.3 /-13.0 / 35.5 / 1.4$ \\
\hline \multirow[t]{2}{*}{$\mathrm{NH}_{4}^{+}$} & CONUS & 1.2 & $0.9 /-0.3 /-20.8 / 33.4 / 55.0$ & $1.5 / 0.3 / 22.2 / 43.2 / 0.8$ & $1.5 / 0.3 / 26.4 / 44.3 / 0.8$ \\
\hline & Europe & 1.0 & $0.8 /-0.2 /-16.8 / 36.9 / 0.5$ & $1.6 / 0.6 / 62.8 / 68.7 / 0.9$ & $1.5 / 0.5 / 53.8 / 60.3 / 0.8$ \\
\hline \multirow[t]{2}{*}{$\mathrm{NO}_{3}^{-}$} & CONUS & 1.1 & - & $1.6 / 0.5 / 41.3 / 85.4 / 1.4$ & $1.6 / 0.5 / 49.8 / 90.2 / 1.5$ \\
\hline & Europe & 1.8 & - & $2.3 / 0.5 / 30.3 / 51.1 / 1.2$ & $2.2 / 0.4 / 24.7 / 47.0 / 1.1$ \\
\hline \multirow[t]{2}{*}{$\mathrm{Cl}^{-}$} & CONUS & 0.1 & - & $0.1 / 3.1 \times 10^{-3} / 2.7 / 105.8 / 0.4$ & $0.1 / 8.7 \times 10^{-3} / 7.8 / 110.1 / 0.4$ \\
\hline & Europe & 0.3 & - & $2.4 / 2.1 / 681.2 / 681.2 / 2.9$ & $2.3 / 2.0 / 663.3 / 663.6 / 2.8$ \\
\hline $\mathrm{BC}$ & CONUS & 0.4 & $0.3 /-0.1 /-17.9 / 44.4 / 0.3$ & $0.3 /-0.1 /-15.6 / 44.0 / 28.2$ & $0.3 /-0.1 /-17.7 / 44.3 / 0.2$ \\
\hline OC & CONUS & 1.2 & $0.9 /-0.3 /-23.2 / 59.3 / 1.0$ & $1.1 /-0.1 /-7.7 / 56.7 / 1.0$ & $1.1 /-0.1 /-11.0 / 54.3 / 0.9$ \\
\hline $\mathrm{TC}$ & CONUS & 3.1 & $1.4 /-1.7 /-54.4 / 62.8 / 2.8$ & $1.7 /-1.4 /-45.7 / 57.1 / 2.6$ & $1.6 /-1.5 /-47.1 / 57.1 / 2.7$ \\
\hline \multirow[t]{2}{*}{$\mathrm{PM}_{2.5}$} & CONUS & 8.8 & $7.2 /-1.6 /-17.9 / 37.0 / 4.3$ & $9.2 / 0.4 / 4.1 / 33.5 / 3.9$ & $8.7 /-0.1 /-1.1 / 29.4 / 3.6$ \\
\hline & Europe & 14.6 & $6.7 /-7.9 /-53.9 / 54.6 / 10.6$ & 9.7/-4.9/-33.8/37.6/8.6 & $10.0 /-4.6 /-31.7 / 36.1 / 8.4$ \\
\hline \multirow[t]{2}{*}{$\mathrm{PM}_{10}$} & Europe & 26.3 & $15.1 /-11.2 /-42.6 / 46.8 / 15.9$ & $18.7 /-7.6 /-28.8 / 36.1 / 13.9$ & $19.9 /-6.4 /-24.4 / 33.5 / 13.1$ \\
\hline & East Asia & 107.9 & $45.4 /-62.5 /-58.0 / 59.3 / 70.7$ & $52.5 /-57.4 /-53.2 / 54.2 / 66.0$ & $57.8 /-50.1 /-46.5 / 50.0 / 61.6$ \\
\hline \multirow[t]{2}{*}{ Col.CO } & Globe & $1.4 \times 10^{18}$ & - & $1.3 \times 10^{18} /-1.4 \times 10^{17} /$ & $1.2 \times 10^{18} /-1.5 \times 10^{17} /$ \\
\hline & & & & $-10.2 / 16.5 / 3.1 \times 10^{17}$ & $-11.0 / 17.2 / 3.2 \times 10^{17}$ \\
\hline Col.NO 2 & Globe & $5.3 \times 10^{14}$ & - & $8.4 \times 10^{14} / 3.1 \times 10^{14} /$ & $8.3 \times 10^{14} / 3.0 \times 10^{14} /$ \\
\hline & & & & $59.2 / 70.0 / 5.4 \times 10^{14}$ & $57.6 / 69.2 / 5.4 \times 10^{14}$ \\
\hline TOR & Globe & 30.4 & $29.9 /-0.5 / 1.6 / 16.3 / 6.1$ & $30.5 / 0.1 / 0.4 / 15.0 / 5.8$ & $29.9 /-0.5 /-1.7 / 16.4 / 6.1$ \\
\hline
\end{tabular}

$\mathrm{H}_{2} \mathrm{SO}_{4}$ resulting from the use of a lower mass accommodation coefficient. $\mathrm{SO}_{4}^{2-}$ burden is higher by $8.3 \%$ in MAM_NEW_5YA than MAM_SIM_5Y, which is likely due to greater $\mathrm{SO}_{2}$ oxidation in MAM_NEW_5YA. Higher $\mathrm{SO}_{4}^{2-}$ burden results from higher $\mathrm{SO}_{2}$ burden. Higher $\mathrm{SO}_{2}$ burden leads to more $\mathrm{SO}_{2}$ to be oxidized to produce $\mathrm{SO}_{4}^{2-}$, which outweighs the impacts from less $\mathrm{H}_{2} \mathrm{SO}_{4}$ condensation due to lower mass accommodation coefficient. More $\mathrm{SO}_{4}^{2-}$ result in more $\mathrm{NH}_{4}^{+}$. The burdens of $\mathrm{BC}$ and $\mathrm{POM}$ are lower by 16.5 and $23.8 \%$, respectively, in MAM_NEW_5YA than in MAM_SIM_5Y, which is likely due in part to greater dry deposition fluxes and in part to a slower primary carbon aging rate resulting from reduced condensation of gas species in MAM_NEW_5YA. Condensation onto the primary carbon mode produces aging of the particles in this mode. A lower accommodation coefficient is used in MAM_NEW_5YA, which results in less condensation. Therefore, the fraction of aged particles has decreased. The global burdens of most aerosol species are in the range of previous studies. For example, global burdens of $\mathrm{SO}_{4}^{2-}$ and $\mathrm{NH}_{4}^{+}$from MAM_SIM_5Y and MAM_NEW_5YA are 23.4 and $17.0 \%$, respectively, and 16.7 and $12.5 \%$, respectively, lower than Liu et al. (2012), which is likely because MAM_SIM_5Y contains no $\mathrm{SO}_{4}^{2-}$ emissions but Liu et al. (2012) included additional $\mathrm{SO}_{4}^{2-}$ emissions of $1.66 \mathrm{Tg} \mathrm{S} \mathrm{yr}^{-1}$. Higher $\mathrm{SO}_{4}^{2-}$ emission leads to more $\mathrm{SO}_{4}^{2-}$ concentrations and thus more $\mathrm{NH}_{4}^{+}$in Liu et al. (2012). Compared with Horowitz et al. (2006), global burdens of BC and OC from MAM_NEW_5YA are lower by 72.9 and $52.3 \%$, respectively. Compared with Liu et al. (2012), MAM_NEW_5YA gives comparable BC and POM burdens but much lower SOA (by a factor of 3.0). Compared with Textor et al. (2006), POM burden is a factor of 3.5 lower in MAM_NEW_5YA. The lower BC, OC, POM, and SOA burdens are likely due to the uncertainties in the $\mathrm{BC}$ and $\mathrm{OC}$ 
emissions used as well as differences in the model treatments for SOA formation and POM aging.

\section{Conclusions and future work}

In this work, a new gas-phase chemistry mechanism and several advanced inorganic aerosol treatments have been incorporated into CESM/CAM5.1-MAM7. These include (1) the CB05_GE gas-phase chemical mechanism coupled with MAM7; (2) the condensation and aqueous-phase chemistry involving $\mathrm{HNO}_{3} / \mathrm{NO}_{3}^{-}$and $\mathrm{HCl} / \mathrm{Cl}^{-}$; (3) an ion-mediated nucleation (IMN) parameterization for new particle formation from ions, (4) an inorganic thermodynamic module, ISORROPIA II, that explicitly simulates thermodynamics of $\mathrm{SO}_{4}^{2-}, \mathrm{NH}_{4}^{+}, \mathrm{NO}_{3}^{-}, \mathrm{Cl}^{-}$, and $\mathrm{Na}^{+}$as well as the impact of crustal species, such as $\mathrm{Ca}^{2+}, \mathrm{K}^{+}$, and $\mathrm{Mg}^{2+}$, on aerosol thermodynamics. CB05_GE with new and modified inorganic aerosol treatments in MAM7 simulates 139 species with 273 chemical reactions, which is more accurate than simple gas chemistry coupled with default MAM7. Seven 1 yr simulations for 2001 and three 5-year simulations for 2001-2005 with different model configurations are performed to evaluate the capabilities of the original and improved CESM/CAM5 and the mechanisms underlying differences among model predictions.

Compared to the simple gas-phase chemistry, the 2001 simulation with CB05_GE can predict many more gaseous species, and give improved performance for the prediction of organic carbon and $\mathrm{PM}_{2.5}$ over CONUS, $\mathrm{NH}_{3}$ and $\mathrm{SO}_{4}^{2-}$ over Europe, $\mathrm{SO}_{2}$ and $\mathrm{PM}_{10}$ over East Asia, and cloud properties such as CF, CDNC, and SWCF on the global scale. MAM_CON simulates $\mathrm{NO}_{3}^{-}$and $\mathrm{Cl}^{-}$, which are important inorganic aerosols. With species-dependent accommodation coefficients for gas condensation, more $\mathrm{H}_{2} \mathrm{SO}_{4}$ can participate in homogeneous nucleation, resulting in the improvement in the prediction of $\mathrm{PM}_{2.5}, \mathrm{PM}_{10}, J, \mathrm{CDNC}$, and SWCF. IMN can increase the predictions of $J$ and $\mathrm{PM}_{\text {num }}$ in the upper atmosphere and thus improve the prediction of AOD, CCN, and cloud properties, and SWCF on the global scale, $\mathrm{PM}_{2.5}$ over CONUS and Europe, $\mathrm{PM}_{10}$ over Europe and East Asia, and PM composition over Europe. The 2001 simulation with ISORROPIA II can improve the prediction of major gas and aerosol species significantly, including $\mathrm{HNO}_{3}, \mathrm{NH}_{4}^{+}, \mathrm{NO}_{3}^{-}, \mathrm{Cl}^{-}, \mathrm{BC}, \mathrm{OC}, \mathrm{TC}$, and $\mathrm{PM}_{2.5}$ over CONUS; $\mathrm{SO}_{2}, \mathrm{NH}_{3}, \mathrm{NO}_{2}, \mathrm{SO}_{4}^{2-}, \mathrm{NH}_{4}^{+}, \mathrm{NO}_{3}^{-}$, and $\mathrm{Cl}^{-}$over Europe; and $\mathrm{CO}$ and $\mathrm{SO}_{2}$ over East Asia. Such improvements lead to improved prediction of SWD, SWCF, and CCN5 on the global scale. The 2001 simulation with the new and modified inorganic aerosol treatments appreciably improve the prediction of OLR, CF, COT, CWP, PWV, CCN, CDNC, SWCF, $J$ on the global scale, and $\mathrm{HNO}_{3}$ (CONUS and Europe), $\mathrm{NH}_{4}^{+}$(CONUS), $\mathrm{PM}_{2.5}$ (CONUS and Europe), and $\mathrm{PM}_{10}$ (Europe and East Asia). The 2001 sensitivity simulation with adjusted emissions further improves model predic- tion of $\mathrm{CO}$ and $\mathrm{SO}_{2}$ over East Asia; $\mathrm{SO}_{2}, \mathrm{HNO}_{3}, \mathrm{NO}_{3}^{-}, \mathrm{Cl}^{-}$, $\mathrm{BC}$, OC, and TC over CONUS; $\mathrm{SO}_{2}, \mathrm{NH}_{3}, \mathrm{NH}_{4}^{+}, \mathrm{HNO}_{3}$, $\mathrm{NO}_{3}^{-}$, and $\mathrm{Cl}^{-}$over Europe; and column $\mathrm{CO}$ and SWD on the global scale. The change of emissions can affect primary gaseous precursors directly, and secondary gaseous species indirectly through gas-phase chemistry. Meanwhile, secondary aerosols can be affected by gaseous precursors, and therefore have impacts on cloud properties as well as direct and indirect effects on radiation. Reducing the uncertainty of emissions can thus help reduce the model biases significantly.

The comparison of the 2001-2005 simulations with prescribed SST shows that MAM_NEW_5YA with CB05_GE can appreciably improve the prediction of AOD, COT, CWP, CCN5, CDNC, SWD, LWD, OLR, and SWCF on the global scale; OC, TC, and $\mathrm{PM}_{2.5}$ over CONUS; $\mathrm{PM}_{10}$ over East Asia; and $\mathrm{SO}_{2}, \mathrm{PM}_{2.5}$, and $\mathrm{PM}_{10}$ over Europe. The performance is overall similar for all radiative variables and most chemical species between MAM_NEW_5YA with prescribed SST and MAM_NEW_5YB in a fully coupled mode.

In addition to uncertainties in emissions, additional uncertainties exist in the model treatments. For example, the large biases in the prediction of $\mathrm{O}_{3}$ over Europe and East Asia is mainly due to insufficient $\mathrm{NO}_{\mathrm{x}}$ titration resulting from the uncertainties in the $\mathrm{NO}_{\mathrm{x}}$ emissions. The large biases in $\mathrm{PM}_{10}$ over East Asia and Europe may be mainly due to the inaccurate prediction of dust. The large bias in $\mathrm{Cl}^{-}$over Europe may be due to the inaccurate prediction of $\mathrm{HCl}$ and coarse $\mathrm{Cl}^{-}$, resulting from the irreversible condensation of $\mathrm{HCl}$ over coarse mode particles and the uncertainty in the mass accommodation coefficient of $\mathrm{HCl}$ used. A reversible condensation treatment should be used for volatile species in the future which can more accurately simulate the gas/particle partitioning of those volatile species over coarse mode particles. Assumptions associated with equilibrium partitioning for fine particles such as metastable conditions may be responsible for biases over desert/arid regions under low RH conditions. In the default and modified nucleation treatments, it only considers $\mathrm{H}_{2} \mathrm{SO}_{4}, \mathrm{NH}_{3}, \mathrm{H}_{2} \mathrm{O}$, and ions involved in new particle formation. Missing species (e.g., organics, iodine compounds, and DMS) may also contribute to new particle formation. Uncertainties in treating organic gas-aerosol partitioning may contribute to the inaccurate prediction of SOA, OC, TC, and PM. The large biases in CDNC, COT, and liquid water path (CWP) indicate the uncertainties in cloud microphysics schemes and aerosol-cloud interaction parameterizations, which also limit the ability of climate and Earth system models to quantify aerosol indirect effects (Stephens, 2005; Gettelman et al., 2008). In addition to uncertainties in the model treatments, uncertainties in the model simulation settings such as the use of a coarse-grid resolution and a large model time step of $1800 \mathrm{~s}$ for solving the chemical system in this work may contribute to the model biases. The representations of some of the aforementioned uncertain processes in 
Table 7. Global Burdens of Major Gaseous and Aerosol Species from the 2001-2005 Simulations.

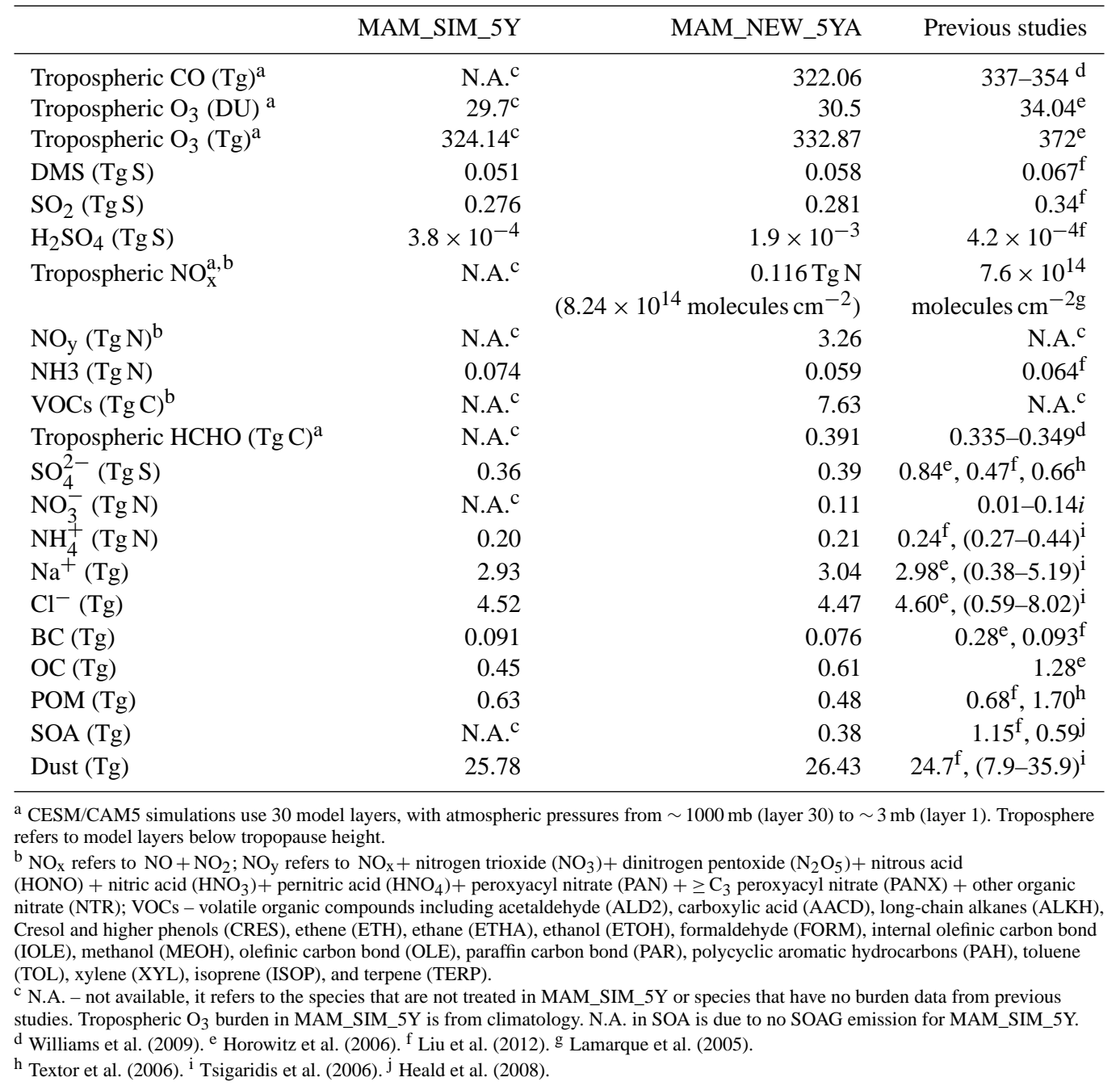

CESM/CAM5.1 are being further improved by the authors' group. Decadal simulations using improved CESM/CAM5.1 will be conducted in the future to study the interactions among atmospheric chemistry, aerosol, and climate change and reduce associated uncertainties.

\section{The Supplement related to this article is available online at doi:10.5194/acp-14-9171-2014-supplement.}

Acknowledgements. This work is sponsored by the US National Science Foundation EaSM program AGS-1049200. The authors would like to thank Fangqun Yu for providing the IMN scheme, A. Nenes for providing ISORROPIA II, X. Liu for providing a version of MAM7 that works in CAM5.0 and CAM5.1, R. Bennartz and J. Rausch for providing CDNC data, S. J. Ghan and R. C. Easter for insightful discussions, and S. Zhu, a former postdoc researcher of the air quality forecasting laboratory at NCSU for early work on the incorporation of CB05_GE and its coupling with MAM3. The authors would also like to thank the four reviewers for their valuable suggestions that helped improve the technical quality of this work. MODIS data and CERES data are provided by NASA via http://ladsweb.nascom.nasa.gov and http://ceres.larc.nasa.gov/order_data.php, respectively. Other surface network data were downloaded from their respective web sites. We would like to acknowledge high-performance computing support from Yellowstone (ark:/85065/d7wd3xhc) provided by NCAR's Computational and Information Systems Laboratory, sponsored by the US National Science Foundation.

Edited by: X. Liu

\section{References}

Abdul-Razzak, H. and Ghan, S. J.: A Parameterization of Aerosol Activation, Part 2: Multiple Aerosol Types, J. Geophys. Res., $105,6837-6844,2000$. 
Adams, P. J. and Seinfeld, J. H.: Predicting global aerosol size distributions in general circulation models, J. Geophys. Res., 107, 4370, doi:10.1029/2001JD001010, 2002.

Appel, K. W., Pouliot, G. A., Simon, H., Sarwar, G., Pye, H. O. T., Napelenok, S. L., Akhtar, F., and Roselle, S. J.: Evaluation of dust and trace metal estimates from the Community Multiscale Air Quality (CMAQ) model version 5.0, Geosci. Model Dev., 6, 883-899, doi:10.5194/gmd-6-883-2013, 2013.

Arstila, H., Korhonen, P., and Kulmala, M.: Ternary nucleation: Kinetics and application to water-ammonia-hydrochloric acid system, J. Aerosol Sci., 30, 131-138, doi:10.1016/S00218502(98)00033-0, 1999.

Barth, M. C., Rasch, P. J., Kiehl, J. T., Benkovitz, C. M., and Schwartz, S. E.: Sulfur chemistry in the National Center for Atmospheric Research Community Climate Model: Description, evaluation, features and sensitivity to aqueous chemistry, J. Geophys. Res., 105, 1387-1415, 2000.

Berndt, T., Sipilä, M., Stratmann, F., Petäjä, T., Vanhanen, J., Mikkilä, J., Patokoski, J., Taipale, R., Mauldin III, R. L., and Kulmala, M.: Enhancement of atmospheric $\mathrm{H}_{2} \mathrm{SO}_{4} / \mathrm{H}_{2} \mathrm{O}$ nucleation: organic oxidation products versus amines, Atmos. Chem. Phys., 14, 751-764, doi:10.5194/acp-14-751-2014, 2014.

Bennartz, R.: Global assessment of marine boundary layer cloud droplet number concentration from satellite, J. Geophys. Res., 112, D02201, doi:10.1029/2006JD007547, 2007.

Bey, I., Jacob, D. J., Yantosca, R. M., Logan, J. A., Field, B. D., Fiore, A. M., Li, Q., Lui, H. Y., Mickley, L. J., and Schultz, M. G.: Global modeling of tropospheric chemistry with assimilated meteorology: Model description and evaluation, J. Geophys. Res., 106, 23073-23095, 2001.

Bretherton, C. S. and Park, S.: A new moist turbulence parameterization in the community atmosphere model, J. Climate, 22, 3422-3448, 2009.

Byun, D. W. and Schere, K. L.: Review of the governing equations, computational algorithms, and other components of the Models3 Community Multiscale Air Quality (CMAQ) Modeling System, Appl. Mech. Rev., 59, 51-77, 2006.

Capaldo, K. P., Pilinis, C., and Pandis, S. N.: A computationally efficient hybrid approach for dynamic gas/aerosol transfer in air quality models, Atmos. Environ., 34, 3617-3627, 2000.

Collins, W. D., Bitz, C. M., Blackmon, M. L., Bonan, G. B., Bretherton, C. S., Carton, J. A., Chang, P., Doney, S. C., Hack, J. J., Henderson, T. B., Kiehl, J. T., Large, W. G., McKenna, D. S., Santer, B. D., and Smith, R. D.: The Community Climate System Model version3 (CCSM3), J. Climate, 19, 2122-2143, doi:10.1175/JCLI3761.1, 2006.

Dunne, J. P., John, J. G., Adcroft, A. J., Griffies, S. M., Hallberg, R. W., Shevliakova, E., Stouffer, R. J., Cooke, W., Dunne, K. A., Harrison, M. J., Krasting, J. P., Malyshev, S. L., Milly, P. C. D., Phillipps, P. J., Sentman, L. T., Samuels, B. L., Spelman, M. J., Winton, M., Wittenberg, A. T., and Zadeh, N.: GFDL's ESM2 global coupled climate-carbon earth system models. Part I: Physical formulation and baseline simulation characteristics, J. Climate, 25, 6646-6665, 2012.

Dutkiewicz, S., Sokolov, A. P., Scott, J., and Stone, P. H.: A ThreeDimensional Ocean-Seaice-Carbon Cycle Model and its Coupling to a Two-Dimensional Atmospheric Model: Uses in Climate Change Studies, Rep. 122, Joint Program on the Sci. and
Policy of Global Change, 51 pp., Mass. Inst. of Technol., Cambridge, May 2005.

Emmons, L. K., Walters, S., Hess, P. G., Lamarque, J.-F., Pfister, G. G., Fillmore, D., Granier, C., Guenther, A., Kinnison, D., Laepple, T., Orlando, J., Tie, X., Tyndall, G., Wiedinmyer, C., Baughcum, S. L., and Kloster, S.: Description and evaluation of the Model for Ozone and Related chemical Tracers, version 4 (MOZART-4), Geosci. Model Dev., 3, 43-67, doi:10.5194/gmd3-43-2010, 2010.

ENVIRON: Comprehensive Air Quality Model with extensions User's Guide, Novato, California, USA, 5.3 Edn., 2010.

Faraji, M., Kimura, Y., McDonald-Buller, E., and Allen, D.: Comparison of the carbon bond and SAPRC photochemical mechanisms under conditions relevant to southeast Texas, Atmos. Environ., 42, 5821-5836, doi:10.1016/j.atmosenv.2007.07.048, 2008.

Fast, J. D., Gustafson Jr., W. I., Easter, R. C., Zaveri, R. A., Barnard, J. C., Chapman, E. G., Grell, G. A., and Peckham, S. E.: Evolution of ozone, particulates, and aerosol direct radiative forcing in the vicinity of Houston using a fully coupled meteorology-chemistry-aerosol model, J. Geophys. Res., 111, D21305, doi:10.1029/2005JD006721, 2006.

Fountoukis, C. and Nenes, A.: ISORROPIA II: a computationally efficient thermodynamic equilibrium model for $\mathrm{K}^{+}-\mathrm{Ca}^{2+}$ $\mathrm{Mg}^{2+}-\mathrm{NH}_{4}^{+}-\mathrm{Na}^{+}-\mathrm{SO}_{4}^{2-}-\mathrm{NO}_{3}-\mathrm{Cl}-\mathrm{H}_{2} \mathrm{O}$ aerosols, Atmos. Chem. Phys., 7, 4639-4659, doi:10.5194/acp-7-4639-2007, 2007.

Gettelman, A., Morrison, H., and Ghan, S. J.: A new two-moment bulk stratiform cloud microphysics scheme in the community atmosphere model, version 3 (CAM3). Part II: Single-column and global results, J. Climate, 21, 3660-3679, 2008.

Ghan, S. J., Liu, X., Easter, R. C., Zaveri, R., Rasch, P. J., and Yoon, J.-H.: Toward a minimal representation of aerosols in climate models: comparative decomposition of aerosol direct, semidirect, and indirect radiative forcing, J. Climate, 25, 6461-6476, 2012.

Guenther, A., Karl, T., Harley, P., Wiedinmyer, C., Palmer, P. I., and Geron, C.: Estimates of global terrestrial isoprene emissions using MEGAN (Model of Emissions of Gases and Aerosols from Nature), Atmos. Chem. Phys., 6, 3181-3210, doi:10.5194/acp-63181-2006, 2006.

Heald, C. L., Henze, D. K., Horowitz, L. W., Feddema, J., Lamarque, J.-F., Guenther, A., Hess, P. G., Vitt, F., Seinfeld, J. H., Goldstein, A. H., and Fung, I.: Predicted change in global secondary organic aerosol concentrations in response to future climate, emissions, and land use change, J. Geophys. Res., 113, D05211, doi:10.1029/2007JD009092, 2008.

Heintzenberg, J.: Fine particles in the global troposphere, A review, Tellus B, 41, 149-160, 1989.

Hoffmann, T., O’Dowd, C. D., and Seinfeld, J. H.: Iodine oxide homogeneous nucleation: An explanation for coastal new particle production, Geophys. Res. Lett., 28, 1949-1952, 2001.

Horowitz, L. W.: Past, present, and future concentrations of tropospheric ozone and aerosols: methodology, ozone evaluation, and sensitivity to aerosol wet removal, J. Geophys. Res., 111, D22211, doi:10.1029/2005JD006937, 2006.

Hu, X.-M., Zhang, Y., Jacobson, M. Z., and Chan, C. K.: Coupling and evaluating gas/particle mass transfer treatments for aerosol simulation and forecast, J. Geophys. Res., 113, D11208, doi:10.1029/2007JD009588, 2008. 
Iacono, M. J., Delamere, J. S., Mlawer, E. J., and Clough, S. A.: Evaluation of upper tropospheric water vapor in the NCAR Community Climate Model (CCM3) using modeled and observed HIRS radiances, J. Geophys. Res., 108, 4037, doi:10.1029/2002jd002539, 2003.

Iacono, M. J., Delamere, J. S., Mlawer, E. J., Shephard, M. W., Clough, S. A., and Collins, W. D.: Radiative forcing by long-lived greenhouse gases: Calculations with the AER radiative transfer models, J. Geophys. Res., 113, D13103, doi:10.1029/2008jd009944, 2008.

Jacobson, M. Z.: Studying the effect of calcium and magnesium on size-distributed nitrate and ammonium with EQUISOLV II, Atmos. Environ., 33, 3635-3649, 1999.

Jacobson, M. Z.: A solution to the problem of nonequilibrium acid/base gas-particle transfer at long time step, Aerosol Sci. Tech., 39, 92-103, 2005.

Jacobson, M. Z.: Short-term effects of Controlling Fossil-Fuel Soot, Biofuel Soot and Gases, and Methane on Climate, Arctic Ice, and Air Pollution Health, J. Geophys. Res., 115, D14209, doi:10.1029/2009JD013795, 2010.

Karamchandani, P., Zhang, Y., Chen, S.-Y., and Balmori-Bronson, R.: Development of an extended chemical mechanism for globalthrough-urban applications, Atmospheric Pollution Research, 3, 1-24, doi:10.5094/APR.2011.047, 2012.

Kelly, J. T., Bhave, P. V., Nolte, C. G., Shankar, U., and Foley, K. M.: Simulating emission and chemical evolution of coarse seasalt particles in the Community Multiscale Air Quality (CMAQ) model, Geosci. Model Dev., 3, 257-273, doi:10.5194/gmd-3257-2010, 2010.

Koloutsou-Vakakis, S., Rood, M. J., Nenes, A., and Pilinis, C.: Modeling of aerosol properties related to direct climate forcing, J. Geophys. Res., 103, 17009-17032, doi:10.1029/98JD00068, 1998.

Kulmala, M., Vehkamaki, H., Petaja, T., Dal Maso, M., Lauri, A., Kerminen, V.-M., Birmili, W., and McMurry, P.: Formation and growth rates of ultrafine atmospheric particles: A review of observations, J. Aerosol Sci., 35, 143-176, 2004.

Lamarque, J.-F., Kiehl, J. T., Hess, P. G., Collins, W. D., Emmons, L. K., Ginoux, P., Luo, C., and Tie, X. X.: Response of a coupled chemistry-climate model to changes in aerosol emissions: global impact on the hydrological cycle and the tropospheric burdens of $\mathrm{OH}$, ozone, and $\mathrm{NO}_{\mathrm{x}}$, J. Geophys. Res., 32, L16809, doi:10.1029/2005GL023419, 2005.

Lamarque, J.-F., Emmons, L. K., Hess, P. G., Kinnison, D. E., Tilmes, S., Vitt, F., Heald, C. L., Holland, E. A., Lauritzen, P. H., Neu, J., Orlando, J. J., Rasch, P. J., and Tyndall, G. K.: CAM-chem: description and evaluation of interactive atmospheric chemistry in the Community Earth System Model, Geosci. Model Dev., 5, 369-411, doi:10.5194/gmd-5-369-2012, 2012.

Lawrence, D. M., Oleson, K. W., Flanner, M. G., Thornton, P. E., Swenson, S. C., Lawrence, P. J., Zeng, X., Yang, Z.-L., Levis, S., Sakaguchi, K., Bonan, G. B., and Slater, A. G.: Parameterization improvements and functional and structural advances in version 4 of the Community Land Model, J. Adv. Model. Earth Syst., 3, 2011MS000045, doi:10.1029/2011MS000045, 2011.

Liao, H., Adams, P. J., Chung, S. H., Seinfeld, J. H., Mickley, L. J., and Jacob, D. J.: Interactions between tropospheric chemistry and aerosols in a unified general circulation model, J. Geophys Res., 108, 4001, doi:10.1029/2001JD001260, 2003.

Liu, X., Easter, R. C., Ghan, S. J., Zaveri, R., Rasch, P., Shi, X., Lamarque, J.-F., Gettelman, A., Morrison, H., Vitt, F., Conley, A., Park, S., Neale, R., Hannay, C., Ekman, A. M. L., Hess, P., Mahowald, N., Collins, W., Iacono, M. J., Bretherton, C. S., Flanner, M. G., and Mitchell, D.: Toward a minimal representation of aerosols in climate models: description and evaluation in the Community Atmosphere Model CAM5, Geosci. Model Dev., 5, 709-739, doi:10.5194/gmd-5-709-2012, 2012.

Marsh, A. R. W. and McElory, W. J.: The dissociation constant and Henry's law constant of $\mathrm{HCl}$ in aqueous solution, Atmos. Environ., 19, 1075-1080, 1985.

Martensson, E. M., Nilsson, E. D., deLeeuw, G., Cohen, L. H., and Hansson, H. C.: Laboratory simulations and parameterization of the primary marine aerosol production, J. Geophys. Res., 108, 4297, doi:10.1029/2002JD002263, 2003.

Meng, Z. and Seinfeld, J. H.: Time scales to achieve atmospheric gas-aerosol equilibrium for volatile species, Atmos. Environ., 30, 2889-2900, 1996.

Meng, Z., Dabdub, D., and Seinfeld, J. H.: Size- and chemicallyresolved model of atmospheric aerosol dynamics. J. Geophys. Res., 103, 3419-3435, 1998.

Merikanto, J., Napari, I., Vehkamaki, H., Anttila, T., and Kulmala, M.: New parameterization of sulfuric acid-ammonia-water ternary nucleation rates at tropospheric conditions, J. Geophys. Res., 112, D15207, doi:10.1029/2006JD007977, 2007.

Morrison, H. and Gettelman, A.: A new two-moment bulk stratiform cloud microphysics scheme in the community atmosphere model, version 3 (CAM3). Part I: Description and numerical tests, J. Climate, 21, 3642-3659, 2008.

Nenes, A., Pandis, S. N., and Pilinis, C.: ISORROPIA: A new thermodynamic equilibrium model for multiphase multicomponent inorganic aerosols, Aquat. Geochem., 4, 123-152, 1998.

Park, S. and Bretherton, C. S.: The university of Washington shallow convection and moist turbulence schemes and their impact on climate simulations with the community atmosphere model, J. Climate, 22, 3449-3469, 2009.

Raes, F., Augustin, J., and Vandingenen, R.: The role of ion-induced aerosol formation in the lower atmosphere, J. Aerosol Sci., 17, 466-470, doi:10.1016/0021-8502(86)90135-7, 1986.

Reiter, R.: Phenomena in atmospheric and environmental electricity, Elsevier, New York, 1992.

Sander, S. P., Friedl, R. R., Golden, D. M., Kurylo, M. J., Huie, R. E., Orkin, V. L., Moortgat, G. K., Ravishankara, A. R., Kolb, C. E., Molina, M. J., and Finlayson-Pitts, B. J.: Chemical Kinetics and Photochemical Data for Use in Atmospheric Studies, National Aeronautics and Space Administration, Jet Propulsion Laboratory California Institute of Technology Pasadena, California, 2003.

Seinfeld, J. H. and Pandis, S. N.: Atmospheric chemistry and physics: From air pollution to climate change, 2 Edn., John Wiley \& Sons, Inc, 2006.

Sihto, S.-L., Kulmala, M., Kerminen, V.-M., Dal Maso, M., Petäjä, T., Riipinen, I., Korhonen, H., Arnold, F., Janson, R., Boy, M., Laaksonen, A., and Lehtinen, K. E. J.: Atmospheric sulphuric acid and aerosol formation: implications from atmospheric measurements for nucleation and early growth mechanisms, 
Atmos. Chem. Phys., 6, 4079-4091, doi:10.5194/acp-6-40792006, 2006.

Sokolov, A. P., Schlosser, C. A., Dutkiewicz, S., Paltsev, S., Kicklighter, D., Jacoby, H. D., Prinn, R. G., Forest, C. E., Reilly, J. M., Wang, C., Felzer, B., Sarofim, M. C., Scott, J., Stone, P. H., Melillo, J. M., and Cohen, J.: The MIT Integrated Global System Model (IGSM) Version 2: Model Description and Baseline Evaluation, Rep. 124, Joint Program on the Sci. and Policy of Global Change, 46 pp., Mass. Inst. of Technol., Cambridge, July 2005.

Spracklen, D. V., Carslaw, K. S., Kulmala, M., Kerminen, V.-M., Mann, G. W., and Sihto, S.-L.: The contribution of boundary layer nucleation events to total particle concentrations on regional and global scales, Atmos. Chem. Phys., 6, 5631-5648, doi:10.5194/acp-6-5631-2006, 2006.

Stephens, G. L.: Cloud feedbacks in the climate system: A critical review, J. Climate, 18, 237-273, 2005.

Stier, P., Feichter, J., Kinne, S., Kloster, S., Vignati, E., Wilson, J., Ganzeveld, L., Tegen, I., Werner, M., Balkanski, Y., Schulz, M., Boucher, O., Minikin, A., and Petzold, A.: The aerosol-climate model ECHAM5-HAM, Atmos. Chem. Phys., 5, 1125-1156, doi:10.5194/acp-5-1125-2005, 2005.

Textor, C., Schulz, M., Guibert, S., Kinne, S., Balkanski, Y., Bauer, S., Berntsen, T., Berglen, T., Boucher, O., Chin, M., Dentener, F., Diehl, T., Easter, R., Feichter, H., Fillmore, D., Ghan, S., Ginoux, P., Gong, S., Grini, A., Hendricks, J., Horowitz, L., Huang, P., Isaksen, I., Iversen, I., Kloster, S., Koch, D., Kirkevåg, A., Kristjansson, J. E., Krol, M., Lauer, A., Lamarque, J. F., Liu, X., Montanaro, V., Myhre, G., Penner, J., Pitari, G., Reddy, S., Seland, $\varnothing .$, Stier, P., Takemura, T., and Tie, X.: Analysis and quantification of the diversities of aerosol life cycles within AeroCom, Atmos. Chem. Phys., 6, 1777-1813, doi:10.5194/acp-6-1777-2006, 2006.

Tsigaridis, K., Krol, M., Dentener, F. J., Balkanski, Y., Lathière, J., Metzger, S., Hauglustaine, D. A., and Kanakidou, M.: Change in global aerosol composition since preindustrial times, Atmos. Chem. Phys., 6, 5143-5162, doi:10.5194/acp-6-5143-2006, 2006.

Usoskin, I. G. and Kovaltsov, G. A.: Cosmic ray induced ionization in the atmosphere: full modeling and practical applications, J. Geophys. Res., 111, D21206, doi:10.1029/2006JD007150, 2006.

van Dingenen, R. and Raes, F.: Ternary nucleation of methane sulphonic acid, sulphuric acid and water vapour, J. Aerosol Sci., 24, 1-17, doi:10.1016/0021-8502(93)90081-J, 1993.

Van Pelt, R. S. and Zobeck, T. M.: Chemical constituents of fugitive dust, Environ. Monit. Assess., 130, 3-16, doi:10.1007/s10661006-9446-8, 2007.

Vehkamaki, H., Kulmala, M., Napari, I., Lehtinen, K. E. J., Timmreck., C., Noppel, M., and Laaksonen, A.: an improved parameterization for sulfuric acid-water nucleation rates for tropospheric and stratospheric conditions, J. Geophys. Res.-Atmos., 107, 4622, doi:10.1029/2002JD002184, 2002.

Wang, K., Zhang, Y., Nenes, A., and Fountoukis, C.: Implementation of dust emission and chemistry into the Community Multiscale Air Quality modeling system and initial application to an Asian dust storm episode, Atmos. Chem. Phys., 12, 1020910237, doi:10.5194/acp-12-10209-2012, 2012.

Wang, M. and Penner, J. E.: Aerosol indirect forcing in a global model with particle nucleation, Atmos. Chem. Phys., 9, 239-260, doi:10.5194/acp-9-239-2009, 2009.
Williams, J. E., Scheele, M. P., van Velthoven, P. F. J., Cammas, J.-P., Thouret, V., Galy-Lacaux, C., and Volz-Thomas, A.: The influence of biogenic emissions from Africa on tropical tropospheric ozone during 2006: a global modeling study, Atmos. Chem. Phys., 9, 5729-5749, doi:10.5194/acp-9-5729-2009, 2009.

Yu, F.: Ion-mediated nucleation in the atmosphere: Key controlling parameters, implications, and look-up table, J. Geophys. Res., 115, D03206, doi:10.1029/2009JD012630, 2010.

Yu, F., Wang, Z., Luo, G., and Turco, R.: Ion-mediated nucleation as an important global source of tropospheric aerosols, Atmos. Chem. Phys., 8, 2537-2554, doi:10.5194/acp-8-2537-2008, 2008.

Yu, F., Luo, G., Liu, X., Easter, R. C., Ma, X., and Ghan, S. J.: Indirect radiative forcing by ion-mediated nucleation of aerosol, Atmos. Chem. Phys., 12, 11451-11463, doi:10.5194/acp-1211451-2012, 2012.

Zaveri, R. A., Easter, R. C., and Peters, L. K.: A computationally efficient multicomponent equilibrium solver for aerosols (MESA), J. Geophys. Res., 110, D24203, doi:10.1029/2004JD005618, 2005.

Zaveri, R. A., Easter, R. C., Fast, J. D., and Peters, L. K.: Model for Simulating Aerosol Interactions and Chemistry (MOSAIC), J. Geophys. Res., 113, D13204, doi:10.1029/2007JD008782, 2008.

Zender, C. S., Bian, H., and Newman, D.: The mineral Dust Entrainment And Deposition (DEAD) model: Description and 1990s dust climatology, J. Geophys. Res., 108, 4416, doi:10.1029/2002JD002775, 2003.

Zhang, G. J. and McFarlane, N. A.: Sensitivity of climate simulations to the parameterization of cumulus convection in the Canadian Climate Centre general circulation model, Atmos. Ocean, 33, 407-446, 1995.

Zhang, K. M. and Wexler, A. S.: An Asynchronous Time-Stepping (ATS) integrator for atmospheric applications: Aerosol dynamics, Atmos. Environ., 40, 4574-4588, 2006.

Zhang, Y., Bischof, C. H., Easter, R. C., and Wu, P.-T.: Sensitivity analysis of a mixed-phase chemical mechanism using automatic differentiation, J. Geophys. Res., 103, 18953-18979, 1998.

Zhang, Y., Seigneur, C., Seinfeld, J. H., Jacobson, M., Clegg, S. L., and Binkowski, F. S.: A comparative review of inorganic aerosol thermodynamic equilibrium modules: similarities, differences, and their likely causes, Atmos. Environ., 34, 117-137, 2000.

Zhang, Y., Pun, B., Vijayaraghavan, K., Wu, S.-Y., Seigneur, C., Pandis, S. N., Jacobson, M. Z., Nenes, A., and Seinfeld, J. H.: Development and application of the Model of Aerosol Dynamics, Reaction, Ionization, and Dissolution (MADRID), J. Geophys. Res., 109, D01202, doi:10.1029/2003JD003501, 2004.

Zhang, Y., McMurry, P. H., Yu, F., and Jacobson, M. Z.: A comparative study of nucleation parameterizations: 1 . Examination and evaluation of the formulations, J. Geophys. Res., 115, D20212, doi:10.1029/2010JD014150, 2010.

Zhang, Y., Chen, Y., Sarwar, G., and Schere, K.: Impacts of gasphase mechanisms on weather research forecasting model with chemistry (WRF/Chem) predictions: Mechanism implementation and comparative evaluation, J. Geophys. Res., 117, D01301, doi:10.1029/2011JD015775, 2012a.

Zhang, Y., Karamchandani, P., Glotfelty, T., Street, D. G., Grell, G., Nenes, A., Yu, F., and Bennartz, R.: Development and initial application of the global-through-urban weather research 
and forecasting model with chemistry (GU-WRF/Chem), J. Geophys. Res., 117, D20206, doi:10.1029/2012JD017966, 2012 b.
Zuend, A., Marcolli, C., Peter, T., and Seinfeld, J. H.: Computation of liquid-liquid equilibria and phase stabilities: implications for RH-dependent gas/particle partitioning of organic-inorganic aerosols, Atmos. Chem. Phys., 10, 7795-7820, doi:10.5194/acp10-7795-2010, 2010. 